\title{
Governance systems of yarshagumba collection and trade in the border region of India, Nepal and China
}

\author{
Dissertation \\ zur Erlangung des mathematisch-naturwissenschaftlichen Doktorgrades \\ "Doctor rerum naturalium" \\ der Georg-August-Universität Göttingen \\ im Promotionsprogramm Geowissenschaften / Geographie \\ der Georg-August University School of Science (GAUSS) \\ vorgelegt von \\ Corinna Angela Monika Wallrapp
}

aus Gräfelfing

Göttingen 2019 


\section{Betreuungsausschuss:}

Prof. Dr. Heiko Faust, Humangeographie, Geographisches Institut Göttingen

Dr. Markus Keck, Humangeographie, Geographisches Institut Göttingen

\section{Mitglieder der Prüfungskommission}

Referent/in: Prof. Dr. Heiko Faust, Humangeographie, Geographisches Institut Göttingen Korreferent/in: Dr. Markus Keck, Humangeographie, Geographisches Institut Göttingen

weitere Mitglieder der Prüfungskommission:

- Prof. Dr. Christoph Dittrich, Humangeographie, Geographisches Institut Göttingen

- Prof. Dr. Martin Kappas, Abteilung der Kartographie, GIS und Fernerkundung, Geographisches Institut Göttingen

- apl. Prof. Dr. Lasafam Iturrizaga, Abteilung Physische Geographie (Fachgebiet Hochgebirgsgeograhie), Geographisches Institut Göttingen

- Dr. Michael Klinge, Abteilung Physische Geographie, Geographisches Institut Göttingen

Tag der mündlichen Prüfung: Montag, den 20.5.2019 


\section{Executive Summary}

Worldwide, the commercial collection of non-timber forest products (NTFP) has increased, with growing demands on domestic and international markets. This provides income opportunities for local people and links usually remote rural areas, where the resources are collected, with global markets. At the same time, it also enforces dependencies, increases the risks of overexploitation and extinction of the resource and often leads to contestation between different actors for access to these lucrative resources. Thus, actors modify and adapt existing governance systems to secure or gain access to the resource and profit from it. Commercialisation of NTFP leads to both positive and negative developments in remote rural areas.

Most studies examining the commercialisation of NTFP apply an apolitical research approach, analysing the livelihood dependency of local communities on the resource, the impacts on environmental aspects and the commodity chain starting from the production or collection via processing to the marketing of the product on the national or international market. These studies are generally uncritical towards power relations, marginalisation processes within the local population due to their livelihood dependencies on one or few resources, and the related negotiation processes between state authorities and non-state actors as ways of understanding actors' access and involvement in the processes and steps of collecting, processing and trading. Looking at these factors is especially critical when the resources are extracted and traded in the margins of states, like borderlands.

Following this gap in the literature, this thesis aims to provide an in-depth understanding of negotiation processes among state authorities and non-state actors, which shape governance systems and networks regulating access, extraction and trade of locally available natural resources in borderlands. Central questions are: How do actors adapt governance systems regulating commercial collection and trade of the resource in response to changes in relation to the resource, like an increased resource value? What kinds of production networks emerge in borderlands? What roles do state and non-state actors play in the negotiation processes shaping governance systems that control access to and benefit from commercial NTFP collection and trade in borderlands?

The thesis uses the case of yarshagumba collection and trade in the remote high Himalaya of the Nepal-India trans-boundary region within the Kailash Landscape to explore these questions. Yarshagumba is a resource collected in the high alpine grasslands of the Himalayas and traded to and consumed mainly in mainland China. The common pool resource 'yarshagumba' has been transformed from a non-valued natural resource to a highly demanded product on the international market. 
The study consists of two parts: (1) the collection and (2) the trade of yarshagumba, in which I focus on different aspects of governance systems and negotiation processes between actors. In part 1, I conduct a comparative analysis of the community-led and governmental governance systems in the yarshagumba collection sites and their adaptive capacity and multi-level learning processes. In part 2, I study the trans-border connectivities, power and embeddedness of state and non-state actors within the informal yarshagumba trade network in the borderland of India and Nepal. Thus, I apply different concepts, such as governance of commons, access to natural resources, adaptation of governance systems, global production networks and borderlands, and analyse the two parts separately using the broader field of research 'political ecology' as the basis.

The study follows an inductive qualitative research approach applying different data collection techniques such as guided interviews, focus group discussions, participatory observation and document analysis. In order to analyse interactions, relations and impacts across the NepaliIndian border, the study understands the border region on both sides of the border as one conjunct research area. This approach is especially helpful in the analysis of the informal crossborder trade network of yarshagumba across the Indian-Nepali border.

The collection and trade of yarshagumba is part of complex political, social and economic systems in the borderlands within the Kailash Landscape. These systems are regulated by diverse governance systems and networks and involve various types of actors on multiple scales and beyond state borders. These governance systems are the outcome of negotiation processes between state authorities and non-state actors to respond to the pressures on the existing resource due to the value increase and the new demands and interests of actors. Every yarshagumba collection site has an individually-designed governance system consisting of governmental regulations and local communal arrangements, which are either complementary to or replace governmental regulations. Currently, both the revision of government policies in India and Nepal and the communal management arrangements are immediate amendments in reaction to the pressures on the resource, rather than long term strategic interventions. This adaptation and learning process is so far missing.

Borderlands are regions with opportunities producing cross-border social and economic spaces through trans-border connectivities and cross-border networks. There, sovereign power and the border as line of separation are continuously negotiated and reinforced by state authorities and non-state actors for personal gain. Both state authorities and non-state actors are closely enmeshed in these formal and informal governance and network structures, whereby state authorities can play different roles and can have several functions. The dichotomies of formal / informal and legal / illegal become blurred and regulatory spaces are re-interpreted by state as well as non-state actors.

In both parts of my case study the results show that the local people are vulnerable to some extent, as they depend on the global market developments and are exposed to the governmental regulations, but they are not passive players in the collection and trading systems. They are active participants along with the state authorities in shaping governance 
systems and trading networks suitable and appropriate to their demands and interests. Local people are not in resistance to government authorities in borderlands, but out of necessity, jointly negotiate spaces with state representatives across borders.

As a result of these negotiation processes between actors, I conclude that, in the margins of states, like borderlands, governance systems and networks for commercial collection and trade of NTFP move in and out of legality and use or bypass governmental regulations. Rather than formal rules and regulations, negotiation processes between actors play a key role to determine who has access to the resource and who benefits from the trade network. Thus, these governance systems and networks in borderlands are complex constellations. They are more than institutions. They are an interplay of rights, institutions, power structures, and social and economic relations between actors beyond borders adapting to changing conditions. They are dynamic and differ from resource to resource and from location to location.

For sustainable and equitable management of natural resources in margins of states, policymakers need to consider the political, social and economic dimensions related to natural resource management and resource production networks. Besides other recommendations, they should reflect on state authorities' own role, behaviour and involvement in the systems and cross-border networks. A change in the way of thinking is required, by recognizing the communal management arrangements and starting to formalize these when appropriate to ensure natural resource governance systems that are context-specific, innovative, legally sanctioned and enforced. 


\section{Acknowledgement}

There are many people who have contributed to this thesis; that I could start, that I kept on going and finally submitted the thesis. I would like to thank all of them.

First, I would like to thank my two supervisors Prof. Dr. Heiko Faust and Dr. Markus Keck for their motivation, often pragmatic advice, cheering me up and for answering sometimes the same questions several times - most of the time patiently, sometimes not so patiently. Especially, I would like to thank Heiko and Markus for understanding my situation, accepting my request to supervise my $\mathrm{PhD}$, for believing in me and for responding always immediately to my requests, which contributed that I can complete this work within a limited time frame.

Also, I would like to thank my GIZ supervisors Manfred Seebauer and Kai Windhorst who have supported me in overcoming some administrative hurdles, allowed me to integrate the PhD into my regular job and provided me the freedom I needed to collect my data. In addition, many thanks to my colleagues from ICIMOD, especially Dr. Tashi Dorji, who supported me and convinced me to write a PhD, Dr. Rajan Kotru and Dr. Janita Gurung for hardly getting tired of listening to my yarshagumba stories, Dr. Vishwas Chitale for his support in preparing study maps, and thanks to many of the other KSLCDI team members. Also, many thanks to the KSLCDI partners in India, Nepal and China for their various support to the field trips, workshops, posters, manuals, translations and meetings related to yarshagumba. Especially, I would like to acknowledge the support of the members of ANCA and CHEA. I absolutely enjoyed the joint field trips to the Kailash Landscape, although it was sometimes freezing cold. These were very special and great experiences for me, which I will never forget.

My special thanks go to Ashish Chaudary and Shankar Badal, who accompanied me and walked with me most of the time during the fieldwork. Ashish was never tired of answering my questions and of starting conversations with local people about yarshagumba; neither during steep exhausting climbs, during early breakfast or at late evening hours. Also many thanks to Ganshyam Pande and Nabin Bisht for their time and efforts to get a better picture of the yarshagumba phenomenon in the Indian part of the Landscape. Further, without the help of the porters Chandra, Dharmanand, Narad and Tekendra, who accompanied us, the trips to the collection sites would have not been possible and not so pleasant.

I would like to address special appreciation and thanks to the interview partners, local leaders and community members, who welcomed us into their homes and tents, offered us tea and food, guided our way, provided places to stay and places to cook our food in the camp sites when the wind was blowing or it was raining or snowing. Thank you for your hospitality, for your time and patience in answering my questions. Although, or maybe because, the conditions were sometimes so harsh in the collection sites your hospitality was amazing and overwhelming 
for me. I fear that, although the data are analysed and published, the impact for improving your situations will be marginal.

Also, I would like to thank my friends in Kathmandu Abhimanyu, Vishwas, Himani, Marijn and Basel for encouraging me to start the $\mathrm{PhD}$, as well as not to give up after the 'nice' field trips. My friends, Kristin and Eileen, I have to thank in particular. You were both never tired of reading my very first drafts, editing my texts and listening to my worries and complaints about the theories and scientific writing. Katha and her family contributed a lot that I felt at home in Göttingen. Thank you very much for that. Special thanks go to the Goe-Wald climbing gang, especially Ansgar, Ingo and Jens. Without regularly going climbing and spending time out in the forest, I would have not been so productive and balanced during all the time here.

Finally yet importantly, I have to thank Mathew and my family for supporting, believing in me and for continuously encouraging me 'all will be fine, just continue'. 


\section{Table of Contents}

Executive Summary

i

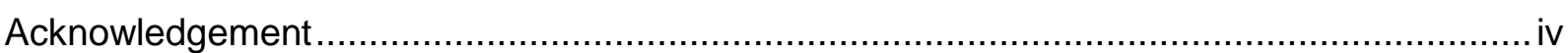

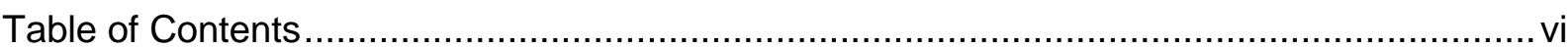

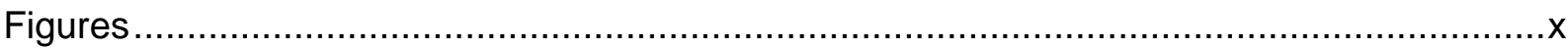

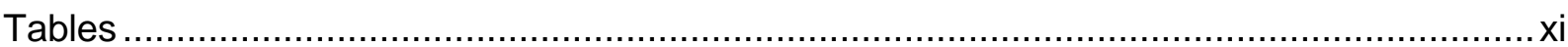

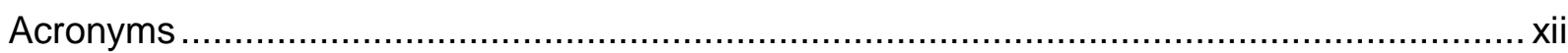

Preface

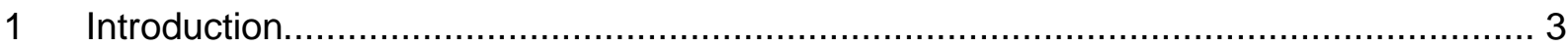

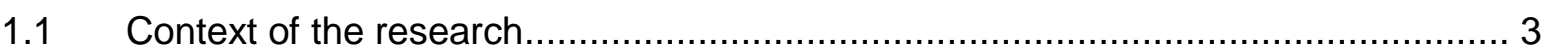

1.1.1 Management of commercial collection of NTFP …..................................... 4

1.1.2 NTFP collection and trade in the Himalayas .............................................. 5

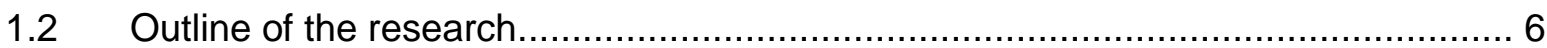

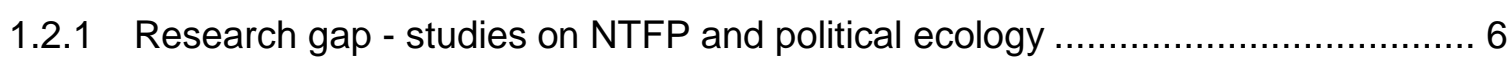

1.2.2 Aim of the research, its approach and research questions ............................10

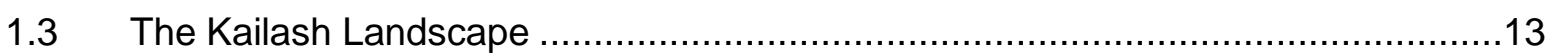

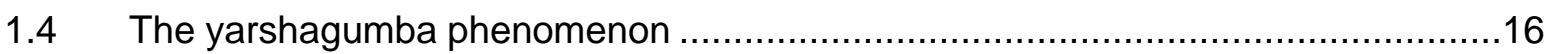

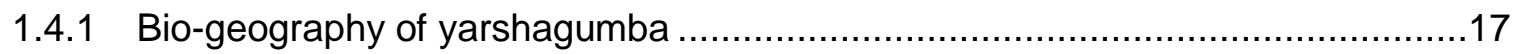

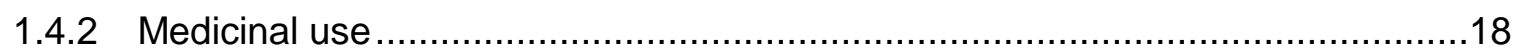

1.4.3 Ecological and social developments in the Himalayas ...................................18

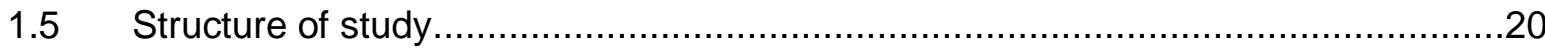

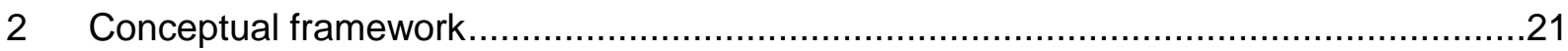

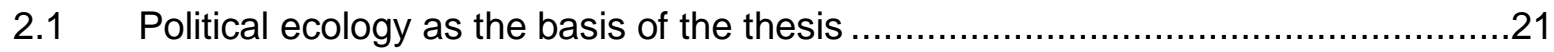

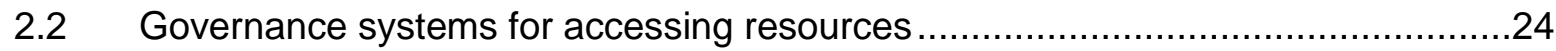




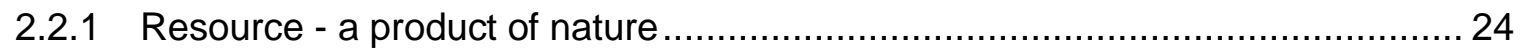

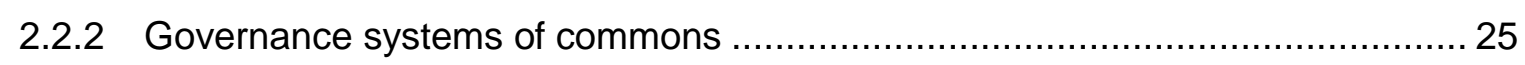

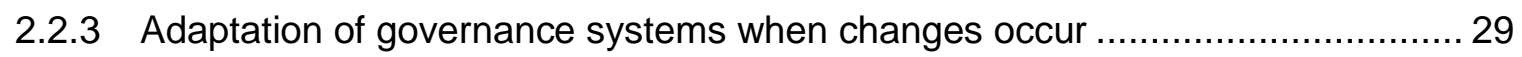

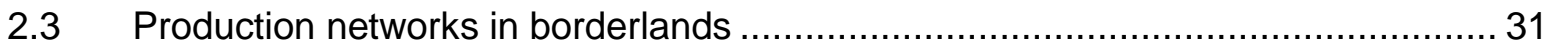

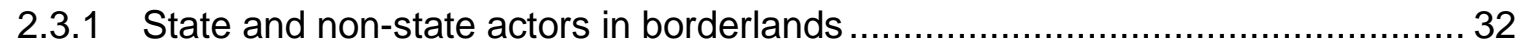

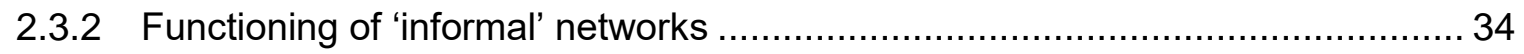

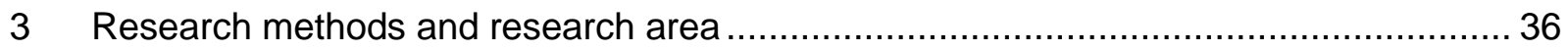

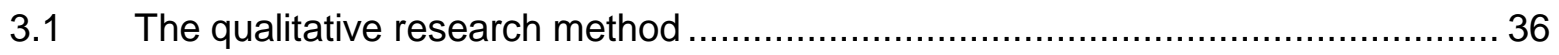

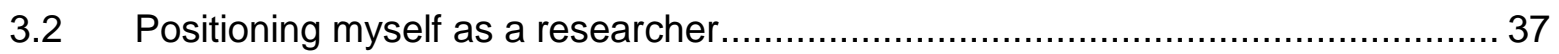

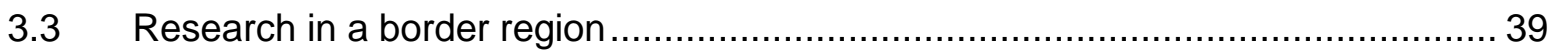

3.4 Identification and selection of yarshagumba collection sites ................................ 40

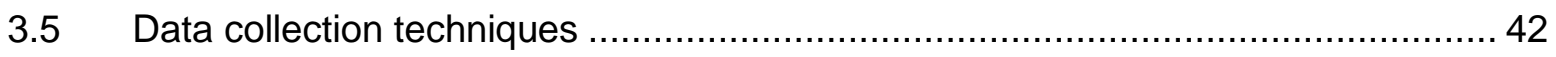

3.5.1 Guided interviews and informal conversations........................................ 42

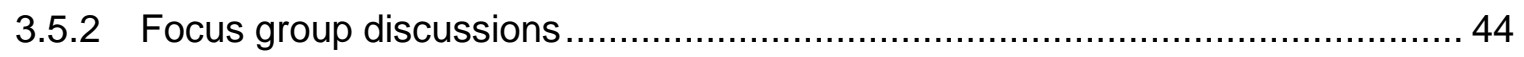

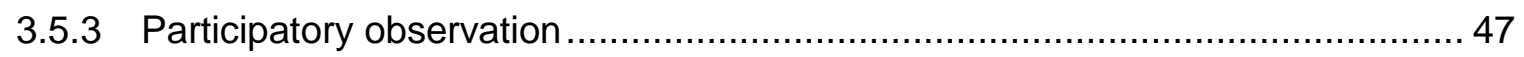

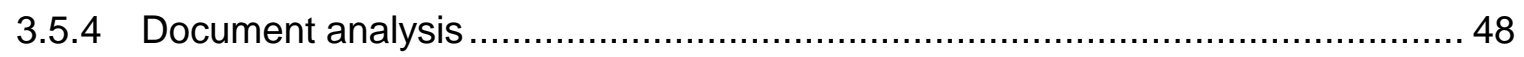

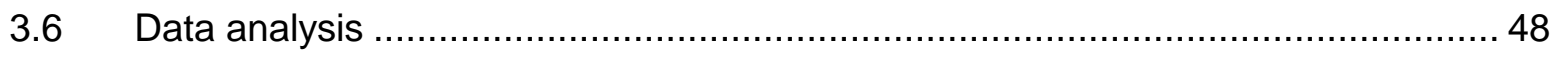

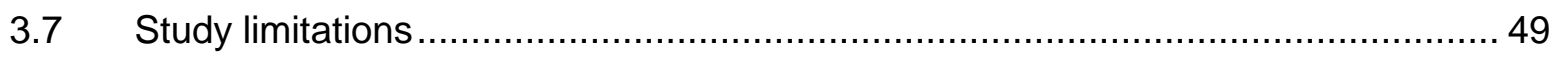

4 Institutional Issues, Power Struggles and Local Solutions - Governance Systems of Yarshagumba Collection in India and Nepal in the Kailash Landscape ...............................51

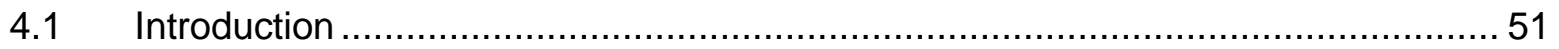

4.2 Theoretical considerations and methodical implementation................................52

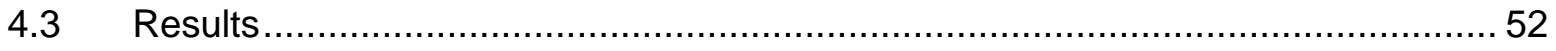

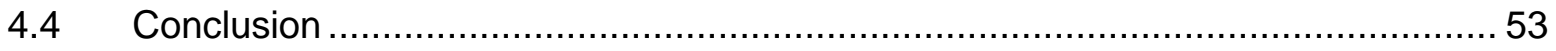

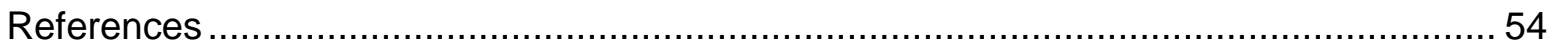

5 Governing the yarshagumba 'gold rush': A comparative study of governance systems in

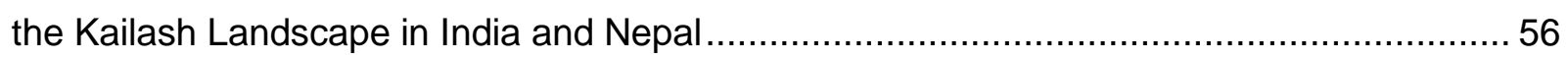


Abstract

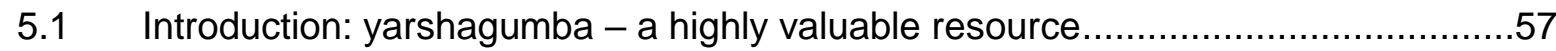

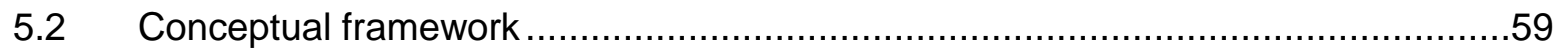

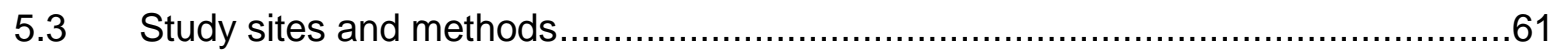

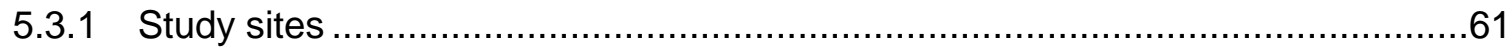

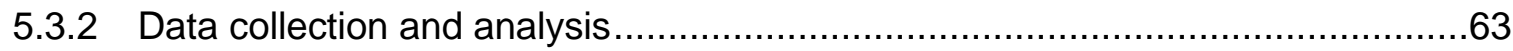

5.4 Results - Development of yarshagumba governance systems .........................64

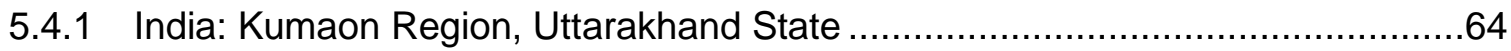

5.4.2 Nepal: Api Nampa Conservation Area (ANCA), Darchula District.......................67

5.5 Discussion - Governance systems and their learning processes ........................70

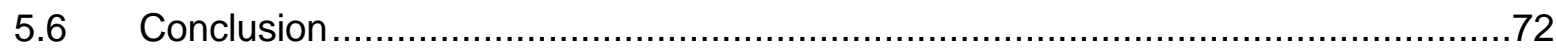

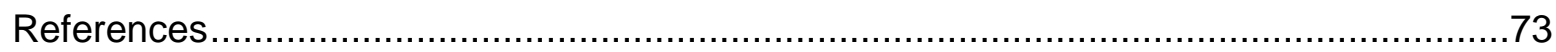

6 Production networks and borderlands: cross-border yarsagumba trade in the Kailash

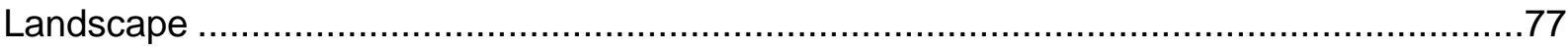

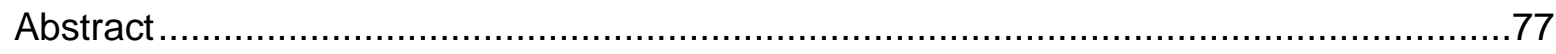

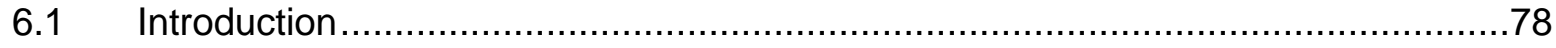

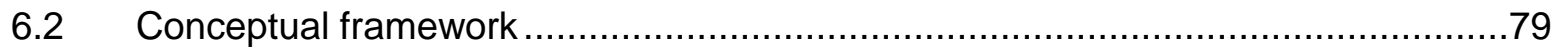

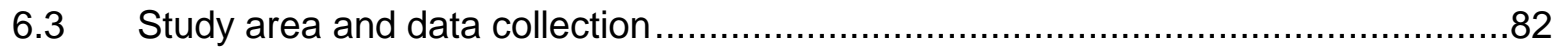

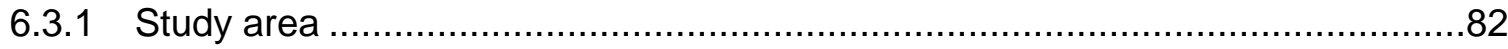

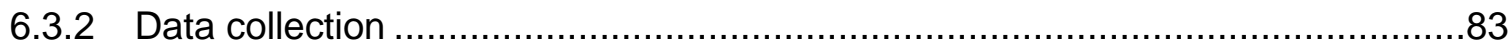

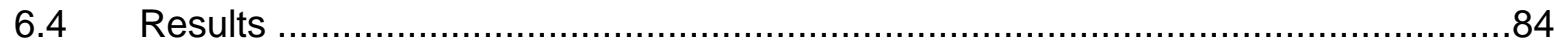

6.4.1 The governmental marketing system for yarsagumba in India (no. 1 in figure 6) 85

6.4.2 The informal trade network across the border from India to Nepal (no. 2 in figure 6) $\quad 87$

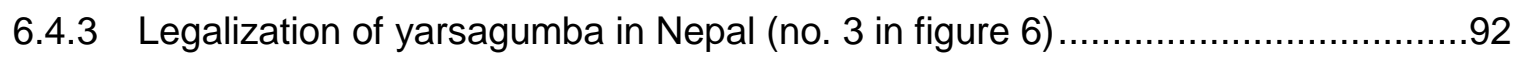

6.4.4 Alternative trading routes for yarsagumba from India to China (no. 2 in figure 6) 93 


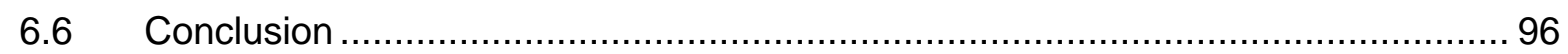

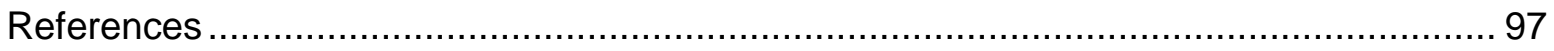

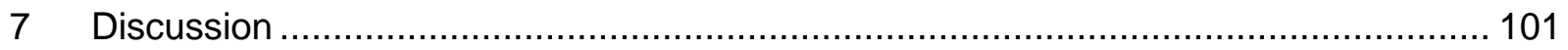

7.1 Governance systems and networks are more than institutions ......................... 101

7.2 Negotiation processes between state and non-state actors............................. 102

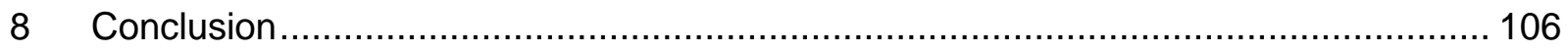

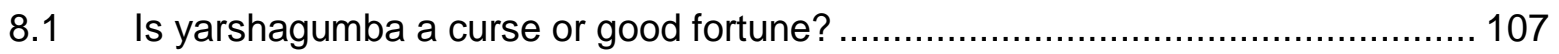

8.2 Recommendations for policy-making processes ..................................... 108

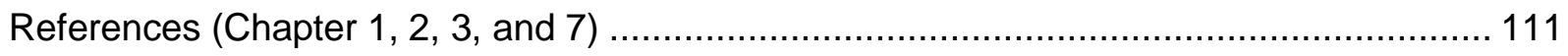

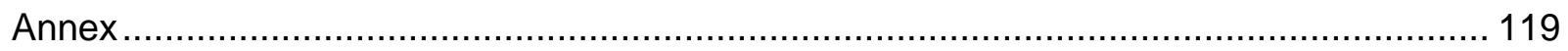

Annex 1: Pictures of the yarshagumba collection........................................................ 119

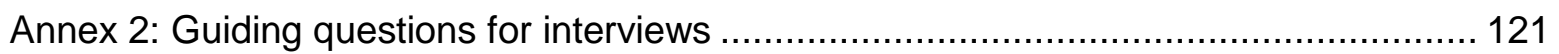

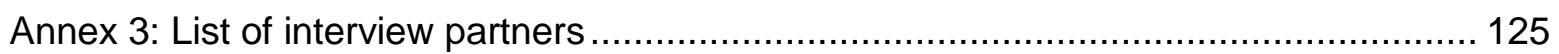

Annex 4: List of focus group discussions .......................................................... 128 


\section{Figures}

Figure 1: Localising the study area: a) overview map of Asia, b) map of the Kailash Landscape and c) the border region of India, Nepal and China with the four research valleys and selected yarshagumba collection sites (detailed and Kailash map: own source, based on ICIMOD 2017; overview map: map data 2018 google) .............................................15

Figure 2: Sketch map of the Indian part of the study area (own source August 2016) ..........45

Figure 3: Focus group discussion with presentation in Bhuddi (own source May 2017)........46

Figure 4: Map of study area and potential yarshagumba habitat (own source, based on ICIMOD (2017))

Figure 5: Map of the borderland of India, Nepal and China in the Kailash Landscape (detailed map: own source; overview map: map data 2018 google). .82

Figure 6: Trade network of illegal (red) and legal (green) product flows of yarsagumba in the Indian/Nepali borderland with relevant state and non-state actors. No. 1 (left) outlines the product flow of yarsagumba using the governmental marketing mechanism in India, no. 2 (middle) the informal trade network from India to Nepal and no. 3 (right) the legalization process in Nepal. The thick arrows show the dominant, the thin arrows the subordinate trading routes. .85

Figure 7: The Kailash Landscape with the Mahakali river as the border between India and Nepal (own source May 2017). .88

Figure 8: A 'rope bridge' over the Mahakali River (own source May 2017) .88 


\section{Tables}

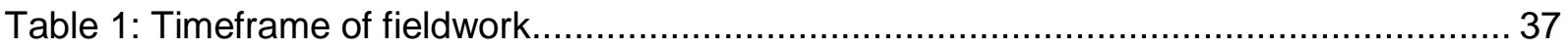

Table 2: Detailed characteristics of the collection sites (modified according to Wallrapp et al.

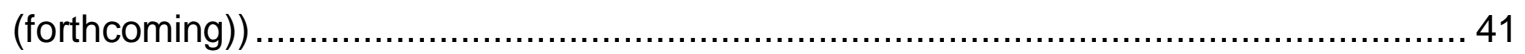

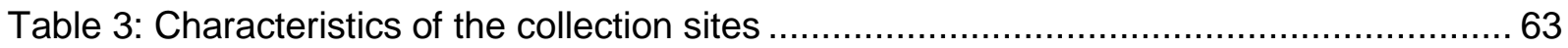

Table 4: Interviews and focus group discussions conducted in 2016 and 2017 ..................64 64 


\section{Acronyms}

ANCA Api Nampa Conservation Area

CHEA Central Himalayan Environment Association

DNPWC Department of National Parks and Wildlife Conservation

DoF Department of Forests

FGD $\quad$ Focus group discussion

GIZ Deutsche Gesellschaft für Internationale Zusammenarbeit (GIZ) GmbH

GPN Global production network

ICIMOD International Centre for Integrated Mountain Development

KSLCDI Kailash Sacred Landscape Conservation and Development Initiative

MAP Medicinal and aromatic plant

MoFSC Ministry of Forests and Soil Conservation

NTFP Non-timber forest product

SFD State Forest Department

TAR Tibet Autonomous Region 


\section{Preface}

An extract from my field notes from Nepal, May 2017:

'After a long day of walking along the Mahakali River in Nepal, which forms the border to India, we reach a small remote village with approximately 30 houses. An elderly woman welcomes us. Her son sits next to her, busy packing food items. It is the beginning of May. The yarshagumba season has started. The village seems empty. Many residents of the nearby villages have already gone or are preparing to go to the remote yarshagumba collection sites up in the mountains in the coming days. After drinking tea the son takes us to the only 'lodge' of the village, where we can get dinner and stay the night. The 'lodge' is a two-story building with a shop and restaurant on the ground floor and sleeping and storage space under the roof. Next to the 'lodge' is the newly constructed Api Nampa Conservation Area (ANCA) office where staff is busy registering yarshagumba collectors and collecting the fees for the entry permit to the collection sites. Some villagers take a permit; others just pass by. On the other side, the local police post is located with a few police officers stationed there. Not far away down at the Mahakali River a steel rope is installed to cross the river - and border. Local people use it for their daily movements across the river. It is not an official border crossing point, but Indian and Nepali authorities seem to accept its existence and "do not bother much" (interview with young man from the village). We sit down, drink tea and observe the life around the 'lodge'. The lodge-owner sells food items like rice, sugar, packed noodle soups and biscuits and other equipment like plastic sheets, foam mats, batteries, torches and ropes - essential items to camp in the remote yarshagumba collection sites for several weeks. In the evening a man arrives who is returning from collection. He is in a good mood and orders several drinks of locally brewed strong alcohol. Later we will get to know that he had taken a loan from the lodge-owner to purchase food and equipment in exchange for selling his collected yarshagumba to the lodge-owner for an agreed price in advance. During the evening, more people arrive: other villagers and a local shepherd and trader with more than 40 goats to transport grain, salt and other items to the upper valley and across the border to Taklakot, China. They come to have drinks and snacks and to hear the latest news. Also some of the ANCA officials and police officers join.

The described village lies in a very strategic location in the transboundary region of India, Nepal and China. On the one hand, it is an important overnight station along the trail from Darchula town, Nepal, to Taklakot, China and from the yarshagumba collection sites to town; on the other hand, it links India and Nepal through an important unofficial border crossing point. This remote village is a central trading hub, where most likely legal and illegal yarshagumba worth more than one million USD passes through in a 


\section{Preface}

season. State representatives and non-state actors are closely enmeshed and involved in the yarshagumba network. The simple 'lodge' is a multi-functional place, where traders, yarshagumba collectors, state representatives, businessmen and villagers meet and exchange news, commodities and money.' 


\section{Introduction}

Worldwide, the commercial collection of non-timber forest products (NTFP) has become more and more important as a livelihood source for local communities (Belcher and Schreckenberg 2007; Neumann and Hirsch 2000). It has linked rural areas, where the resources are collected, with global markets, but it has also enforced dependencies between actors. In particular, when prices of the collected resources are high, actors struggle and negotiate to have access to the resource and to benefit from the trade (Le Billon 2001). In these negotiation processes, state and non-state actors form new and adapt existing governance systems regulating resource access and extraction. Actors also build up social and economic trading networks in order to suit their own interests and meet their own demands (Folke et al. 2005; Pahl-Wostl 2009; Van Schendel and Abraham 2005). Regions along borders provide opportunities for forming crossborder networks and using regulatory spaces beyond the national territory for their own benefits. These negotiation processes between actors about access to resources and the resulting trading networks are the focus of this thesis using the case of yarshagumba in the borderlands of India, Nepal and China within the Kailash Landscape. Yarshagumba is a resource collected in the high alpine grasslands of the Himalayas and traded to and consumed mainly in mainland China.

In this chapter, I provide the context and outline of the thesis, as well as a short description of the Kailash Landscape, the phenomenon of yarshagumba and the structure of the thesis.

\subsection{Context of the research}

Worldwide billions of people use medicinal and aromatic plants (MAP) or NTFP for various healthcare, religious as well as cultural purposes and as fibre, food supplements or construction material (Uprety et al. 2016; WHO 2002). This has led to increased commercial collection and harvesting of MAP and NTFP with growing demands on domestic and international markets (Hamilton 2004; Neumann and Hirsch 2000; WHO 2013). For the people involved in the collection and trade, this development provides, on the one hand, income opportunities; on the other hand, the high demands increase the risk of overexploitation and extinction of the resource, and the rise of social conflicts about access to the resource. Thus, commercialisation of collection and trade of NTFP leads to both positive and negative developments in rural areas and, therefore, to pressures on available governance systems to adapt and manage the collection and trade in an equitable and sustainable way (Belcher and Schreckenberg 2007; Kusters et al. 2006). 


\subsubsection{Management of commercial collection of NTFP}

Medicinal plants are an environmental product group traded at local, national and international levels, typically unprocessed, in response to demands from pharmaceutical, cosmetic and food industries (Lange 2006). Most of them are not cultivated but are harvested wild in remote regions of the world (Belcher und Schreckenberg 2007). According to a study by Vasisht et al. (2016) over 700.000 t of medicinal plants, valued at USD 3.6 billion, were globally registered as being exported in 2014. Further, the study calculated that the global export grew by $2.4 \%$ in volume and $9.2 \%$ in value per year from 2000 until 2014. In Asia, India and China are the top consumers of medicinal plants (Kala et al. 2006; Vasisht et al. 2016). Nepal, situated between these two large economies, officially exports over $3000 \mathrm{t}$ (estimated worth USD 3.4 million) to China and nearly $1000 \mathrm{t}$ (estimated worth USD 15.7 million) to India annually (Vasisht et al. 2016). However, most likely the actual figures for Nepal are much higher (He et al. 2018; Pouliot 2016; Pyakurel et al. 2018).

According to global studies, the commercialisation of NTFP collection creates employment opportunities and contributes significantly to community livelihoods and local economic development (Belcher und Schreckenberg 2007; Hamilton 2004; Kusters et al. 2006; Neumann and Hirsch 2000; Schippmann et al. 2006). In many regions of the world, harvesting NTFP is the main source of cash income for local people (Lange 2006; Rasul et al. 2012). This is also the case in many parts of the Himalayan region (Kala et al. 2006; Negi et al. 2016; Olsen 2005; Pouliot et al. 2018; Pyakurel et al. 2018; Shrestha et al. 2014; Wangchuk et al. 2012).

The increased demands for NTFP as well as the intensified collection threaten the sustainable growth of NTFP. Human aspects and environmental conditions are deeply connected and reinforce each other. They are, according to the understanding of 'political ecology,' interlinked with each other and cannot be analysed separately. The management of benefit-sharing and sustainable harvesting practices of a NTFP depends on the biology and habitat of the resource, its market development and the established governance systems for resource management (Negi et al. 2015; Weckerle et al. 2010). Governance systems consisting of various types of actors and institutions regulate, constrain, enable and legitimate the behaviour of individuals and groups in society and the interactions between them (North 1990; Scott 1999). They determine the property rights and regulations for extraction and usage of resources (Ghate and Chaturvedi 2016).

Worldwide, NTFP are collected within different governance systems and property rights regimes. Each habitat has different regulations for extraction and usage of resources. The habitats of NTFP can be state-owned, community or private property such as communitymanaged forests, grazing grounds or protected areas (Acheson 2006; Agrawal and Ostrom 2001). Whether state-owned property with governmental regulations, community property with local-level management or private property is the most suitable governance system for ensuring just access and sustainable management of resources has been under discussion for many years among scholars, policy-makers and representatives of development agencies. There is no simple answer (Acheson 2006; Agrawal 2003; Dietz et al. 2003) and the answers 
have changed over time according to the prevalent discourses of resource management (Doolittle 2010).

\subsubsection{NTFP collection and trade in the Himalayas}

The ecological diversity of the Himalayan Mountains makes the area a habitat with a vast range of available NTFP with high market values (Kala et al. 2006; Uprety et al. 2016). Due to the rising demand for NTFP from the Himalayan region, prices on the local, national and international markets have increased over the last years (Pyakurel et al. 2018). Consequently, over the last decades, the region has faced more intense harvesting of NTFP by the local communities and at the same time the region has faced habitat loss for NTFP due to land use change, deforestation and over-grazing (Ives and Messerli 1989; Uprety et al. 2016). In addition, power asymmetries between actors within the collection and trading networks and poor legal frameworks threaten the sustainable management of NTFP in the region (Gaull and Hauser 2009; Heinen and Shrestha-Acharya 2011; Kunwar et al. 2013; Pauls and Franz 2013). This is in line with the understanding of political ecology regarding, on the one hand, how humans affect the environment and political and economic relations determine environmental changes; and on the other hand, how environmental changes lead to socio-economic changes and further to political implications (Bryant and Bailey 1997; Robbins 2012).

Out of all NTFP collected in the Himalayas, yarshagumba (English: caterpillar fungus; ophiocordyceps sinensis) is the most valuable medicinal product ${ }^{1}$ (Negi et al. 2016; Shrestha et al. 2014). It is collected in the Himalayan high alpine grasslands of Bhutan, India and Nepal and on the eastern Tibetan plateau in China, and it is mainly traded and consumed in mainland China (Winkler 2009). Its prices have increased tremendously since the late 1990s (Yeh and Lama 2013) leading to rapid socio-economic transformations in the communities and ecological changes in the high-alpine grasslands (Cannon et al. 2009; Negi et al. 2006; Shrestha and Bawa 2014). Over the last few years in several collection sites in Nepal and India, it was documented that the yarshagumba collectors have perceived that their collected amount of yarshagumba per season is declining. The collectors relate this perception mainly to overharvesting and overall degradation of the habitat (Negi et al. 2016; Pant et al. 2017; Shrestha and Bawa 2014; interviews in the collection sites April to June 2017). Further, in the whole Himalayan region the number of collectors has risen and social conflicts about access to the collection site have increased leading to several casualties during the season every year (ANCA 2016; ICIMOD 2015; ICIMOD 2016; Mansarowar National Daily 2017; Singh 2017; The Record Nepal 2014). Most of the habitats for yarshagumba in the Himalayas in India and Nepal are either state-owned or community properties located within protected areas, community

\footnotetext{
${ }^{1}$ Although, strictly speaking, yarshagumba is neither a medicinal plant nor a NTFP, it is placed under these categories in Nepali and Indian official documents, as well as in scientific literature (Caplins 2016; Pant et al. 2017). Specifically, it is not a NTFP because it is not a forest product, but instead grows above the tree-line, and it is a fungus, rather than a plant. As a natural product collected for medicinal purposes, it fits within these categories for the purpose of discussion of resource management and trade.
} 
forests or state forests (Negi et al. 2006; Pant et a. 2017), which determines the access and management rights of collectors from nearby villages and from villages further away.

In general, as is well documented in the literature, for natural products with high market prices the collection is intensified, which raises the pressure on the resource. This creates new demands and conflicts between users about access and extraction, and increases the risk of overharvesting and extinction of the resource (Belcher and Schreckenberg 2007; Kusters et al. 2006). Further, high prices encourage informal trade structures (cf. Le Billon 2001). These developments are also seen in the case of yarshagumba, which I call the 'yarshagumba phenomenon' (further details about the yarshagumba phenomenon are provided in section 1.4). The governance systems in which NTFP are embedded, are under pressure to adapt and respond properly to these forces, especially when these changes happen suddenly (cf. Anderies et al. 2004; Dietz et al. 2003; Pahl-Wostl 2009; Young 2009). How do communities and government authorities in the Himalayas adapt to these changing developments, forces and conditions? What negotiation processes are triggered between actors to secure or gain access to the highly valuable resource and benefit from its trade?

'Bundles of rights' alone do not determine the access to resources. People's ability to access a resource and to participate in its trade also depends on social relations, cultural norms, their power within the context, and political and economic conditions (Hendersen et al. 2002; Ribot and Peluso 2003). Introducing the case study and the local context of the thesis, the extract from my field notes presented in the preface shows that power and political and economic interests of state and non-state actors influence access to the resource yarshagumba, the benefits from the high-value resource and the traded quantity. The people living in the borderlands of India, Nepal and China, called the Kailash Landscape (further introduced in section 1.3), are highly connected across the borders and take advantage of the possibilities in the borderland by establishing trans-border networks. This enables them to participate in a very lucrative, but partly informal production network.

\subsection{Outline of the research}

This section includes the elaboration on the research gap in the available literature on commercialisation of NTFP in relation to studies on governance systems and political ecology. Policy implications of this gap are also addressed. This literature review is followed by an explanation of the aim of the thesis and an introduction to the two parts of the thesis - the collection and trade of yarshagumba.

\subsubsection{Research gap - studies on NTFP and political ecology}

Most studies analysing the commercial collection and trade of NTFP apply a value or commodity chain approach; only few of them link the commercialisation of NTFP to in-depth analysis of dependencies and power relations between actors influencing the collection, 
processing and trading processes. Many comparative and case studies of NTFP collection for the national or international market apply a value or commodity chain approach to analyse the actors' involvement and economic benefits in the production, processing and marketing of the commodity in a linear network structure. They measure the contribution of NTFP commercialisation to local livelihood systems and how costs and benefits are distributed along the value chain and between the different actors (Belcher und Schreckenberg 2007; Kusters et al. 2006; Neumann and Hirsch 2000; Shrestha et al. 2017). Further, these studies analyse the relation between commercialisation of collection of NTFP and environmental impacts. Kusters et al. (2006) conclude, although communities are highly depending on the resource and have a high interest to ensure sustainable resource production, often the commercial collection of NTFP has negative environmental impacts. Also, they highlight that most of the NTFP are not cultivated, but collected wild in remote areas, where often property rights regimes are either not clear or not respected by collectors.

In this regard, studies from the Himalayan region examine property right regimes and their impact on access rights of local population to their resources, as well as on resource management. In particular, these studies focus on the community-managed forests and protected areas in Nepal and India and on the analysis of the socio-economic and ecological situation and/or management structures for NTFP (Agrawal and Ostrom 2001; Dhakal 2014; Kanel and Kandel 2004; Kumar 2006; Paudel 2004; Singh 2016; Subedi et al. 2013; Thoms 2008). These studies on value chains and property rights regimes examine the close relationship between socio-economic systems and environmental systems, as well as resource rights and regulations, however, the political dimension within the value chain of a NTFP and how these processes trigger changes within governance systems are less addressed.

Also in relation to yarshagumba collected in the Himalayas and on the Tibetan plateau, several studies have been published to analyse its impacts on livelihood systems and on the ecology of its habitat over the last 10 to 15 years (Baral et al. 2015; Caplins 2016; Childs and Choedrup 2014; Hopping et al. 2018; Linke 2017; Negi et al. 2006; 2016; Pant et al. 2017; Pyakurel et al. 2018; Tan 2018). Most of these studies are case studies focusing on one specific collection site or valley in the mountains of Bhutan, China, Nepal or within India's Uttarakhand state (Bum 2016; Cannon et al. 2009; Pouliot et al. 2018; Sharma 2004; Shrestha and Bawa 2013; 2014; Shrestha et al. 2014; 2017; Singh et al. 2010; Stewart 2014; Thapa et al. 2014; Weckerle et al. 2010). The studies mainly apply an apolitical approach, analysing the livelihood dependency of local communities on the resource and the management systems regulating the collection in specific sites. The studies are generally uncritical towards power relations and negotiation processes between state authorities and non-state actors as ways of understanding actors' access and involvement. The political and economic dimension in relation to environmental change in line with the understanding of 'political ecology' receives relatively little attention.

One of the aspects of political and economic dimension in relation to environmental change is the marginalisation of the local population. The marginalisation of the local population can be one outcome of their dependency on one resource as livelihood income, which is something 
only a few recent studies in the region have explored. These studies analyse governance systems and power relations involved in the collection and trade of NTFP using the perspective of political ecology (Caplins 2016; Stewart 2014; Tsing 2015; Yeh and Lama 2013). They emphasize the social construction and production of resources, which leads to a process of marginalisation of local communities that depend on natural resources like NTFP. Although NTFP habitats are usually located in remote regions, they are not isolated, but connected to global markets through the commercial collection and trade of NTFP. The regions are integrated in market structures and processes associated with globalisation. The local communities can become marginalised within the processes of globalisation and commercialisation of resources due to communities' increased dependency on one resource, the power asymmetries between actors, and the political and economic dimensions within the production network of resources (Stewart 2014; Yeh and Lama 2013).

In contrast, marginalisation is not necessarily an outcome of all commercial NTPF collection processes in rural areas. While Stewart (2014) and Yeh and Lama (2013) elaborate in detail about the marginalisation processes of the local Tibetan population in relation to yarshagumba collection on the eastern side of the Tibetan plateau in China, Caplins (2016) emphasizes that the dependency of the local population on yarshagumba in the Garhwal region, India, also empowers the local population to regulate the access to their collection sites and to manage their resources themselves. She focuses mainly on the perspective of the local population and their adaptation processes to the changing conditions. The role of the state as sovereign forming regulatory spaces, as well as the interrelations between state and non-state actors and the negotiation processes that are triggered between them regarding who will benefit from the resource have not been explored in detail. In this thesis, I build up on the approach and findings of Caplins (2016) to look further in detail at the governance systems of the commercial collection of yarshagumba and its adaptation processes, the role of the state authorities and local population, and their interrelations between each other. The marginalisation processes play a role in the whole yarshagumba phenomenon, but they will be not explicit analysed further in this thesis.

In the commercialisation of NTFP, besides the collection of NTFP, the trade plays a key role in the production network of resources. Up to now, knowledge about governance systems and interrelations of state and non-state actors within the NTFP trade structures and the networks across borders is limited. He et al. emphasize that "details of market flows and the value of plant material traded are rather scarce in the literature, and the governance of cross-border trade for MAPs [in the Himalaya] is particularly poorly understood" (2018: 101). Although the NTFP collection and sale in Nepal, especially of yarshagumba, is such an important livelihood source for communities in the mountain region (Childs and Choedrup 2014; Shrestha et al. 2017; Uprety et al. 2016) as well as important revenue for the Government of Nepal, only a few recent regional studies on trans-boundary commodity trade networks between Nepal and India (Choudhary et al. 2014; Gellner 2013; Hausner and Sharma 2013; Subedi et al. 2013) and between Nepal and China (Harris 2013; He et al. 2018; Shneiderman 2013) exist. Some of the studies focus on value chain analysis of specific NTFP or medicinal plants (Choudhary et al. 
2014; Subedi et al. 2013); others follow traditional trading routes and network structures across borders in the Himalayan region to study the trade flows and volumes (Harris 2013; He et al. 2013).

Shneiderman (2013), Gellner (2013) and Hausner and Sharma (2013) use a different approach by taking a non-state centric perspective (cf. Scott 2009) to analyse social and economic crossborder network relations of local communities looking from both sides of a border. Building on the ideas of Scott (2009) and Goodhand (2005), they understand border regions and borderlands as regions at the margin of states, where sovereignty is not fully enforced or even non-existent. They argue that state and non-state actors act within, beside and outside governmental regulations and form new regulatory spaces and networks beyond national borders (cf. Van Schendel and Abrahahm 2005). Scott (2009) speaks of resistance of the local population to the sovereign power of the state. Like Caplins (2016), these scholars focus mainly on the perspective of the local population to analyse and explain their point of view and understanding of networks, trade and cross-border movement.

So far in the literature on commercialisation of NTFP, the interrelation of the governmental systems and the perspectives of actors to analyse the local realities in relation to access to resources and cross-border networks and trade are limited. Furthermore, in borderlands at the margins of states, the roles and relations of state and non-state actors across the border and their negotiation processes to form adaptive governance systems and networks for crossborder trade have not been examined in depth as yet. These topics are therefore the focus of this thesis.

These gaps in the research also translate into a lack of attention to aspects of political ecology in policy discourses in relation to the yarshagumba phenomenon. In the last five years, the issues related to yarshagumba in the high mountain areas have arrived on the agendas of government officials in the ministries and state departments of India and Nepal. However, policy- and decision-makers in the governments of India and Nepal continue to see the issues as regulatory and managerial challenges. The prevalent opinion on government level is that overharvesting of yarshagumba and social conflicts about access to its collection sites are mainly due to the increased number of collectors and unsustainable harvesting rules and techniques. For them, the solution is to get a deeper understanding of the bio-geographical conditions of yarshagumba to address its challenges (ICIMOD 2016; interviews with government representatives of State Forest Department (SFD) of Utttarakhand State, India and of Department of Forests (DoF) and Department of National Parks and Wildlife Conservation (DNPWC), Nepal, 2016 and 2017). They argue that if the bio-geography of yarshagumba is better understood (further details see section 1.4) and its carrying capacity within a habitat known, revised governmental regulations can be formulated, in order to limit the total collected amount per collection site and to ensure sustainable harvesting of the resource by the collectors. This will lead to a sustainable income source for the local people. The more complex interrelations between state and non-state actors on multiple scales, the governance systems 
in the collection sites and which role the border plays in this regard, aspects that political ecology points to, are given less attention so far.

\subsubsection{Aim of the research, its approach and research questions}

This thesis aims to contribute to the broader questions of commercialisation of NTFP collection and trade, governance systems of common resources and related negotiation processes of state and non-state actors to benefit from the extraction and trade of local resources. Following the perspective of political ecology, the thesis provides an in-depth understanding of negotiation processes of state authorities and non-state actors to shape governance systems for regulating NTFP collection and to shape trade networks in order to benefit from the available resources. Central questions are:

- How do actors adapt governance systems regulating commercial collection and trade of the resource in response to changes in relation to the resource, like an increased resource value?

- What kinds of production networks emerge in borderlands?

- What roles do state and non-state actors play in the negotiation processes shaping governance systems that control access to and benefit from commercial NTFP collection and trade in borderlands?

The thesis uses the case of yarshagumba collection and trade in the remote high Himalaya of the Nepal-India trans-boundary region within the Kailash Landscape to explore these questions. The Chinese part of the Kailash Landscape is less in the focus. The production network of yarshagumba in this trans-boundary region became highly complex because its value increased tremendously within a short time (Pouliot et al. 2018). On the one hand, more actors appeared demanding access to the resource, the dependency of the local communities on the resource increased, signs of habitat degradation became visible and the risk of overexploitation of yarshagumba has risen (Pant et al. 2017; Shrestha et al. 2017). As a result, local communities are vulnerable to other actors' decisions, any environmental or economic changes, and deteriorations of the situation.

On the other hand, state and non-state actors reacted to the changing conditions through innovative human actions. They formed new institutions, established networks using opportunities across national borders and adapted governance systems to regulate the resource extraction and trade for their own benefit. I argue that the local population are not vulnerable and passive players in the yarshagumba phenomenon. They are active participants, along with the local state authorities, in shaping the governance systems to regulate the access and to benefit from the resource. These established governance systems are the outcomes of negotiation processes between state and non-state actors. Rather than formal rules and regulations, negotiation processes between actors play a key role in determining who has access to the resource and who benefits from the trade network. 
The thesis analyses the developments of governance systems in Nepal and India and the relationships between actors on local, national and trans-boundary levels for collection and trade of yarshagumba. The case study asks how governance systems have adapted to the changes due to the value increase of yarshagumba and the further developments it has triggered in the trans-boundary region. It also asks what kinds of production network for yarshagumba emerged in the borderland within the Kailash Landscape. Further, what roles do state authorities, communities and other actors in the borderland play to change, bypass or use regulations in order to develop new governance systems to benefit from the collection and trade of yarshagumba? In this regard, political ecology provides an important basis to critically scrutinize the political, social and economical dimensions of the collection and trade of the natural resource yarshagumba.

The thesis focuses on two different aspects of the production network of yarshagumba: the collection and the trade. The consumption of yarshagumba is not further addressed here. Using the field of political ecology as the basis for the thesis I integrate different research concepts, like governance of and access to natural resource (Agrawal 2003; Ostrom 1990; 2005; PahlWostl 2009; Ribot and Peluso 2003), global production networks (Hendersen et al. 2002) and studies on borderlands (Gellner 2013; Goodhand 2005; Van Schendel and Abraham 2005) to focus in detail on specific aspects of the collection and trade of yarshagumba in part 1 and part 2. The focus of parts 1 and 2 is further described in the following.

The first part of the thesis focuses on the governance systems regulating access to and management of yarshagumba collection. The extended abstract Wallrapp et al. (2018) 'Institutional Issues, Power Struggles and Local Solutions - Governance Systems of Yarshagumba Collection in India and Nepal in the Kailash Landscape'2 (presented in Chapter 4) and the publication Wallrapp et al. (forthcoming) 'Governing the yarshagumba 'gold rush': comparative study of governance systems in the Kailash Landscape in India and Nepal3 (presented in Chapter 5) contribute to the scientific discussion on governance of commons when rapid changes in the social-ecological systems occur (Ostrom 1990). Adaptive capacities of systems and learning processes have been identified as essential elements of governance systems for governing social-ecological systems during periods of abrupt change (Dietz et al. 2003; Agrawal 2003); in this case, the tremendous increase of the value of yarshagumba within a short time. The case study focuses on the adaptive capacity and multi-level learning

\footnotetext{
2 Wallrapp, C. Keck, M. and Faust, H. (2018): Institutional Issues, Power Struggles and Local Solutions - Governance Systems of Yarshagumba Collection in India and Nepal in the Kailash Landscape. In: Aktuelle Forschungsbeiträge zu Südasien, 8.Jahrestagung des AK Südasien, 19./20. Januar 2018, Köln edited by C. Butsch, A. Follmann and Müller J. Schriftenreihe des Arbeitskreises Südasiens in der Deutschen Gesellschaft der Geographie.

3 Wallrapp, C., Keck, M. and Faust, H. (forthcoming): Governing the yarshagumba 'gold rush': a comparative study of governance systems in the Kailash Landscape in India and Nepal. In: International Journal of Commons, accepted for publication.
} 
processes of community-led and governmental governance systems in India and Nepal, building the analysis mainly on the resource governance learning concept of Pahl-Wostl (2009).

The case study is a comparative analysis of the governance systems in India and Nepal, as the two regions in India and Nepal differ in terms of both legal and social context. In Nepal yarshagumba collection and sale in all community forests and conservation areas is legal (MoSFC 2017). In India, in contrast, the commercial collection of yarshagumba is legal only in community forests and sale is allowed only with the previous approval of the State Forest Department (Uttarakhand Biodiversity Board 2017). However, collection happens wherever possible in India and an informal trading network to Nepal enables the trade of the collected products (Caplins 2016; Negi et al. 2016). In order to get a better understanding of the existing and adapting governance systems, the comparative study asks the following research questions:

- What developments can be identified in the institutional settings and the management mechanisms in areas where yarshagumba is collected?

- What are the learning processes of governmental actors, communities and formal and informal institutions and how do these influence each other in the process of adapting to rapid changes in the high alpine grasslands of India and Nepal?

The second part of the thesis focuses on the trade of yarshagumba by studying the trans-border connectivities, power and embeddedness of state and non-state actors in the borderland of the Kailash Landscape. While yarshagumba is traded from the Himalayan Mountains of India and Nepal via several towns and cities into China, I focus only on the production network in the rural Kailash Landscape within India and Nepal. The production network consists of three processes interrelated with each other. Firstly, the governmental marketing system for NTFPs in India is legal, but disadvantageous, for Indian collectors and traders. Secondly, their preferred informal trade route to sell their yarshagumba harvest runs from India through Nepal. Thirdly, the legalization process through the Nepali governmental mechanism is used for yarshagumba harvested both in India and Nepal. The publication Wallrapp et al. (2019) 'Production networks and borderlands: the cross-border yarshagumba trade in the Kailash Landscape'4 (presented in Chapter 6) analyses this part of the production network in-depth by linking the concept of global production networks by Hendersen et al. (2002) with findings from borderland studies (Doevenspeck 2011; Goodhand 2005; Nordstrom 2000; Van Schendel and Abhraham 2005). Taking a non-state centric perspective (Gellner 2013; Scott 2009), studying the cross-border activities from both sides of the state border (Baud and Van Schendel 1997) and using the perspective of the local population and of relevant local state actors (cf. Doevenspeck 2011) enables an in-depth analysis of the informal cross-border trade network of yarshagumba in the borderland of the Kailash Landscape. In the case study, we focus the analysis on the power and embeddedness of state authorities and non-state actors on both sides of the border and

\footnotetext{
${ }^{4}$ Wallrapp, C., Faust, H. and Keck, M. (2019): Production networks and borderlands: cross-border yarsagumba trade in the Kailash Landscape. In: Journal of Rural Studies 66: 67-76.
} 
relate the findings to the function of a border as line of separation. The guiding research questions are:

- How are state authorities and non-state actors in the yarshagumba trade network socially and economically embedded and connected across the border?

- What role does the border play in the trading system of yarshagumba in the borderlands of the Kailash Landscape?

In the process of trans-border connectivity, actors in borderlands question, negotiate, subvert and re-enforce borders. At the same time borders influence the configuration of production networks in borderlands.

The production networks of NTFP in border regions are complex. By dividing the analysis of the production network of yarshagumba into two parts - the collection and the trade - I am able to present an in-depth case study on the commercial collection and trade of NTFP in margins of states, like mountain and border regions, using a political ecology perspective and combining it with other related fields of research. Both parts examine negotiation processes of state and non-state actors, the social, economic and political relations between actors and the existing governance systems consisting of governmental regulations and communal arrangements, which determine access to a resource and its trading network.

Looking beyond the case study, the thesis contributes to the field of governance of commons and global production networks. It provides suggestions to further link the concept of global production networks with findings of borderland studies. Furthermore, for policy-makers and for international and national development agencies supporting the policy-making process, the thesis is highly relevant to have an in-depth understanding of the underlying political and economic dimension of resource extraction and market structures of NTFP in the Himalayas in order to decide about the 'right' steps towards development of the region and sustainability of natural resources.

\subsection{The Kailash Landscape}

The Kailash Landscape is a cross-border area encompassing parts of three countries: China, India and Nepal. It is an area of approximately $31,000 \mathrm{sqkm}$ and includes the State of Uttarakhand in India, Pulan County in the Tibet Autonomous Region (TAR) in China and parts of far western Nepal including the districts Darchula, Baitadi, Bajhang and Humla (currently under Province 7 following federal restructuring) and the protected area Api Nampa Conservation Area (ANCA) (ICIMOD 2010).

In 2009, the Governments of China, India and Nepal agreed to work together on cross-country issues in the border region, which they called the Kailash Landscape. In the Himalayas, the Kailash Sacred Landscape Conservation and Development Initiative is the first initiative between the three countries to exchange data and work jointly on identified local, national and 
cross-country issues related to environment and livelihood systems. Since 2009 several crosscountry projects have been initiated based on a regional cooperation framework.

The Kailash Landscape is a culturally rich and ecologically diverse region with an elevation range from below 600 masl up to over 7000 masl (ICIMOD 2010). Especially the Indian and Nepali parts of the region are characterised by high mountains and deep valleys with forest cover, agricultural areas and alpine grasslands above 3200 to 5000 masl. In contrast, the northern part of the Kailash Landscape on the Tibetan Plateau in TAR, China is mainly characterised by high alpine rangelands with pastoral activities (ICIMOD 2017).

The region is far from the capital cities Delhi, Beijing and Kathmandu and considered remote and on the margin of these states from the viewpoint of the different governments. On the other hand, the region is highly culturally, economically and socially connected across the three countries, as it has been for centuries (Bergmann, 2016; ICIMOD 2011), and as this study shows, the region is highly influenced by global demands and processes.

The research for this thesis was conducted in only specific areas of the Kailash Landscape, mainly focusing on the high mountain areas of Nepal and India. Yarshagumba is mainly collected in these areas, and the borderland of Nepal and India along the Mahakali valley is an area with well-established cross-border trade networks for yarshagumba and other medicinal and wildlife products from the region. On the Chinese side of the Kailash Landscape yarshagumba is not found. I conducted research on both sides of the border in the Kumaon region in the State of Uttarakhand in India and the adjacent protected area ANCA in Darchula District in Nepal. Within this area, I focused on two valleys on the Indian side, Darma and Johar valleys, and two valleys on the Nepali side, Chamelyia and Mahakali valleys. The selection of the valleys is further described in section 3.4. In the following I use the term Kailash Landscape to indicate not the entire transboundary region, but instead this selected study area within this wider region. See figure 1 for localising the study area within the context of the Kailash Landscape and Asia. 


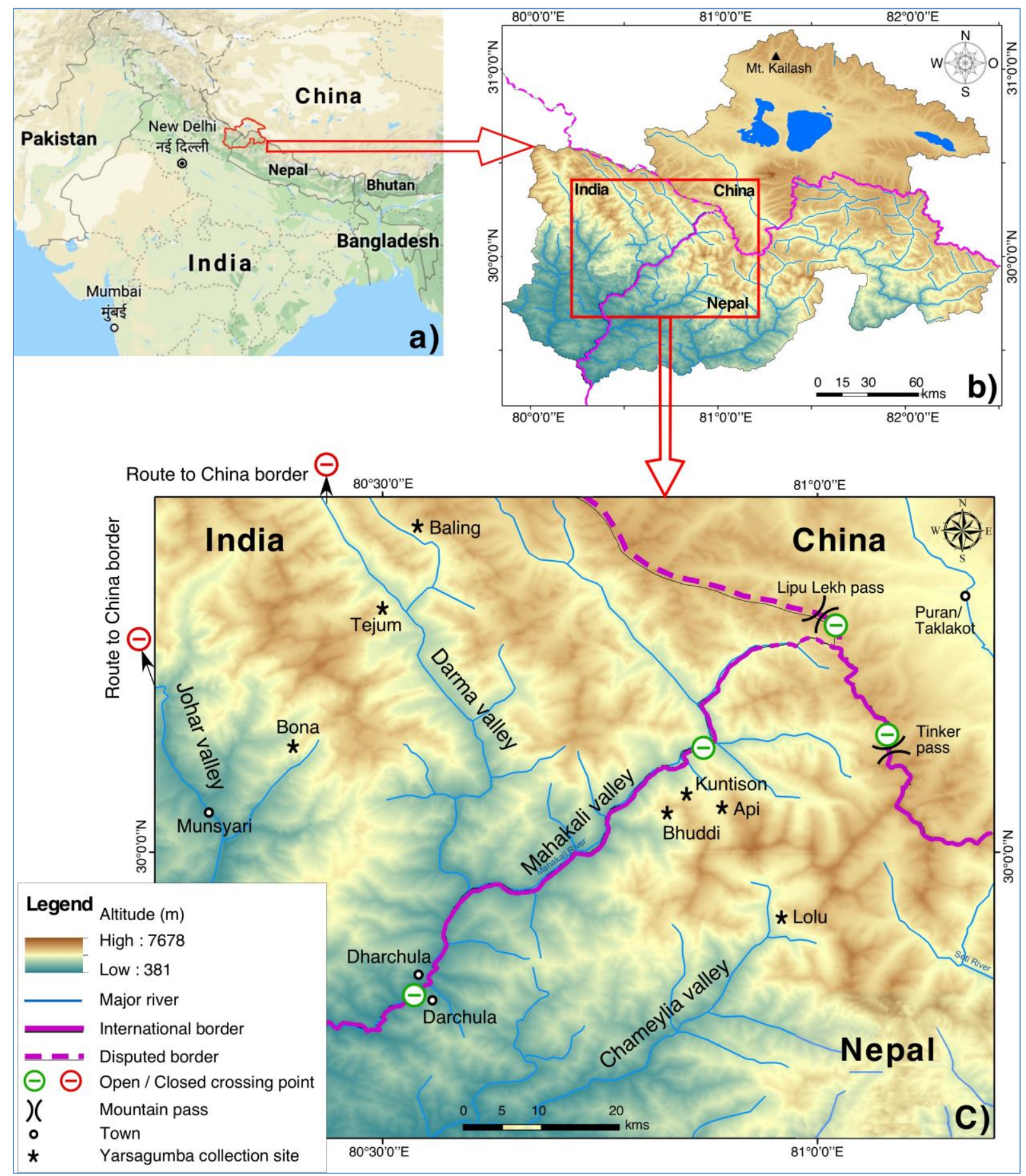

Figure 1: Localising the study area: a) overview map of Asia, b) map of the Kailash Landscape and c) the border region of India, Nepal and China with the four research valleys and selected yarshagumba collection sites (detailed and Kailash map: own source, based on ICIMOD 2017; overview map: map data 2018 google)

In the Kailash Landscape, two ethnic groups are predominant: a community that is known as the Rang in India and the Shauka in Nepal, and a community that can be characterised by their religious affiliation to the Hindu community. The Rang/Shauka community is an indigenous group and listed as indigenous tribe in India and Nepal. They are located in the upper parts of the Johar, Darma and Chaudans valley in India and in the upper parts of the Mahakali valley in 
Nepal. In the Chamelyia valley in Nepal and in the lower parts of the Indian and Nepali valleys the Hindu community is dominant.

The Rang/Shauka community traditionally practiced transhumance and trans-Himalayan trade linking the Gangetic plains with the trading town Taklakot/Burang in Pulan County, China on the Tibetan Plateau (Leder 2003). Over the centuries, they have established a well-functioning trade system with social and economic networks across the neighbouring countries (Bergmann 2016). In line with this trading system, they have established a livestock grazing system that is highly adapted to the diverse ecosystems in the Himalayan region, which offer only seasonally sufficient resources for grazing. Due to these limited resources and harsh conditions, the Rang/Shauka community has developed a close sense of community and strict customary laws to regulate access to and usage of their trading routes and pasture areas (Hoon 1996; Leder 2003). Their summer pasture areas are nowadays also yarshagumba collection sites. Although the Indo-China war in 1962 and the dominance of the Chinese on the Tibetan Plateau reduced their seasonal movements and trade systems, they continue some of their practices and most customary laws are still alive (Bergmann 2016). The Hindu communities of this study area in the lower parts of the valleys are less homogenous and depend mainly on subsistence farming and external labour work (Pathak et al. 2017).

The increased demands of NTFPs and particularly the price increase of yarshagumba in the late 1990s on the Chinese market (Pauls and Franz 2013; Yeh and Lama 2013) changed the livelihood strategies of most local people in the Kailash Landscape over the last 10 to 15 years (Negi et al. 2006; 2016; Pant et al. 2017). Besides yarshagumba, chiraito (swertia chiravita), panch aunle (dactylorhiza hatagirea), kutki (neopicrorhiza scrophulariflora), jatamansi (nardostachys jatamansi), ban lasun (wild garlic) and satuwa (paris polyphylla) are important NTFP for commercial collection and trade in the Kailash Landscape (Kala et al. 2006; Olsen 2005; Uprety et al. 2016; interview with representatives of trader associations). However, since the early 2000s yarshagumba is the most valuable natural resource in the Himalayas (Childs and Choedup 2014; Shrestha and Bawa 2014; Shrestha et al. 2017). It is therefore not surprising that the local population has adapted their livelihood systems to concentrate on yarshagumba collection and sale in the region and that other actors from distant villages and even state representatives are interested in benefitting from this highly valuable resource. Consequently, the access to the collection sites and the trade of yarshagumba is highly contested by the different actors.

\subsection{The yarshagumba phenomenon}

Yarshagumba is biologically, ecologically, socially, economically and politically an interesting resource and since its market increase, has triggered many changes and developments in the Himalayan region. In the following, I call these changes and developments the yarshagumba phenomenon. 


\subsubsection{Bio-geography of yarshagumba}

Yarshagumba, or yarsagumba, is the Nepali word for ophiocordyceps sinensis, or in English 'caterpillar fungus'. In Tibetan language the fungus is called yartsa gunbu, which means literarily 'summer grass - winter worm', or dōng chóng xià căo in Chinese, which means the inverse 'winter worm - summer grass' (Yeh and Lama 2013). These names reflect the indigenous understanding of a life cycle in which an insect transforms into a piece of grass. In this study I will use the term yarsagumba or yarshagumba.

The rare fungus is found only in the high mountain areas of the Himalayas of India, Nepal and Bhutan and the eastern part of the Tibetan Plateau in China (Cannon et al. 2009; Sharma 2004; Shrestha and Bawa 2013; Singh et al. 2010; Thapa et al. 2014; Winkler 2009). It is distributed in grass- and shrub-lands at an altitude of 3000 to 5200 masl and that receive a minimum of $250 \mathrm{~mm}$ average annual precipitation (Negi et al. 2015; Winkler 2009).

In the scientific understanding, yarshagumba is a parasitic fungus growing in the body of a caterpillar of the ghost moth of the family Hepialidea (Cannon et al. 2009). It is actually a combination of two separate organisms forming a complex. The caterpillar larva of the ghost moth acts as the host insect for the fungus. The parasitic fungus infects the larvae while in the ground during the summer. Before the caterpillar larva can mature into a moth, the mycelium overtakes the caterpillar's body, replacing the caterpillar with fungus and thereby killing the caterpillar. In the following spring, just when the snow is melting, the fruiting body of the fungus grows out of the now dead caterpillar's head and protrudes above ground. This protrusion resembles a grass sprout and signals the presence of the body of the fungus in the ground to the local collectors (Negi et al. 2006). If the yarshagumba is not picked by collectors at an early stage while coming out of the ground, the fungus produces spores in the fruiting body and disperses them in late summer (Shrestha et al. 2014).

Many details of the complex interaction between the two life cycles of the fungus and of the moth are not yet fully scientifically understood. The complex biology and difficult accessibility of the habitat of the yarshagumba makes scientific research difficult. Uncertainties are still associated with the specific species of the moth, its life cycle and larval stage as well as its primary food source(s) and other details related to the complex relation between the moth and the fungus (interview with Dr. C. S. Negi, Pithoragarh, India, January 2017). Therefore, it has so far not been possible for biologists and ecologists in the Himalayas to precisely calculate and define the sustainable harvesting amount of yarshagumba and carrying capacity of the habitat (ICIMOD 2016). The bio-geography of the yarshagumba depends on various factors like the complex interaction between the fungus, the host caterpillar, the alpine plants upon which the moths feed and the overall ecological and climatic conditions in the high-alpine grasslands. This makes the production of yarshagumba vulnerable to any changes in its environmental habitat (Hopping et al. 2018; Negi et al. 2015). 


\subsubsection{Medicinal use}

Since several hundreds of years yarshagumba has been known for medicinal use in Tibetan and Chinese medicine. The caterpillar fungus was first mentioned in Tibetan medical texts in the fifteenth century followed by Chinese texts two centuries afterwards (Winkler 2005). Traditional Chinese medicine values it as a tonic to replenish kidney, liver and immune functions and as an aphrodisiac for both men and women. Tibetan medicine uses it for treating hepatitis $B$ and enhancing the immune system, kidney, lung and heart function. It is also used for improving health conditions including fatigue, dizziness, amnesia, heart and respiratory diseases (Yeh and Lama 2013). Baral et al. (2015: 63ff.) provide a summary of potential pharmaceutical use, including what has so far been explored and documented in various studies, mainly from China.

In contrast to the Chinese and Tibetan medicine, in the ayurvedic and other types of traditional medicine in Nepal and in India yarshagumba is hardly known or utilized (Negi et al. 2016). This could be an explanation of why yarshagumba was not valued in the Himalayas before the late 1990s until the demand and prices on the Chinese market increased and the Himalayan region became connected to the Chinese market (Linke 2017; Yeh and Lama 2013).

\subsubsection{Ecological and social developments in the Himalayas}

In the late 1990s, individuals who knew about the high prices for yarshagumba in China searched for new collection sites and were successful in the high alpine grasslands of the southern side of the Central Himalayas in parts of India, Nepal and Bhutan. With this, in the following years, what had been an unknown and unvalued natural resource found in the Himalayas changed to a highly valued and demanded product on the international market. This trend is still on-going and, subsequently, causes rapid socio-economic and ecological developments in the yarshagumba collecting sites in the Himalay as well as in the nearby villages and towns.

The increase in the prices of yarshagumba triggered a 'gold rush' in the Himalayas and increased the dependency of local people on this single resource. For example in the local market in Darchula town, Nepal, the prices increased from approximately 100 USD per $\mathrm{kg}$ in the early 2000s to approximately 12.000 USD per kg in 2017 (interview with representative of ANCA, Nepal, May 2017; Pouliot et al. 2018). Over the last two decades, yarshagumba collection became one of the main sources of income in many high Himalayan mountain villages of Bhutan, India, and Nepal (Cannon et al. 2009; Childs and Choedrup 2014; Negi et al. 2006; 2016; Shrestha et al. 2014; 2017). Today, according to a recent study in ANCA (Nepal) the "average [annual] household cash income from $O$. sinensis is USD $2174 \ldots$ confirming the dominant role of $O$. sinensis in cash generation" (Pouliot et al. 2018: 65). Also on the Indian side Negi et al. highlight the high significance of yarshagumba harvest for the local people: "In fact, the income generated by the Yartsa Gunbu, restricted to a bare one and half months period far exceeds the traditional sources of income combined" (2016: 202). This cash income 
has led people to stop engaging in their traditional livelihood systems like farming and livestock keeping and causes a high dependency of the local people on the collection of yarshagumba every year (Childs and Choedrup 2014; Negi et al. 2016; Shrestha et al. 2017; Wangchuk and Wangdi 2015).

Besides the socio-economic developments, yarshagumba collection has also triggered socioecological implications in the mountain regions and in particular in the collection sites. In the Kailash Landscape each year around 10,000 to 30,000 collectors from nearby villages and other villages in lower areas stay for one to two months (from the end of April until mid-June) in the collection sites and set up temporary campsites along the tree line at altitudes between 3400 and 3800 masl. Earlier, only 10 to 20 shepherds stayed on these pasture areas for livestock grazing in the summer months. Nowadays, the number of collectors has risen to 200 to 3000 per season per site. The actual number of collectors varies from site to site and depends on the location, dimension and management system at the site (ANCA 2016). During their stay they cut firewood daily, tread down plants, while camping and searching for yarshagumba, and lack adequate waste disposal and sanitation facilities.

Collectors stated that in the collection sites of India and Nepal the total amount of collected yarshagumba per person has declined over the past 5 years (ICIMOD 2015; Negi et al. 2015), which was also analysed by Hopping et al. (2018) in the whole Himalayan region and by Stewart (2014) on the Tibetan Plateau. A number of different reasons for the decline are possible. Most likely, the increased numbers of collectors and their stay in the collection sites have an effect on the yarshagumba production and its habitat. Locals also perceive that the fragile high alpine eco-systems are degrading, which might have an impact on the life cycle and food sources of the ghost moth as well. Further, collectors, for instance, harvest pre- and post-mature yarshagumba, which influences the life cycle of the caterpillar fungus (Shrestha and Bawa 2013). Additionally, it is likely that climate change and its effects on the biogeography of yarshagumba also play a role in the production of the fungus as well as the survival and reproduction of the host, the ghost moth (Hopping et al. 2018; Negi et al. 2015; Stewart 2014).

The tremendous increase in numbers of people accessing the grasslands for the collection of yarshagumba, the high dependency of collectors on yarshagumba harvest for cash income, the perceived degradation of the habitat and the perceived decline of the yarshagumba harvest per collector are challenges faced in most of the collection sites in the region. These developments are described and analysed by several scholars in case studies within the region (e.g. Cannon et al. 2009; Linke 2017; Negi et al. 2016; Thapa et al. 2014; Shrestha and Bawa 2013; 2014; Pant et al. 2017; Tan 2018; Weckerle et al. 2010). Most of these case studies focus on the analysis of the socio-economic and ecological situation and/or management structures in one particular valley or collection site. The governance systems and the negotiation processes of actors involved in the yarshagumba collection and trade and how that influences the access, benefits and availability of yarshagumba is less examined in the literature. These aspects are the focus of this thesis. 


\subsection{Structure of study}

For analysing the negotiation processes between state and non-state actors in the production network of yarshagumba I apply different concepts, which are further elaborated in chapter 2. Chapter 3 provides details about the methods for the qualitative research, the applied techniques for data collection, the selection process of the study area and the method for data analysis. The analysis of part 1 of the thesis, focusing on the negotiation processes and governance systems regulating the collection of yarshagumba in the Kailash Landscape, is presented in Chapter 4 and 5. Chapter 4 presents more an overview of the issues related to yarshagumba collection and the respective governance systems in the two countries, India and Nepal. Chapter 5 also analyses and compares the current governance systems in the collection sites in India and Nepal, but provides more details and analysis regarding their adaptive capacities and learning processes.

The analysis in part 2 of the thesis, focusing on the negotiation processes and trade of yarshagumba between India and Nepal in the Kailash Landscape, is presented in chapter 6. Chapter 6 includes a detailed analysis of the governance systems in the borderlands of the two countries, India and Nepal, the configuration and power relations within the informal crossborder network linking state and non-state actors from both countries for trading yarshagumba, and what role the border plays in this regard. Further, in chapter 7, I discuss the central questions of the thesis on the governance systems and roles of state and non-state actors in negotiation processes to shape governance systems in borderlands for accessing and benefitting from local available natural resources. Finally, in chapter 8, I draw conclusions from this research and provide recommendations for ways that policy-makers and international and national development agencies can think differently in policy-making processes related to natural resource management. 


\section{Conceptual framework}

The collection and trade of yarshagumba are part of complex political, social and economic systems in the region regulated by diverse governance systems and involving various types of actors on multiple scales and beyond state borders. I argue that members of the local population are not vulnerable and passive players in the yarshagumba phenomenon, but active participants, along with the local state authorities. Together, both shape the governance systems and networks to regulate the access and to benefit from the locally available resource. These governance systems are the outcomes of negotiation processes between state and nonstate actors. Rather than formal rules and regulations, negotiation processes between actors play a key role in determining who has access to the resource and who benefits from the trade network.

The thesis consists of two parts: (1) the collection and (2) the trade of yarshagumba, in which I focus on different aspects of governance systems and negotiation processes between actors. Thus, I apply different concepts and analyse the two parts separately.

In order to analyse these complex systems and negotiation processes of actors, the conceptual framework of this thesis is based on the broader field of research known as 'political ecology' (section 2.1). For part 1, regarding the collection, the further concepts of governance systems, property rights, common pool resources, adaptive capacity and learning processes are highly relevant (section 2.2). For part 2, regarding the trade, the analysis is based on the concept of global production networks and the research field of borderlands (section 2.3). These concepts are discussed in this chapter in relation to the understanding of political ecology to form the conceptual framework of the thesis. Additionally, in the respective chapters 4 to 6 the concepts are discussed in relation to the specific research questions for part 1 and part 2.

\subsection{Political ecology as the basis of the thesis}

Political ecology developed as a radical critique against the apolitical and de-politicizing effect of mainstream environmental research and practice (Mung'ong'o 2009). Environmental scholars tend to describe resource scarcity, environmental change or conflicts in relation to population growth and intensifying per capita human impacts on the environment. Further, they tend to emphasize 'technical' solutions to environmental problems (Watts 2000). This is for example, also reflected in the prevailing opinion of the policy-makers in Nepal and India about the phenomenon yarshagumba, described in section 1.2.1. Worldwide, this apolitical perspective and the related environmental practices has especially had impact in the research field of development studies on the understanding of phenomena such as deforestation, soil degradation and water scarcity, particularly in the so-called 'third world'. This has also 
influenced the design and implementation of governmental and non-governmental interventions in the form of development programmes (Blaikie and Brookfield 1987; Bryant and Bailey 1997). In contrast, political ecology is a field of research based on the concept of 'political economy' that attempts to provide a framework for understanding the political sources, conditions and ramifications of human-environmental interactions and to promote alternative understandings of livelihood struggles (Peet et al. 2011; Robbins 2012; Watts 2000).

Blaikie and Brookfield, the pioneers of political ecology, have defined the field of research as one that "combines the concerns of ecology and a broadly defined political economy. Together, this encompasses the constantly shifting dialectic between society and land-based resources, and also within classes and groups within society itself" (1987: 17). Watts defines "political ecology' as a lens "to understand the complex relations between nature and society through a careful analysis of what one might call the forms of access and control over resources and their implications for environmental health and sustainable livelihoods" (2000: 257). Fundamental questions of political ecology are related to just and equal access to resources, their distribution and control, and their relationship to the regimes of regulations (Bauriedl 2016). Contemporary political ecology is not a single theory, but rather a broad field of research that examines the interrelations of political economy, ecological processes, power relations and discourses within the environment (Newell 2012) acting on multiple scales (Robbins 2012).

The common premise within political ecology is that, on the one hand, environmental changes and ecological conditions are the product of political and economic processes and, on the other hand, these processes generate or exacerbate environmental changes and conditions (Paulson and Gezon 2004). Environmental changes, crises and conflicts are not created in isolation from political decisions, social and economic conditions. Therefore, they cannot be understood and solved in isolation from the political and economic context. There are strong interrelations between socio-political conditions and environmental changes, crises and conflicts. Thus, the central assumption is that environmental change is not a neutral process amenable to technical management. Rather, environmental change has political sources, conditions and ramifications that affect existing socio-economic inequalities and political processes (Bryant and Bailey 1997: 28).

Other linked assumptions that inform the work of political ecologists are: "they accept the idea that costs and benefits associated with environmental change are for the most part distributed among actors unequally ... [which inevitably] reinforces or reduces existing social and economic inequalities ... [which holds] political implications in terms of the altered power of actors in relation to other actors" (Bryant and Bailey 1997: 28f.). The first part of the assumption refers to the capacities of each person, household or social group to respond to changes to which all are equally exposed. Depending on each ones' capacities a person or group benefits or bears the costs of environmental changes.

The second part of the assumption stresses the point of marginalisation of actors and that environmental and developmental concerns are inseparable. Any change in the environment 
must affect the political and economic conditions and vice versa. In particular, if communities depend on natural resources for their livelihoods, any changes in relation to the natural resource will have effects on the socio-economic situation and with it on the political status quo and governance system. One of the contributions of political ecology was a refined concept of marginality in which its political, ecological and economic aspects may be mutually reinforcing: "land degradation is both a result and a cause of social marginalisation" (Blaikie and Brookfield 1987: 23). Furthermore, pressure of production on resources is transmitted through social relations, which impose excessive demands on the environment (Watts 2000). Consequently, local populations are vulnerable and are becoming marginalised, because the local production systems undergo transitions to overexploitation of natural resources on which these populations depend, as a response to state development interventions and/or increasing integration in regional and global markets (Robbins 2012; Yeh and Lama 2013).

The local communities can become marginalised within the process of commercialisation of resources due to communities' increased dependency on one resource, the power asymmetries between actors, and the political and economic dimensions within the production network of resources. The communities' high dependency on one resource as their main or only livelihood source makes them vulnerable to environmental changes, changes within the market structure of the resource or changes in property rights or rules for collection and trading due to governmental interventions (Yeh and Lama 2013). Global market demands and political and economic decisions of state authorities and powerful non-state actors like traders and consumers, influence the behaviour of local collectors and push them further into dependency on the resource and on other actors' decisions (Caplins 2016; Caplins et al 2018; Stewart 2014). This leads to the marginalisation of local people and degradation of the habitats, which reinforce each other.

The third part of the assumptions refers to the possibilities for resistance and adaptation. Thus, environmental change not only signifies wealth creation for some and impoverishment for others, but it also thereby alters the ability of actors to control or resist other actors. In relation to that, Robbins (2012) emphasizes that political ecology promotes the understanding of livelihood struggles from multiple dimensions and perspectives. To overcome these forces of marginalisation, often local people have created alternatives, adaptations and creative human actions. An example of this in our case is the establishment of communal arrangements for securing or gaining access for local communities to collection sites of yarshagumba. Further, local communities have resisted state interventions or regulations, like state-dictated conservation and protected area guidelines (Bloomer 2009; Robbins 2012). These 'creative' human actions are not always legitimated by law, but can be socially accepted (Scott 1999).

Proximity and access to natural resources combined with the impact of these resources on one's livelihood contributes to the fact that illegal extraction or trade of resources are socially accepted and therefore legitimized by society (Caplins et al. 2018; Shova and Hubacek 2011; Van Schendel and Abraham 2005). In relation to NTFP collection in India and Nepal, scholars document that despite the existence of "various policy measures, excessive and illegal 
gathering of medicinal plants persists" (Negi et al. 2010: 104). These activities or arrangements encourage conflicts between state authorities and communities, as well as between different communities, about resource access (Le Billon 2001). State and non-state actors form new institutions and networks and negotiate power to legitimate access and trade of resources, also beyond national borders (Van Schendel and Abraham 2005). These 'creative' human actions raise questions about governance systems, property rights, legitimacy, function of borders as well as the state and non-state actors' interrelations in these networks and governance systems. Therefore, besides regulatory spaces, social and economic dimensions are central in this thesis to analyse the negotiation processes between actors to shape governance systems for accessing and benefiting from local resources.

\subsection{Governance systems for accessing resources}

Governance systems for natural resources regulate the human-environmental relationships. They are not fixed and static; they are complex constellations. States and communities adapt and modify systems to the changing political and economic conditions and to their own interests. This is also the case in the high alpine grasslands, where changes are triggered by the transformation of the common pool resource 'yarshagumba' from a non-valued resource to a highly demanded product. The governance systems developed in the yarshagumba collection sites are the outcome of negotiation processes of state and non-state actors to adapt to the pressures on the existing governance systems due to the change in the value of the locally available common pool resource. These resource governance systems consist of governmental regulations and communal management arrangements, which have been adapted to the changing conditions. The governance of common pool resources and their adaptation processes and legitimacy are conceptualised in this section.

\subsubsection{Resource - a product of nature}

Before going into the conceptualization of governance systems I reflect on the word 'natural resource'. In recent debates about human-environmental relationships and especially within political ecology, scholars argue that nature, which is not influenced by humans, does not exist. All nature is socially constructed or produced, which is then called 'natural resource' (Castree 2001). The transformation of nature into a resource is influenced by human desires, demands and practices; or, from a political economy perspective, determined by the conditions, means and forces of production through markets and actors (Mung'ong'o 2009). Le Billon (2001) emphasizes that resources are not, they become. Castree and Braun (2001) use the term "social nature" to emphasize on the different ways in which actors socially construct nature. However, it should be not be overlooked that still nature and, therefore, resources have a biophysical and material basis (Demeritt 2000; Escobar 1999), which is in this case study the bio-geography of yarshagumba growing in the high alpine grasslands. 
Castree highlights that "nature is defined, delimited, and even physically reconstituted by different societies, often in order to serve specific, and usually dominant, social interests. In other words, the social and the natural are seen to intertwine in ways that make their separation - in either thought or practice - impossible" (2001: 1). In the case of the resource yarshagumba, most of the actors within the production network, like collectors, traders and state authorities, see yarshagumba only as a lucrative income or revenue source, which suddenly 'appeared' in their mountain regions. In contrast, the Chinese consumers see the species yarshagumba as a highly valuable medicinal product used for curing health issues (Baral et al. 2015). The Nepali and Indian local communities hardly used the product as medicine and do not value it accordingly. For them, it is important that it grows on their high alpine grasslands and ancestors' lands and they can claim property rights for exclusive collection. Until the discovery of yarshagumba, the high alpine grasslands in the Himalayas were of little interest to the governmental authorities and distant communities in Nepal and India. In the last few years, it has led to the design and enforcement of policies and guidelines and to conflicts and negotiation processes between actors. The transformation of nature into tradable commodities is thus a deeply political and social process. It involves the definition of property rights, the organisation of labour and the allocation of profits (cf. Le Billon 2001; Mung'ong'o 2009).

This transformation of resources is not a static process; it is dynamic, continuously changes over time and is influenced by contemporary discourses on for example governance systems for conservation and natural resource management, as well as in our case on medicinal practices. Additionally, institutions, knowledge and power of actors determine the production networks and market structures of commodities (Doolittle 2010; Mung'ong'o 2009). Further, production networks influence the production of nature and impact the local realities (Yeh and Lama 2013). Governance systems determine how much impact is made on the local natural resources due to the commercialisation of the resource, but also the other way around, governance systems adapt to the local realities. They reinforce and influence each other. Thus, yarshagumba and the respective high alpine grasslands are both resources produced through the global market demands.

\subsubsection{Governance systems of commons}

Worldwide, most of the natural resources in remote areas, like forests and high alpine grazing grounds, are still common pool resources (Acheson 2006; Bauer 2004; Herrera et al. 2014). Common pool resources are defined through subtractability (if the resource is used by one person it cannot be used by another one anymore) and difficulties of excluding other people from having access and using the resource (Ostrom 1990; Ostrom et al. 1999). To manage common pool resources justly and sustainably, an effective governance system is required (Dietz et al. 2003).

Governance systems determine property rights and rules to curb the exploitation rate of the resource by establishing a management mechanism to limit access, extraction and trade of the resource (Acheson 2006; Agrawal 2003; Ostrom 1990). Governance systems are understood 
as an interplay of different institutions to describe the process of decision-making and the process by which decisions are implemented (Pahl-Wostl 2009). Institutions regulate, constrain, enable and legitimate the behaviour of individuals and groups in society and the interactions between them (North 1990; Scott 1999). They determine the "framework within which human interaction takes place" (North 1990: 4). In the literature, the distinction is made between formal (governmental) and informal (socially-accepted) institutions. Formal institutions are usually linked to official, governmental or bureaucratic formalities and are legally binding. Informal institutions are mainly based on social norms, socially and culturally shared understandings and rules, which are not formally encoded (Ghate and Chaturvedi 2016; PahlWostl 2009). The actual natural resource governance systems are a complex blend of various formal and informal institutions (Cleaver 2003). All institutions influence the decision-making process of actors regarding the management of natural resources (Ghate and Chaturvedi 2016; Pahl-Wostl 2009).

\section{Property rights and related discourses}

Property rights legitimate the access to and usage of resources. Specifically, for natural resources, property rights can include distinct usage rights, rights to exclude others, management rights, and rights to sell (Agrawal and Ostrom 2001). Worldwide, habitats of NTFP lie within state-owned, community or private property such as community-managed forests, grazing grounds or protected areas (Acheson 2006; Agrawal and Ostrom 2001; Ostrom 1990; Ostrom et al. 1999). Each property rights regime has different regulations for extraction and usage of resources determined by its regulations and laws. However, often property rights for commercial collection or home consumption of NTFP are not clearly regulated and legitimised by state authorities, or property rights contradict each other. Further, often they are not efficiently enforced (Agrawal and Ostrom 2001; Herrera et al. 2014). Whether state-owned, collective or private properties are the most suitable property regimes to manage natural resources has been debated between scholars for several decades. The respective prevailing opinion and discourses have changed over time and have influenced the decision- and policymakers and conservation and development programmes on state-level in the past up to now, worldwide, as well as in India and Nepal.

Over decades, conservation and natural resource management, for example of forests and grazing grounds, has been based on the model of state-driven, top-down protection and management of valuable resources (Singh 2016). This discourse was mainly guided by the understanding that communities are not able to manage resources sustainably due to the "tragedy of the commons" (Hardin 1968). The "tragedy of the commons" emphasizes that it is rational for everyone to free ride on the efforts and costs of others, when incentives for sustainable usage are lacking (Agrawal 2003; Ostrom 1990). Consequently, traditional community lands were nationalised. Communities depending on resources for their livelihood either lost access to these resources or, if they continued using these resources, the activities 
were declared illegal and they were fined and sanctioned by government authorities (Bauer 2004; Doolittle 2010; Herrera et al. 2014).

Building on the discussion about the problematic of 'freeriders' and 'tragedy of the commons', studies about governance of commons come to the conclusion that effective and sustainable natural resource management of common pool resources, if certain conditions are fulfilled to implement, monitor and enforce rules and regulations (Agrawal 2003; Dietz et al. 2003; Ostrom 1990). Ostrom derived eight design principles of sustainable governance of collective property (1990: 90). These are: "clearly defined boundaries, proportional equivalence between benefits and costs, collective-choice arrangements, monitoring, graduated sanctions, conflict-resolution mechanisms, minimal recognition of rights to organise and nested enterprises." In following studies, several scholars reviewed and refined the criteria list (Agrawal 2003; Baland and Platteau 1996; Wade 1994). The scholars tried to generalise the conditions by defining technical and organisational factors influencing the natural resource management. In addition to the criteria list, Agrawal (2003) highlights that local context, power and micro-level politics within communities and groups are critical to understanding how resources are used and managed. This outcome by Agrawal (2003) creates the link to political ecology by looking beyond the more technical and organisational factors describing governance of natural resources. Agrawal puts emphasis also on the socio-economic and political relations of resource management.

Over the past two to three decades, there has been a growing consensus that the active participation of communities is a necessary ingredient to ensure successful conservation and management of common pool resources (Agrawal and Ostrom 2001; Doolittle 2010). This change of the prevailing opinion in the scientific world as well as within governments and leading governmental and non-governmental development organisations has led to the development and implementation of community forest programmes and establishment of conservation areas. In the study area of this research, community forests ${ }^{5}$ and the protected area ANCA in Nepal were established. In these governance models, the communities are seen as partners, who participate in the design, implementation and monitoring of management strategies for the management of their natural resources (Howard 2015; Ostrom 1990).

Recently, these models have been more and more frequently criticized as being ineffective in management and often leading to unequally shared benefits within the community. The apparent participation of communities has not led to more empowerment of communities, as participation of community members was rather reported on paper than practiced and implemented on the ground. Additionally, decisions are still made by government authorities,

\footnotetext{
${ }^{5}$ The van panchayats (community forest councils) in Uttarakhand State of India developed already at the beginning of 20th century due to resistance by the local people to the transformation of all forestland into state-owned property under British-India. After several years of protests and conflicts, the British government accepted the formation of van panchayats in the high mountain regions of today's Uttarakhand State of India and handed over patches of forests around the villages to community councils for their own management (Singh 2016).
} 
development organisations or dominant community members (Howard 2015) than through participatory decision-making processes with the involvement of representatives of the community.

Following the changing conceptualizations of property rights for natural resource management over the last decades, we can see that the prevailing opinion about the 'right' way in which property ownership is defined has changed over time depending on the prevalent ideology, culture and contemporary understanding of human-environmental relationships. Influenced by work within political ecology, more recent studies emphasize that, under various regimes of property rights, access to resources is determined by political, social and economic conditions (Agrawal 2003; Paulson and Gezon 2004; Ribot and Peluso 2003; Robbins 2012).

\section{Power, legitimacy and access}

Coming back to the outcome of the work of Agrawal (2003) that local context, power and microlevel politics within communities and groups are critical to understanding how resources are used and managed, I discuss further what legitimates access to resources beyond governmental regulations. The actors' ability to control, maintain or gain access to resources depends also on the power and social and political-economic relations of the actors within the community and social group (Ribot and Peluso 2003).

Power within political ecology is not explicitly conceptualised (Paulson and Gezon 2004). Ribot and Peluso define power as: "[...] embodied in and exercised through various mechanisms, processes and social relations - that affect people's ability to benefit from resources" (2003: 154). As a personal attribute, power is defined as the "ability of an individual to impose his or her will on another, and the power to control settings in which people may act and interact" (Paulson and Gezon 2004: 28). Power shapes environments for human action and interaction and is wielded and negotiated through practices and processes between actors.

The social identity of actors, characterized by factors such as affiliation to a certain ethnic group, common customary rights, shared understandings and beliefs, but also knowledge and social status, influences formal and informal processes facilitating resource access. Social relations like ethnicity and kinship or economic dependencies can build up patron-client relationships, which is especially widespread in the trading network of yarshagumba. It can also encourage privileged access to state officials for non-state actors for e.g. easier documentation practices or handing out of certificates and licences (Adihkari 2015). Consequently, access to and management of natural resources varies from location to location depending on the informal and formal institutional setting, the actors, their knowledge and power relations and the socio-economic and cultural context (Acheson 2006; Ghate and Chaturvedi 2016; Ribot and Peluso 2003). 
What members of society consider as legitimate, changes over time and is subject to continuous discussions on assumptions, discourses, concepts and power within society and between actors within a production network (Lund 2008; Sikor and Lund 2009). Usually, socalled legal activities are legitimated by law, while illegal activities are not legitimated by law. However, some of the power relations, actions, and institutions might be acknowledged or recognized as legitimate by some actors, but not by others, which can create conflicts and tensions. In general, legitimacy refers to the status of an institution and action that is socially accepted by a social group and therefore respected, but not necessary legally sanctioned by law (Scott 1999). These are considered 'licit' actions or interactions (Van Schendel and Abhraham 2005), which are illegal by law, but are socially accepted by the involved actors.

Power relations and legitimacies are not static; they are dynamic processes responding to changing situations (Sikor and Lund 2009). When conditions change, thus, actors constantly negotiate power relations to allocate rights and duties within a governance system, as well as costs and benefits within a production network (Singh 2016; Mung'ong'o 2009).

As discussed above, the understanding of marginalisation of local communities used here is based on political ecology and recognizes regional and global market developments, as well as governmental and non-governmental interventions. The marginalisation of local communities can imply losing access to their own resources, which was especially the case during the transformation of community land into state-owned properties. Marginalisation can also be related to the high dependency of local communities on one resource for income, which makes them vulnerable to any price or market fluctuations or environmental changes (Robbins 2012; Yeh and Lama 2013). Adapting to these pressures and developments, local people form, within the possibilities available to them, their own management mechanisms and governance systems for securing their own access to the resource. This is also seen in this case study, where every collection site of yarshagumba has an individually-designed governance system consisting of governmental regulations and local communal arrangements, which are either complementary to or replace governmental regulations. Thus, governance systems on the ground are complex constellations. They are an interplay of rights, institutions, power structures, and social and economic relations between actors. They differ from location to location. Further, due to the varieties of governance systems in each location, the capacities of governance systems to adapt to sudden changes differ, as do their learning processes.

\subsubsection{Adaptation of governance systems when changes occur}

As emphasized in the section on political ecology, social and ecological systems are highly interlinked and dynamic systems that adapt to changes from outside or within these systems. Governance systems are influenced by short-term disturbances and societal or environmental changes, like climate changes, changes in property rights and management mechanisms through governmental or non-governmental interventions. Additionally, changes in livelihood strategies, population growth and resource demands on local, national and global markets lead to changes within the social-ecological system (Anderies et al. 2004; Folke 2007; Folke et al. 
2005; Pahl-Wostl 2009; Plummer et al. 2013). Triggered by these changes, struggles between different interest groups are part of a constant negotiation process for power between actors to adapt the governance systems according to their interests (Mung'ong'o 2009; Singh 2016).

Governance systems play a decisive and critical role in adapting to the changes, demands and interests of different actors on various levels and to keeping the social-ecological system in balance (Folke et al. 2005). Pahl-Wostl defines the adaptive capacity of governance systems as the "ability of a resource governance system to first alter processes and if required convert structural elements as a response to experienced or expected changes in the societal or natural environment" (2009: 355).

Adaptation of a governance system can happen on several levels and in various forms depending on learning processes within the system. Pahl-Wostl (2009) developed an approach for analysing the multi-level and multi-loop learning processes within governance systems ranging from incremental learning (single-loop learning) to structural change (triple-loop learning). Single-loop learning refers to a gradual improvement of actions towards a strategic goal without questioning the underlying assumptions. Double-loop learning refers to a reflection on assumptions, for example about cause-effect relationships within a value-normative framework. In triple-loop learning, one begins to reconsider underlying discourses, values and beliefs to transform the context within which the governance system is embedded (Pahl-Wostl et al. 2013). Further details on the framework and its application are elaborated in chapter 5.

The 'adaptive capacity' or the 'ability to change' of governance systems depends on the design and constellation of the system itself. It also depends on what kind of actors are involved, the institutions available and implemented, the relationships between actors, their networks across levels, the interactions across administrative boundaries, vertical integration, and the prevalent discourse of governance and property rights (Dietz et al. 2003; Pahl-Wostl 2009; Ostrom 2005; Young 2009).

Instead of depending on one property rights regime, over the last two decades, scholars have argued for more complex governance systems to be able to regulate human-environmental relationships. These systems have a better ability to alter processes and, if required, convert structural elements, like assumptions and prevalent discourses within society, when changes occur. In line with the understanding of political ecology, over the last two decades, several new understandings and ideas for governance systems have developed, combining multiple actors on various scales and levels. These systems consider local realties including power relations between actors, local legitimacies and social and economic conditions (Dietz et al. 2003; Folke et al. 2005; German and Keeler 2010; Sharma-Wallace 2018).

The 'adaptive governance' approach by Folke et al. (2005) highlights the social dimension within governance systems for renewal and reorganisation to connect individuals, organisations and institutions at multiple levels. For a successful learning environment within a governance system, characteristics and roles of key persons are important elements. Key persons can provide leadership, trust, vision and meaning for the transformation of governance systems. In 
contrast, key persons, either state or non-state actors, can also hinder or delay learning processes or misuse knowledge and power for their own interests.

Similarly, 'polycentric institutions' and 'hybrid natural resource governance systems' describe a mode of governance, which is characterized by a balance between local self-organization and governmental regulations as complementary instruments of governance (German and Keeler 2010; Ostrom 2005). Scholars that have developed this model argue for linking stronger governmental actors, research facilities and communal institutions to develop innovative ideas and create an environment for learning processes on various levels and loops (German and Keeler 2010; Pahl-Wostl 2009; Pahl-Wostl et al. 2013).

Governance systems depending only on one single governance regime are less flexible and adaptive. Consequently, instead of understanding governance systems only as an interplay of different institutions, I apply in the thesis a more holistic approach to governance systems, including governmental regulations and communal arrangements, as well as considering different legitimacies, relations and networks of state and non-state actors as part of governance systems. This enables an in-depth analysis of the negotiation processes of state and non-state actors, which shape the governance systems for yarshagumba collection. These governance systems, the negotiation processes between actors and their adaptation and learning processes are further discussed in chapters 4,5 and 7.

\subsection{Production networks in borderlands}

For analysing the trade networks in the borderland of the Kailash Landscape and the related processes of negotiations between the state and the non-state actors, I use the concept of 'global production network' (GPN) by Hendersen et al. (2002) as a basis for analysis and link it to findings of borderland studies. Like the approach of political ecology, the concept of GPN and the research field of borderland studies focus on questions about power and political and economic relations between actors within a certain space or network. The concept of GPN comes from the field of research on political economy and is an approach for analysing the relationships between production, trade and consumption of products. The approach incorporates all kinds of network configurations, including informal arrangements between actors, in a non-linear way by analysing the power and embeddedness of actors within networks (Hendersen et al. 2002; Neilson et al. 2014; Pauls and Franz 2013).

In the GPN concept, actors' embeddedness in production networks is characterized by their personal relationships to other network actors, their opportunities to gain access to resources via theses relations as well as their related personal obligations and dependencies (Keck, 2016; $\mathrm{Li}, 2007)$. Power is defined by the ability of actors to influence other actors in their doings as well as to define, enforce and revoke the prevalent system of rules and regulations (Hendersen et al., 2002; Neilson et al., 2014). These two analytical categories are further discussed in chapter 6 . Here, I want to focus on the specific situation of networks in borderlands as well as 
on the role of the state as actor involved in cross-border networks. In the GPN literature, "to date the explicit theorization of the state's role has been somewhat lacking" (Neilson et al. 2014: 3). Thus, in the following I elaborate further on the state and non-state actors in borderlands and the functioning of informal cross-border networks by linking the concept of GPN with the findings of borderland studies, which is also further discussed in chapter 6 and 7 .

\subsubsection{State and non-state actors in borderlands}

Besides all other actors involved in governance systems for collection and trade of NTFP, the state plays a special role. The state as sovereign designs, revises and enforces formal regulatory spaces to define where, how and by whom collection and trade of resources are allowed to take place. These are formal institutions, like laws, policies, guidelines and strategies, but common contemporary discourses also influence policy- and decision-makers, as discussed earlier. However, the state is clearly not a unitary entity, but a "constellation of functions and capacities" (Neilson et al. 2014), within which the implementation of functions and capacities varies, both from state authority to state authority and from location to location. State authorities are not homogeneous and all-encompassing; "the sovereign power is better conceptualized as multifaceted, partial and conflicted" (Jones 2012: 3). Despite defined territories and sovereign power within a state territory, there are many loosely administered places, where the authority of the state is weak or non-existent. These regions are called the margins of a state. Margins of a state are usually remote, difficult to access and sparsely populated areas, such as high mountain regions and regions close to international borders (Scott 2009).

Like resources, international borders are also socially constructed through the actions of states and individuals (Gellner 2013). From a state-centric perspective a border is a line of separation between sovereign states and regulatory spaces marking the end of the territory of one state and the beginning of another one. This enables a distinction between the 'us' and the 'them' (Newman 2006). States control the movement of people and goods across the border. Thus, borders are normally perceived as institutional mechanism aimed at protecting what is inside by excluding whatever originates from the outside (Newman 2006).

From the perspective of the local population and state authorities located near an international border, rather than a line of separation, for them a border provides besides constraints also opportunities for interactions across the border. Gellner emphasises regarding the borders within South Asia, that "whatever the spurious precision of the lines drawn or claimed in treaties and maps - they are fuzzy and contested, and also because in many places along the borders the local populations have strong ties across them and often carry on daily life in disregard or even in ignorance of them" (2013: 7). Individuals or social groups in these border regions systematically contest or bypass state control. These border-crossers are acquainted with different regulatory spaces and are skilful in using different currencies, languages and social and economic systems. The term 'borderlands' is used by scholars to describe these social, economic and geographical spaces on both sides of a border defined by the creation of 
opportunities and constraints during interactions of actors across borders (Chan and Womack, 2016; Gellner 2013; Goodhand 2005; Scott 2009). In my case study, the borderland of the Kailash Landscape encompasses the triangle where India, Nepal and China meet and where social and economic networks across the borders are established.

Borderlands vary in terms of their structural and political characteristics including terrain, demography, resources and geo-political importance, which influences the extent to which the central state is present, formal regulations are enforced and the border controlled. In borderlands, often local people are more related to the people across the border than to the central state since they may have historical kinship links and have built economic and social networks across the border. The characteristics of a borderland also constitute the relationship between the central state, the local state authorities and the local non-state actors as well as actors across the border (Goodhand 2013). "Territoriality and trans-nationality are negotiated in everyday practices" (Van Schendel and Abraham 2005: 49) by the local people, but also by local state representatives. The result is a variety of forms of everyday trans-nationality that states often treat as suspect, if not illegal, practices.

Local state representatives in borderlands at the margin of states also do not necessarily fully implement and obey the national laws and regulations. Local state representatives often make use of the weak sovereign power at the margins of states for their own advantage and in a way that reinforces the weak sovereign power. They operate "outside the laws of the state, often undermining state's goals of regulation and order" (Jones 2012: 3). Although formal regulatory spaces build the basis for legitimated behaviour, what is often perceived as legal or illegal in borderlands is not only governmental law, but the outcomes of what the local population or local state representatives and powerful non-state actors consider as appropriate (Korf and Raeymaekers 2013; Lund 2008). The 're-interpretation' of laws provides room for rent-seeking and ambiguous behaviour of state representatives as well as local people. State agents are often drawn into cross-border politics of scale, which can entail infiltrating a porous state structure. According to studies on the Bangladesh-Indian border, a heavily guarded segment of the border can easily be an area where border guards are heavily involved in private gain from cross-border movements of goods and people (Jones 2012; Van Schendel and Abraham 2005). To equate the state with legal practices and non-state actors with illegal practices in borderlands is too simplistic. "A state actor can function simultaneously as a formally recognized official, a non-state actor [...] and a black-marketer. A state actor can simultaneously vote sanctions into law and then ignore them for profit or power" (Nordstrom 2000: 42). Clear distinctions between legal and illegal, state and non-state, or local and international are often impossible to make. State and non-state actors in borderlands are closely enmeshed with each other enabling networks in line with, beside or outside national law and legality, where the transitions are fluid.

Local people are, on one hand, less powerful and vulnerable to these porous state structures and interpretations of laws by local state representatives, but, on the other hand, this situation also provides them opportunities to negotiate their own regimes and regulatory spaces within 
or outside state sovereignty (Caplins et al. 2018; Scott 2009). They can actively participate in the formation of networks and negotiation processes with state representatives to shape local governance systems for regulating the local trade network. Therefore, instead of using a statecentric perspective on borderlands by perceiving a border region at the margins of two states and local actors as vulnerable and marginalised, I understand borderlands as a region with opportunities producing social and economic spaces through trans-border connectivity and cross-border networks. There, territoriality, sovereign power and the border as line of separation are continuously negotiated, questioned and reinforced by state and non-state actors.

For many years, studies related to borders and borderlands were highly influenced by a statecentric perspective (Van Schendel and Abraham 2005). "Borderlands are treated not as entities in their own right, but as the margins of states, societies, nations, economies and cultures" (Van Schendel and Abraham 2005: 43). Borderlands were only seen in their relationship to the central state and its territory. More recent studies on borderlands have changed the perspective by seeing the border 'from below' (Doevenspeck 2011) and analysing the region from both sides of a border as one unit of analysis by focusing on local realities (Gellner 2013; Goodhand 2013; Korf and Raymaekers 2013; Shneiderman 2013; Van Schendel and Abraham 2005). I apply these perspectives in my study, which enables me an in-depth analysis of the political, economic and social relations of state and non-state actors in the governance systems and networks in the borderland within the Kailash Landscape.

\subsubsection{Functioning of 'informal' networks}

In borderlands, both formal and informal networks develop. In a borderland setting, making a distinction between formal and informal is often difficult as trade and exchanges across borders can be illegal by law, but 'licit' or socially accepted, sanctioned and protected by powerful local persons and local state representatives, as described in section 2.3.1. Also, what is considered legal on one side of the border may be considered illegal on the other side. The different regulatory spaces on both sides of the border encourage informal cross-border networks to take advantage of the situations on both sides, as in my case the informal trade of yarshagumba from India to Nepal shows. I define 'informal' as a network that is illegal by law but socially accepted, and therefore visible in the borderlands. These networks can include state and nonstate actors. As described in section 2.3.1, state representatives can have several functions within networks and wear several different hats at the same time.

These networks in borderlands are often built on patterns of mobility, trade and exchange as well as on cultural and kinship networks that have been in existence for centuries (Van Schendel and Abraham, 2005). They are often based on specific codes of conduct, nontransparent power relations, and rules that are orally passed on and not formally established. The relationship between actors within these informal networks depends mainly on their personal relations and connections. Trust, credibility and reputation are key features to describe the personal relations between actors in these informal trade networks where formal 
contracts and reliance on legal tools that protect the actors from various forms of abuse are absent (Grillot, 2016; Keck, 2016; Nordstrom, 2000; Tong, 2014).

Following the understanding of Grillot (2016), who analysed businessmen in the SinoVietnamese border, trust is a social mechanism and instrument of social organisation. But its impact can only be measured over the long term. "Trust always involves an element of risk resulting from our inability to monitor other's behaviour, from our inability to have a complete knowledge about other people's motivations and, generally, from the contingency of social reality" (Grillot 2016:180). Such inability becomes exacerbated in the context of informal trade across borders where state and non-state actors are involved.

Belonging to the same community or social group and having the same cultural, social and economic understanding, beliefs and codes of conduct influences the social cohesion and therefore trust-building between actors. Personal ties and knowing someone reduces the risk of fraud, facilitates monitoring each other's behaviour and allows social sanctioning when an actor is perceived to violate the agreement or code of behaviour within the informal network (Van Schendel and Abraham 2005). In addition, the social cohesion within an informal network enables the institutionalization of practices and agreements operating according to a system of rules known to all participants.

Besides the importance of the social relationship and the character and reputation of a person, trust between actors across the border is also influenced by issues related to state stability and security on the state-level. This is especially the case between actors with cultural differences and less social cohesion. Although these disputes can be a long way from the study area or lie long time in the past, the unsolved historical issues can affect the border area and the decisions of the traders themselves.

Any changes within the regulatory space where the cross-border network is situated, like changes in the government regulations or in the geopolitics of the region, and any changes along the product flow, demand adaptation by the actors within the networks to continue benefiting from the trade (cf. Harris 2013; Keck 2016). The systems within a network are institutionalised, but power and relations between state and non-state actors can shift these when changes occur. Thus, the configuration and functioning of the production networks are continuously negotiated between actors. 


\section{Research methods and research area}

This chapter includes a detailed presentation of the applied research methods, techniques, the selection of the research area and the limitations of the study.

\subsection{The qualitative research method}

The focus of the research on negotiation processes about access rights and on informal trade networks in a geopolitically sensitive border region called for a qualitative research approach. While quantitative research aims to explain and confirm isolated cause and effect relations of phenomena, in comparison a qualitative research approach seeks to explore and to understand complex processes and relations by using a mainly inductive approach for developing theories based on the research findings (Flick et al. 2003; Lamnek 2010). By exploring the institutions and actors related to the collection and trade of yarshagumba in the transboundary Kailash Landscape, the study aims to understand the complex institutional systems, relations and negotiation processes between different actors across the border region. Guided interviews and focus group discussions with different types of actors from the two countries - government officials from different departments and authority levels, researchers, community leaders, collectors and traders from India and Nepal - provided different perspectives on the topic and enabled a deep reflection from different angles. Especially in relation to policies and other formal institutions, besides reviewing and analysing the content of different documents, it was relevant for the study to get a deep understanding of how these policies and institutions were interpreted and, therefore, implemented in reality on the ground.

I followed a reflexive and flexible approach to research (Lamnek 2010). I selected the research locations and formulated the first research questions and guiding interview questions on the basis of my previous knowledge about the topic and literature review. While conducting the fieldwork, I continuously reflected on the collected data, adjusted the data collection techniques and specified the focus of the research. During this process various information was explored with attention to its meanings in order to find patterns, anomalies, controversies and processes relevant for the broader focus of my research (Doolittle 2010). In this context, the following data collection techniques were applied: guided interviews, focus group discussions, informal conversations, participatory observation and document analysis, which will be further described and explained in chapter 3.5 .

The empirical fieldwork was conducted from August 2016 until September 2017 in India and Nepal. In China, I did not conduct any interviews or collected data. The main fieldwork period was from end of April until the middle of June, when yarshagumba is collected in the mountains. During this time in 2017 , I visited the two selected valleys in India as well as the two selected 
valleys in Nepal to conduct the bulk of the interviews with the local actors in the collection sites (see table 1). Each field trip was at least 10 days and maximum 21 days including walking up to the yarshagumba collection sites. Other interviews with researchers and government representatives of India and Nepal were conducted in Kathmandu, Dehradun, Nainital and other cities within the whole data collection period.

Table 1: Timeframe of fieldwork

\begin{tabular}{|l|l|c|l|}
\hline & Time of field trips & Country & Location \\
\hline 1 & August 2016 & India & Pithoragarh, Nainital \\
\hline 2 & January 2017 & India & $\begin{array}{l}\text { Nainital, Pithoragarh, Munsiyari (Johar valley), } \\
\text { Dharchula }\end{array}$ \\
\hline 3 & March 2017 & Nepal & ANCA, Darchula \\
\hline 4 & April 2017 & India & $\begin{array}{l}\text { Almora, Pithoragarh, Dharchula, Johar valley, Darma } \\
\text { valley }\end{array}$ \\
\hline 5 & May 2017 & Nepal & ANCA, Darchula, Mahakali and Chameylia valley \\
\hline 6 & June 2017 & India & Dharchula, Darma valley \\
\hline
\end{tabular}

The limited seasonal collection period for yarshagumba was a serious time constraint for gathering data. The collection season usually starts end of April and runs until the snow is melted in the sites and grass is growing, which is usually mid or end of June. In the year 2017, the snow cover was very low and at the beginning of June the grass was already quite high. Consequently, the yarshagumba collection stopped and collectors left the collection sites earlier than usual. The planned visit to the collection site in the Johar valley in mid of June had to be cancelled. I left the option open to return the following year in 2018 to the Johar valley, if it turned out that data were missing. However, after analysing the data for the Indian valleys, I realised I had sufficient information to put the Johar valley into the context of the other valleys in India and Nepal.

\subsection{Positioning myself as a researcher}

Following a pre-condition of qualitative research, the vantage point from which this research was developed presumes that knowledge, data and facts cannot be separated from either the researcher or the context in which data are collected (cf. Doolittle 2010).

From the end of 2013 through 2017, including during the fieldwork period, I was employed as project staff for the German Development Cooperation (GIZ) in the Kailash Sacred Landscape Conservation and Development Initiative. During this time I lived in Kathmandu, Nepal and 
made regular visits to the Kailash Landscape and held meetings with government representatives and project partners from China, India and Nepal for discussing the project and issues in the region including the phenomenon 'yarshagumba'. When I started the PhD programme in May 2016, I had already conducted two joint field trips to yarshagumba collection sites in Nepal with governmental staff from ANCA and project colleagues. The findings triggered the process for the development of local ANCA yarshagumba management regulations aiming to clarify access rights and responsibilities between the different governmental authorities and communities with regard to the collection of yarshagumba in ANCA (see Chapter 5).

Through the project work I had already gained a good understanding of the challenges related to yarshagumba collection and trade in the Kailash Landscape before starting the PhD. However, a deeper understanding of the underlying processes and relations within this complex landscape of actors, especially across the border of India and Nepal, was missing. Thanks to the project set-up and my project supervisor at GIZ I could integrate my thesis research and fieldwork into my regular project work. This kind of double role during this time I experienced positively, because I was well known in the Kailash Landscape and respected and accepted by the local leaders and government authorities, which enabled trust and easier access to the local people. However, I was also perceived as supporting and being related to the ANCA office, the Nepali government authority. Often I was confronted with complaints and certain expectations of the community members to provide support and solutions to their problems. By staying with the community members and getting the approval and trust of the community leaders, this perception was reduced and I was accepted as researcher so that I could ask questions and listen to their conversations.

During all field visits a field assistant accompanied me who was responsible for solving logistical issues and providing explanations and translations from Hindi, Nepali or Kumaoni into English. The trips in Nepal as well as the trip in India in June 2017 were assisted by one Nepali field assistant, who spoke Nepali as well Hindi. An Indian field assistant assisted the other trips in India. Both had good knowledge of the region and about yarshagumba collection previous to the fieldwork. Additionally, two or three porters were part of our research team to walk up to the yarshagumba collection sites, and supported in carrying camping equipment, cooking utensils and food. They also happened to be very good informants, as they were part of the local community and collectors themselves.

Language was an issue throughout the fieldwork, since only a few community members spoke English. Consequently, most of the interviews, conversations and group discussions were conducted in Hindi, Kumaoni or Nepali and needed translation by the research assistant. As is well known, in the course of translation some information always gets lost. I worked to overcome this challenge by reflecting about the content and overall context of the interview after each interview with the field assistant. 


\subsection{Research in a border region}

Research in border regions provides opportunities and challenges, and the research and fieldwork is special in several ways. On the one hand, research in border regions is special due to the circumstance that two sovereign states meet along a borderline creating a space for contact and separation. In order to analyse relations, interactions and impacts across the border related to the yarshagumba collection and trade, the study understood the border region on both sides of the border of India and Nepal as one conjunct research area following the approach of Baud and Van Schendel (1997). This approach was especially helpful in the analysis of the informal cross-border trade network between India and Nepal (see chapter 6) as it enabled looking from both sides of the border at the same phenomenon and same actors. Additionally, the research on the legal frameworks and governance systems in the two countries provided an opportunity to compare the different governance systems for yarshagumba collection and trade with each other. The comparative analysis, which was utilized mainly for comparing the different governance systems of the collection sites, presented in chapter 5, allowed an assessment of whether the findings are for example location specific or linked to legal conditions in a country.

On the other hand, borders are usually located in a peripheral area with great distance to capital cities, and related to this, usually characterised by less infrastructure and other governmental service provisions than areas close to the central state. Here it was no different. Besides this remoteness, the Kailash Landscape is extremely mountainous. Road infrastructure especially on the Nepali side was very limited. Consequently, during the main fieldwork phase I walked over $400 \mathrm{~km}$. Walking for days on the local trails was physically exhausting, but also provided a great opportunity for participatory observation and time for reflection on the previous interviews and discussions.

Additionally, border regions are often considered geopolitically sensitive by state authorities resulting in restrictions for border crossings and high militarization, as is the case in the upper Darma and Johar valley in the Indian mountain areas close to the Chinese border. Both aspects made my research difficult, leading to restrictions, limited access to specific areas and long detours. To give an example: the official border crossing points between Nepal and India, India and China, and Nepal and China within the Kailash Landscape are only open for local citizens. That meant for me, as German citizen, that I was not allowed to cross the bridge in Darchula town from Nepal to Dharchula, India. Instead, I had to drive 12 hours along the river south to cross the border into India at an international border crossing point and drive back another 12 hours north on the other side of the river. Consequently, the fieldwork needed realistic logistical planning and enough time to overcome these circumstances. 


\subsection{Identification and selection of yarshagumba collection sites}

In the upper valleys of the Kailash Landscape every village and community has access to a high-alpine grassland, where yarshagumba is found. In total there are more than 100 collection sites in the region.

In India, due to the partly illegal nature of the collection and sale of yarshagumba, the sites are not officially documented. Therefore the first fieldtrips in August 2016 and January 2017 were used to meet different community representatives and build up trust with community leaders to receive 'permission' to join them for some days in the following season for collection. In this process, the Johar and Darma valley were selected as the main research valleys. In Nepal the situation was easier. Firstly, I had visited some collection sites earlier in 2014 and 2015. Secondly, in the process of the development of the local yarshagumba guidelines for ANCA, representatives of the ANCA office documented the location of yarshagumba collection sites in the two main valleys, Mahakali valley and Chameylia valley. In total 63 sites were listed in these two valleys (ANCA 2016).

After analysing the first information, the individual sites in the valleys differed according to dimension, institutional settings, property rights and management systems. In order to have a realistic representation of the different conditions in the collection sites I chose seven collection sites in four valleys for the case study: Bona, Baling and Tejum in India and Api, Buddhi, Kuntison and Lolu in Nepal. Each site is different from the other ones by representing a different combination of the criteria (table 2). 
Table 2: Detailed characteristics of the collection sites (modified according to Wallrapp et al. (forthcoming))

\begin{tabular}{|c|c|c|}
\hline \multicolumn{2}{|c|}{ Location } & \multirow{2}{*}{$\begin{array}{l}\text { Key characteristics of the collection site } \\
\text { - } \quad \text { Medium size high alpine grassland } \\
\text { - Site located within state forest } \\
\text { - } \quad \text { Site used as grazing ground from Bona community } \\
\text { - } \quad \text { Closed site - access exclusively for selected community members } \\
\text { (Rang community) }\end{array}$} \\
\hline \multirow{3}{*}{$\stackrel{\frac{\pi}{\sigma}}{\underline{\underline{\sigma}}}$} & $\begin{array}{l}\text { Bona - } \\
\text { Johar valley }\end{array}$ & \\
\hline & $\begin{array}{l}\text { Baling - } \\
\text { upper Darma } \\
\text { valley }\end{array}$ & $\begin{array}{l}\text { - } \text { Medium size high alpine grassland } \\
\text { - Site located within community managed forest } \\
\text { - Site used as grazing ground from Baling community } \\
\text { - Traditional grazing institutions } \\
\text { - Closed site - access exclusively for selected community members } \\
\text { (Rang community) }\end{array}$ \\
\hline & $\begin{array}{l}\text { Tejum - } \\
\text { lower Darma } \\
\text { valley }\end{array}$ & $\begin{array}{l}\text { - Small high alpine grassland } \\
\text { - Site located within state forest } \\
\text { - Used as grazing ground by shepherds from villagers from lower valley } \\
\text { - Closed site -access exclusively for selected community members } \\
\text { (mixed community of Hindus and Rang) }\end{array}$ \\
\hline \multirow{4}{*}{$\begin{array}{l}\overline{\frac{\pi}{0}} \\
\frac{0}{2}\end{array}$} & $\begin{array}{l}\text { Api - } \\
\text { upper Mahakali } \\
\text { valley }\end{array}$ & $\begin{array}{l}\text { - Large high alpine grassland } \\
\text { - Site located within community managed forest and protected area } \\
\text { ANCA } \\
\text { - Site used as grazing ground from Rang/Shauka community } \\
\text { - Traditional grazing institutions } \\
\text { - Closed site - access exclusively for selected community members } \\
\text { (Shauka community) }\end{array}$ \\
\hline & $\begin{array}{l}\text { Buddhi - } \\
\text { upper Mahakali } \\
\text { valley }\end{array}$ & $\begin{array}{l}\text { - Small high alpine grassland } \\
\text { - Site located within community managed forest and protected area } \\
\text { ANCA } \\
\text { - Not a traditional grazing ground } \\
\text { - Open site - access not restricted (mainly Hindu community from various } \\
\text { villages) }\end{array}$ \\
\hline & $\begin{array}{l}\text { Kuntison - } \\
\text { upper Mahakali } \\
\text { valley }\end{array}$ & $\begin{array}{l}\text { - Small high alpine grassland } \\
\text { - Not a traditional grazing ground } \\
\text { - Site located within community managed forest and protected area } \\
\text { ANCA } \\
\text { - Closed site - access exclusively for selected community members } \\
\text { (Shauka community) }\end{array}$ \\
\hline & $\begin{array}{l}\text { Lolu - } \\
\text { Chameylia } \\
\text { valley }\end{array}$ & $\begin{array}{l}\text { - Large high alpine grassland } \\
\text { - Used as grazing ground by shepherds from villagers from lower valley } \\
\text { - Site located within protected area ANCA } \\
\text { - Open site - access not restricted (mainly Hindu community from various } \\
\text { villages) }\end{array}$ \\
\hline
\end{tabular}




\subsection{Data collection techniques}

I have applied different qualitative research techniques to understand better the actors' roles, perspectives and power relations influencing the access to and management of yarshagumba collection and the trade networks. The following techniques were used: guided interviews and informal conversations, focus group discussions with community members, participatory observation and document analysis. These will be further described and explained in the following sections.

In total 92 guided interviews on community level were conducted - 41 in India and 51 in Nepal. Out of that 62 were interviews with community members, which includes collectors, traders and other villagers (13 women and 49 men). 30 interviews were with local authorities on community level, such as local representatives from the forest department, community committees, the protected area ANCA and police (3 women and 27 men). Additionally, eight guided interviews with representatives of the Nepali and Indian government, six with researchers and six with representatives of traders' associations, members of NGOs and a journalist were made (all men). In total 13 focus group discussions were conducted - seven in India and six in Nepal with five to fifteen participants each. Detailed lists about the interviews are presented in Annex 3 and 4.

I made efforts to conduct interviews with women and men with different social backgrounds and from all age groups. However, usually more men participated in the focus group discussions and interviews. Although both men and women go for collection to the sites, men are more open to answer questions, while women are more reluctant to speak with outsiders. Also few women work in the local authorities. Therefore, it was not easy to encourage women to conduct an interview.

Although it consumed a lot of time and energy, conducting the interviews with the communities in the yarshagumba collection sites during the season proved beneficial. Instead of visiting them in their homes at any other time of the year, participating in the yarshagumba collection and living in the camp sites enabled me to participate in the daily life of a collector. I could observe camp site settings, social and ecological conditions, collection techniques, open social conflicts between actors and everything else that was happening on the route to and in the collection sites. Further, it enabled me to meet different community members, collectors and traders, and ask the 'right' questions.

\subsubsection{Guided interviews and informal conversations}

Guided interviews and informal conversations were the main techniques I used for data collection. Guided interviews combine predetermined questions and open conversation (Longhurst 2010). They serve the purpose of allowing the interview partners to place their own ideas and thoughts on a certain topic while at the same time making sure that all important areas of the research are covered in the interview (Desai and Potter 2006: 145). The guidelines I developed for the interviews covered a wide range of topics (see the guided questionnaire in 
Annex 2) and were used for all different types of interviewes. Prior to conducting guided interviews the questions were discussed with the research assistant to ensure that the questions were well understood and appropriate to the cultural context. That also gave the opportunity to reflect jointly on topics and add and modify questions accordingly.

In general, the guiding questions were used in an open and context-dependent way for enabling an open conversation (Lamnek 2010). Unstructured interviews provide the interviewees with the opportunity to take the discussion in whichever direction they choose (Desai and Potter 2006: 144). The order of the questions, the number of questions and the questions being asked were adapted to the specific interview situation and interview partner. The guiding questions were adjusted during the time of the fieldwork and continuously updated on the basis of the empirical findings, for example during the first visits in India the interviews focused on collection management systems and policies, whereas later the primary topics changed to property rights, customary rights and power relations between state and non-state actors.

Informal conversations played a crucial role during the whole fieldwork. People were curious about a woman from outside South Asia walking up into the mountains for yarshagumba collection. The research team was constantly asked questions related to the purpose of the visit. Whenever the purpose was explained, usually community members were happy to share their perspective and knowledge in an informal conversation. This information was very helpful for improving the overall understanding of certain issues. Furthermore, the informal way of conversation without recorder and notebook seemed to make it easier for people to share their opinion (cf. King and Horrocks 2010) in my case on property rights, trade and illegal issues, especially in India.

Location and duration of the guided and informal interviews varied significantly. During the day community members often did not have much time, so interviews were sometimes conducted while collecting yarshagumba, while walking, having food or tea together. In these situations, the interviews had more the character of informal conversations than guided interviews. Sometimes the interviewee agreed after a short conversation to meet again later at another time for a longer interview. During the evening hours while preparing dinner or having a drink, usually community members were more flexible and welcoming for longer discussions.

I conducted most of the interviews myself with the help of the research assistant for translation, as most of the interviewees on community level could not speak English, but Nepali, Hindi or Kumaoni. The research assistant usually translated my question and the answer immediately into English. Sometimes during short conversations, he conducted the interview himself and translated only at the end. The interviews with higher government authorities in India and Nepal as well as with researchers were usually conducted in English by myself. During guided interviews, I as well as the research assistant took field notes.

After each guided interview I discussed with the research assistant the key content, situation, impressions and conditions of the conducted interview. First, we shared our field notes and typed memos into the computer. When field notes were not taken during the interview or 
informal conversation, then minutes were typed up based on our recollections of the conversations. The regular reflection on the guiding questions gave the opportunity to identify gaps and further fields of interest, to clarify misunderstandings, to modify questions or rephrase them when not understood.

Most of the time recording interviews or conversations was not suitable or possible in the specific situation, either because interviews were conducted ad hoc, outside at an open place or in a more informal setting like during walking, while having tea or food together with the interview partner. Often also interviewees were not comfortable being recorded, which was of course respected. Therefore, few interviews were recorded. Back in Kathmandu, the few were transcribed and translated from Hindi or Nepali into English.

\subsubsection{Focus group discussions}

The focus group discussions were used complementarily to the individual guided interviews. In general, a focus group discussion is broadly defined as "a research technique that collects data through group interaction on a topic determined by the researcher" (King and Horrocks 2010: 65). In comparison to one-to-one interviews a group interview can reveal the social and cultural context of people's understandings and beliefs as well as their collective opinion about interdependencies and relations (King and Horrocks 2010; Lamnek 2010). In this study, the technique 'focus group discussion' was used for three different purposes.

Firstly, in August 2016 the technique was utilized for getting an overview of the different collection sites and their management systems in the Indian part of the Kailash Landscape. For that a group of six community members from different villages of the Indian part of the Kailash Landscape were brought together to discuss their common understanding of yarshagumba collection sites and issues related to them. While interacting within the group, the task was to draw a sketch map of the region and to locate and differentiate the collection sites. The figure 2 shows the sketch map of the Indian Kailash Landscape. The research assistant and I guided the discussion by asking questions when the discussion stopped or went into a different direction. Furthermore, we observed the interaction between the community members and took notes. 


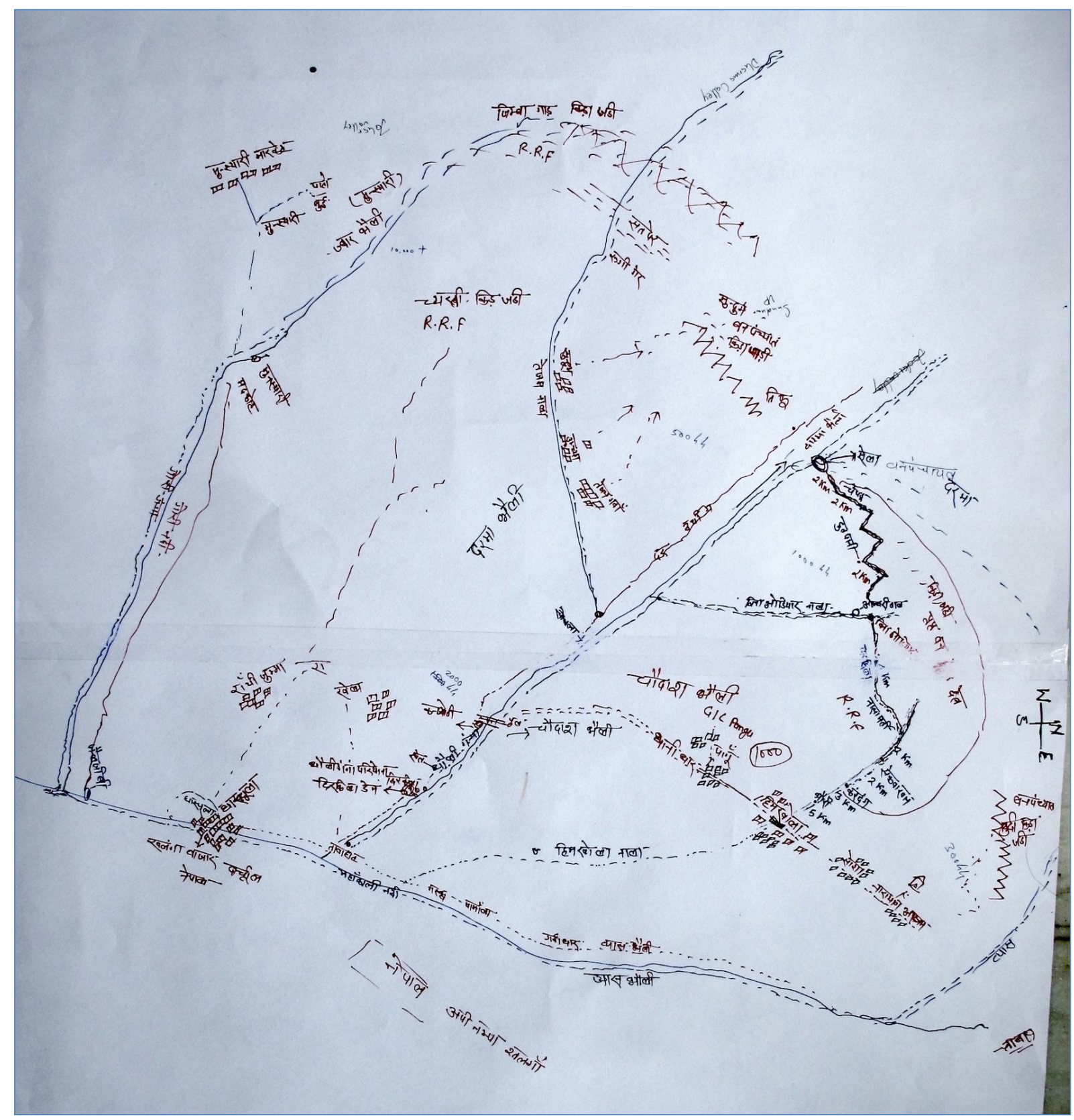

Figure 2: Sketch map of the Indian part of the study area (own source August 2016)

Secondly, two focus group discussions were organised in January 2017 with local representatives from the two selected main research valleys, Johar valley and Darma valley in India. During these sessions the purpose was to introduce the research, to get an overall understanding of the specific issues of access rights to yarshagumba collection and the trading system in India, to build up the trust between the research team and communities and finally to decide about the collection sites for detailed research and visits during the collection season. The groups each consisted of five to ten persons.

The third technique was a modified concept of focus group discussion. It consisted of discussions with community members in the collection sites with the usage of scientific 
knowledge material. In the collection sites, collectors are very busy and do not have much time. Therefore, using posters was a good technique to get the attention of people and make them interested before starting the focus group discussion. A group consisted of five to 15 people.

At the beginning, we, the research team, presented posters about the life cycle of yarshagumba and the perceived issues in the collection sites, like e.g. cutting of firewood or waste disposal, which were reported in the previous field trips and are partly also documented in related studies from the Himalayan region. Especially, presenting and explaining the life cycle stimulated a lot of interaction between the community members (figure 3). Following this, questions related to management systems, roles and responsibilities of institutions and actors were asked to guide the discussion.

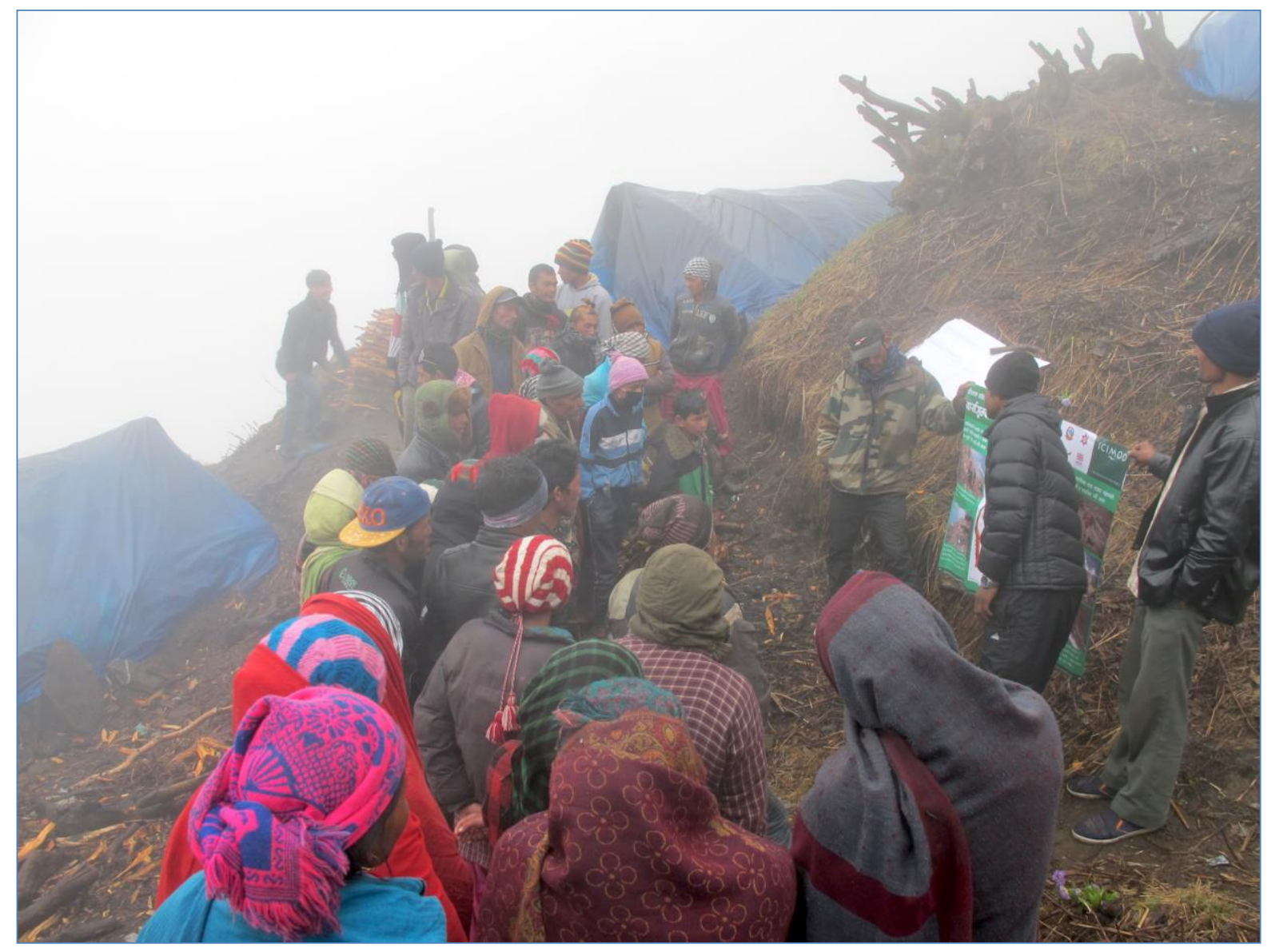

Figure 3: Focus group discussion with presentation in Bhuddi (own source May 2017)

These modified focus group discussions had several positive effects. Presenting knowledge material broke the ice with the community members in the collection sites. For us, within a short time we got the attention and trust from the collectors. For the community members, besides getting to know the 'outsiders' and the purpose of their visit to the collection site and of collecting information, the collectors appreciated that we shared information with them through the knowledge material, which they considered highly valuable. They were thankful for the 
knowledge shared with them and used it further for analysing key issues and possible solutions in their specific collection site.

Usually a focus group discussion took between 30 to 45 minutes, with a maximum of 1.5 hours when the sketch map was prepared. Like after guided interviews, my research assistant and I shared key points of interest for the research, impressions and observations after the focus group discussion and typed them into the computer. We also reflected on our approach, group members, the sequence of posters and the questions we raised, which triggered most or no discussions. If required, we adjusted the technique.

\subsubsection{Participatory observation}

Besides guided interviews, informal conversations and focus group discussions, participatory observation has been an essential part throughout the field trips to the Kailash Landscape, but particularly while staying in the collection sites, in the simple lodges, teahouses and trading hubs along the way as well as in the villages and towns like Darchula, Nepal and Dharchula, India. Experiencing the difficult access to the collection sites (e.g. walking eight to ten hours a day, crossing landslides and icy mountain streams), the harsh conditions while camping at the collection sites (e.g. minus temperatures and snowfall over night, high altitude or continuous rainfall) as well as the difficulty of finding even one yarshagumba on the ground made me understand that although yarshagumba collection is often perceived by town people and government representatives to be 'easy' and 'fast' money, in reality it is hard work and people risk their health and life while going for collection.

Furthermore, it made me realize how far the collection sites are from the influence of the government authorities. This allows the local communities to establish their own systems, which are accepted and legitimized by the local people without government authorities knowing about it. This experience was relevant for an overall understanding of the context of access rights and different perspectives of actors (cf. Lamnek 2010). In addition, by staying together with the collectors and local traders in collection sites or trading hubs a deeper level of trust was built up to share information on difficult and sensitive topics, like prices, the legal and illegal trading system and routes, management systems and the involvement of government authorities in the whole process.

Every day in the evening, I wrote down my impressions, ideas of first findings, gaps and observations (see preface for an extract of my field notes). This included descriptions and impressions of the landscape, the village or campsite setting, social behaviour, the conditions in the collection sites and the collection techniques, as well as still open or new questions. Often these reflections of the day were the basis for the interviews and conversations on the following days. 


\subsubsection{Document analysis}

In addition to qualitative interviews, I analysed different types of documents, which I sometimes used to triangulate the information received in the interviews. Document analysis is, according to Bowen, "a systematic procedure for reviewing or evaluating documents ..." (2009: 27). The systematic analysis consists of skimming documents, selecting relevant ones and coding and summarizing important content (Bowen 2009). The selection of documents has been guided by the research questions. Especially relevant for the research have been documents specifying governmental regulations and strategies. In summary, these different document types were analysed:

- regulations, laws and acts related to forests and protected areas on national and statelevel in India and Nepal,

- regulations, laws and acts related to NTFP collection and trade on national and international level,

- treaties between India and Nepal, India and China, and Nepal and China about movement of goods and people across the national borders,

- policies and strategy papers related to NTFP, forests and protected areas,

- reports and studies from organisations working in the research area and

- newspaper articles.

\subsection{Data analysis}

In order to analyse the data material collected in the field, such as memos of field notes, observations and transcribed and translated interview records, a qualitative content analysis according to Mayring (2010) was chosen. The analysis of Mayring (2010: 13) aims to draw conclusions on certain aspects of communication by analysing, in the broader sense, communication material in the form of texts and by proceeding in a systematic and theory-led fashion. The qualitative content analysis integrates the inductive development of categories and their deductive application. Mayring distinguishes three forms of qualitative content analysis: summary, explication and structuring. In the technique 'summary' the aim is to reduce the material while the main content of the material still remains and at the same time to allow an abstraction of the content. In this way, categories are developed inductively. 'Structuring' means to apply the already defined categories to the summarised text material using a deductive application of categories. That was done according to content and type of material.

I applied the qualitative content analysis following Mayring by sorting and reducing my research data according to similar content. Subsequently, I developed step-by-step categories. Using the example of analysing the governance systems in the collection sites, in the first step categories were developed, like 'informal and formal institutions for regulating grazing and yarshagumba collection.' While reading and reflecting on the different categories in the second step, gaps were detected where further material was needed in order to gain a deeper 
understanding. Using the same example, the outcome of the first content analysis was that formal and informal institutions regulating the access to collection sites were often overlapping and contradicting each other, but at the same time actors confirmed and insisted on the implementation of the regulations.

Using the third form of qualitative content analysis, the explication, I collected and analysed additional data, like legal documents, and conducted interviews with researchers, community leaders and government authorities to gain deeper understanding of the legal rights in forest and grazing areas as well as of legitimization processes within the community. Linking the findings of the data with the conceptual frameworks of my study, the analysis revealed that e.g. especially access rights to high alpine grasslands were interpreted in situations and over time by different type of actors differently, which I identified later as learning processes and learning loops (further analysed in Chapter 5). Using the techniques of 'summary', 'structuring' and 'explication' enabled me step by step to understand more and dig deeper into the complex processes and systems and to link the findings with key theoretical concepts.

\subsection{Study limitations}

This study was limited due to language differences, my positioning as researcher and at the same time as project staff and the partly secretive nature of yarshagumba collection and trade, especially in India. My inability to understand and communicate in Nepali or Hindi shaped the information I was able to gather. Furthermore, my involvement in the Kailash Landscape project coupled with my status as an outsider greatly influenced the opportunities the interview partners and local community members granted me to have access to collection sites and information.

In general, the study on yarshagumba in the borderlands of India and Nepal was also limited due to the partial informality of yarshagumba collection and trade. Given the nature of collection and trade, I was only able to interview a small number of traders, who stated openly that they are directly involved in the informal India-Nepal trade. The traders were willing to talk about the relations within the networks, but reliable figures about trade volumes and values could not be gained from the interviewees. My study attempted to mediate this limitation as well as possible by using related studies from the region and comparing the statements of the interviewees with the data in the studies.

At the beginning of the research, I had the intention to collect data on collected quantities of yarshagumba per collector and season over the last five years as well as data on the environmental degradation of habitats in the collection sites to compare them with different management mechanism and regulations per site in India and Nepal. This would have enabled me to assess the performance and success of sustainable management of the habitat and give an indication of whether sustainable management of yarshagumba collection was occurring in different collection sites. However, that was not possible due to the fact that collectors are usually not honest in answering questions about their collected quantities. Under- or overestimation are both common due to fear of being looted or loosing status. Additionally, the 
publicly available geospatial data of this geo-sensitive border region between India and China are not detailed enough to identify on the images over the last 20 to 30 years the environmental changes in the collection sites, like for example the shifting of the tree-line due to intensive firewood collection.

Therefore, in the thesis I am not able to evaluate the different governance systems in the collection sites according to sustainability of the resource. However, the different adaptation and learning processes by communities and governmental authorities give indications of whether rules for managing the campsites, regulating access and extraction of the resource are designed and implemented. Some communities have introduced very strict access regulations, which limit the number of collectors per seasons; others have set up clear rules for managing the campsites. Consequently, I cannot provide the scientific evidence for the correlation between governance systems and quantity of collected yarshagumba and degradation of the habitats; only indications for good or bad management systems can be derived. 


\section{Institutional Issues, Power Struggles and Local Solutions - Governance Systems of Yarshagumba Collection in India and Nepal in the Kailash Landscape}

Corresponding publication:

Wallrapp, C. Keck, M. and Faust, H. (2018): Institutional Issues, Power Struggles and Local Solutions Governance Systems of Yarshagumba Collection in India and Nepal in the Kailash Landscape. In: Aktuelle Forschungsbeiträge zu Südasien, 8.Jahrestagung des AK Südasien, 19./20. Januar 2018, Köln edited by C. Butsch, A. Follmann and Müller J. Schriftenreihe des Arbeitskreises Südasiens in der Deutschen Gesellschaft der Geographie. ${ }^{6}$

Keywords: Governance of commons, access to resources, yarshagumba, Himalayan Mountains

\subsection{Introduction}

Ophiocordyceps sinensis (English: caterpillar fungus), locally known as yarshagumba, is a fungus, which grows in the body of a larva of a moth in the high alpine grasslands of the Himalayan region between 3200 and 5000 meter above sea level. It is found in some parts of the Tibetan Plateau and in the Himalayan Mountains of Bhutan, India and Nepal (Shrestha and Bawa 2014; Winkler 2009). Collected from May to July, this non-timber forest product is traded as medicinal product mainly to China. The price increased tremendously in the late 1990s (Winkler 2008; Yeh and Lama 2013), which triggered a "gold rush" and led to the development of new collection sites in the Himalayan Mountains (see pictures 1 to 4 in Annex 1). A product unknown by local communities has transformed into a high value resource changing livelihood strategies of entire villages within only ten to fifteen years (Shrestha and Bawa 2014). These developments have evoked institutional issues and power struggles in the rural communities. New and old actors have increasingly questioned existing governance systems regulating livestock grazing and the access to these high alpine grasslands.

The tremendous increase of people accessing the grasslands for the collection of yarshagumba, related conflicts, and the high dependency of collectors on yarshagumba harvest for cash income are challenges faced in most of the collection sites in the region. Additionally, the local population perceives that their habitats are degrading the yarshagumba harvest per collector is declining. These are all aspects analysed by several scholars (cf.

\footnotetext{
${ }^{6}$ As lead author I conducted the primarily research for the publication and contributed the majority of the content, with some theoretical and editorial inputs by the other authors.
} 
Cannon et al. 2009; Negi et al. 2016; Pant et al. 2017; Shrestha and Bawa 2013; Weckerle et al. 2010).

Yet, while most of these studies focus on the analysis of the socio-economic and ecological situation and/or management structures in one particular valley or collection site, the institutional frame of yarshagumba collection is rarely examined. Governance systems of different collection sites are hardly ever compared in the literature.

\subsection{Theoretical considerations and methodical implementation}

Using the conceptual frameworks of "the governance of commons" (Agrawal 2003; Dietz et al. 2003; Folke et al. 2005; Ostrom 1990; Pahl-Wostl 2009) and "hybrid governance" (German and Keeler 2010) we compare the governance systems of yarshagumba collection in two different legal settings of Nepal and India in the border region of the Kailash Landscape.

We analyse governmental actors and institutions in the two countries, and focus on actual communal arrangements regulating the access to and management of yarshagumba collection on the ground. The comparative study provides insights into the dynamics, changes and limitations of the governance systems established since the discovery of yarshagumba.

The empirical fieldwork was conducted in four valleys of the Kailash Landscape. In total, we assessed seven collection sites in two valleys of the Api Nampa Conservation Area (Nepal) and two valleys in the Kumaon Region (India). The qualitative empirical research comprised mainly key informant and in-depth interviews, focus group discussions and participatory field observations.

\subsection{Results}

Yarshagumba is a common pool resource. This kind of resources is defined through subtractability - if the resource is consumed by one person it cannot be consumed by another one anymore - and the difficulty to exclude other people to have access and use the resource (Ostrom 1990). The key concern with commons is that users try to maximize their benefit per unit, while ignoring involved costs per unit imposed on others. Users tend to pursue their shortterm interests, which results in outcomes that are not in anyone's long-term interest, like the complete exploitation of the resource (Agrawal 2003; Ostrom 1990).

Dietz et al. (2003) argue that local communities can manage common pool resources effectively, while they usually fail when sudden changes occur. Therefore, researchers plead for more complex governance systems (Dietz et al. 2003; Folke et al. 2005), linking and combining governmental actors, research facilities and communal institutions to overcome challenges that are the result of depending only on one single governance regime (German and Keeler 2010; Pahl-Wostl 2009). Governmental actors are likely to face challenges 
regarding the enforcement of rights or resentments by holders of customary rights. At the same time, communal arrangements have usually difficulties with applying sanctions and adjusting to rapid changes when new drivers and actors are introduced. Thus, hybrid natural resource governance systems are needed, which are characterized by a balance between local selforganization and governmental regulations as complementary instruments of governance (German and Keeler 2010).

Before yarshagumba was discovered in the Himalayan Mountains, the collection sites were common grazing grounds for the local population. Well-defined boundaries, conflict resolution mechanisms, monitoring and graduated sanctions (Acheson 2006; Ostrom 1990) were principles integrated in the local governance systems managing grazing. Additionally, social homogeneity of users, community sense and social capital made rule devising and enforcement possible. However, these local systems now struggle with new and old actors demanding access to the yarshagumba collection sites, and with community members ignoring social norms to increase their own benefits.

In Nepal the collection and sale of yarshagumba is legal for local communities, whereas in India the extraction of yarshagumba is happening in a legal grey zone. Government institutions in India and Nepal have formulated guidelines, but struggle with their implementation and often neglect local contexts. Communities have created site-specific arrangements since the late 1990s to deal with the pressure and to control and limit access for people from other communities. The limited formalisation of these arrangements leads to disputes and makes collectors vulnerable to criminal elements and ambiguous institutional and individual behaviour. Additionally, it encourages unsustainable harvesting of the resource and rapid habitat degradation.

In sum, our data shows that the governance systems in India and Nepal regulating yarshagumba collection are a complex blend of governmental actors and institutions on various scales and local communal arrangements adapted to the characteristics of each site. Against this background, we argue that neither the sole existence of governmental actors and their formal institutions nor community arrangements alone are sufficient for the effective governance of yarshagumba collection in the remote high alpine grasslands. Instead, they need to be complementary (German and Keeler 2010). New actors and drivers stimulate changes and, thereby, put pressure on the existing governance systems. It requires more complex and adaptive governance systems to be flexible and robust to sudden changes.

\subsection{Conclusion}

Yarshagumba collection sites in the Himalayan mountains of India and Nepal have experienced a "gold rush" in recent years, which has evoked institutional issues and power struggles in the rural communities. In this context, there is a need to create a system to govern these collection sites that builds on trust, open communication and cooperation between the community and the government. We recommend, as a starting point, to establish common platforms for 
stakeholders from different levels and sectors from the government, relevant research facilities and communities on the regional level in both countries. Joint meetings could encourage exchange and understanding, create awareness and provide the opportunity to share local and scientific knowledge among relevant stakeholders. Establishing learning loops is important to be able to adjust to uncertainties and changes in the future - today, yarshagumba has a high market price; tomorrow it might be another natural resource.

\section{References}

Acheson, J.M. (2006): Institutional Failure in Resource Management. In: Annual Review of Anthropology 35: 117-134. doi: 10.1146/annurev.anthro.35.081705. 123238.

Agrawal, A. (2003): Sustainable Governance of Common Pool Resources: Context, Methods, and Politics. In: Annual Review of Anthropology 32: 243-262. doi: 10.1146/annurev.anthro.32.061002.093112.

Cannon, P.F., Hywel-Jones, N.L. Maczey, N., Norbu, L., Tshitila, Samdup, T. and Lhendup, P. (2009): Steps towards sustainable harvest of Ophiocordyceps sinensis in Bhutan. In: Biodiversity Conservation 18: 2263-81. doi: 10.1007/s10531-009-9587-5.

Dietz, T., Ostrom, E., Stern, P.C. (2003): The struggle to govern the commons. In: Science 302: 190712. doi: $10.1126 /$ science. 1091015.

Folke, C., Hahn, T, Olsson, P., Norberg, J. (2005): Adaptive governance of social-ecological systems. In: Annual Review Environmental Resources 30: 441-473. doi: 10.1146/annurev.energy.30.050504.144511.

German, L.A. and Keeler, A. (2010): Hybrid institutions: applications of common property theory beyond discrete property regimes. In: International Journal of the Commons 4 (1): 571-96. doi: 10.18352/ijc.108.

Negi, C.S., Pant, M., Joshi, P. and Bohra, S. (2016): Conserving the caterpillar fungus [Ophiocordyceps sinensis (Berk.) G.H. Sung et al.]: A case study of habitat ecology and sustainability in district Pithoragarh, Western Himalaya, India. In: International Journal of Biodiversity and Conservation. doi: $10.5897 / / J B C 2014.0742$.

Ostrom, E. (1990): Governing the Commons: The Evolution of Institutions for Collective Action, Cambridge: Cambridge University Press.

Pahl-Wostl, C. (2009): A conceptual framework for analysing adaptive capacity and multi-level learning processes in resource governance regimes. In: Global Environmental Change 19: 354-365. doi: 10.1016/j.gloenvcha.2009.06.001.

Pant, B., Rai, R., Wallrapp, C., Ghate, R. and Shrestha, U.B. (2017): Horizontal integration of multiple institutions: Solutions for Yarshagumba related Conflict in the Himalayan Region of Nepal? In: International Journal of the Commons 11 (1): 464-86. doi: 10.18352/ijc.717.

Shrestha, U.B. and Bawa, K.S. (2013): Trade, harvest and conservation of Caterpillar Fungus (Ophiocordyceps sinensis). In: Biological Conservation 159: 514-520. doi: 10.1016/j.biocon.2012.10.032.

Shrestha, U.B. and Bawa, K.S. (2014): Economic contribution of Chinese caterpillar fungus to the livelihoods of mountain communities in Nepal. In: Biological Conservation 177: 194-202. doi: 10.1016/j.biocon.2014.06.019.

Weckerle, C., Yang, Y., Huber, F.K. and Li, Q. (2010): People, money, and protected areas: the collection of the caterpillar mushroom Ophiocordyceps sinensis in the Baima Xueshan Nature Reserve, Southwest China. In: Biodiversity Conservation 19: 2685-98. doi: 10.1007/s10531-010-9867-0.

Winkler, D. (2008): Yartsa Gunbu (Cordyceps sinensis) and the Fungal Commodification of Tibet's Rural Economy. In: Economic Botany 62(3): 291-305. 
CHAPTER 4: Institutional Issues, Power Struggles and Local Solutions ...

Winkler, D. (2009): Caterpillar Fungus (Ophiocordyceps sinensis), Production and Sustainability on the Tibetan Plateau and in the Himalayas. In: Asian Medicine 5: 291-316. doi: 10.1163/157342109x568829.

Yeh, E. and Lama, K. T. (2013): Following the caterpillar fungus: nature, commodity chains and the place of Tibet in China's uneven geographies. In: Social and Cultural Geography 14(3): $318-340$. doi: 10.1080/14649365.2013.765025. 


\title{
5 Governing the yarshagumba 'gold rush': A comparative study of governance systems in the Kailash Landscape in India and Nepal
}

Corresponding manuscript, version of January 2019 (accepted for publication in January 2019):

Wallrapp, C., Keck, M. and Faust, H. (forthcoming): Governing the yarshagumba 'gold rush': a comparative study of governance systems in the Kailash Landscape in India and Nepal. In: International Journal of Commons, accepted for publication. ${ }^{7}$

\begin{abstract}
Under present conditions of economic globalization, social-ecological systems undergo rapid changes. In this context, internal and external forces put heavy pressure on the governance systems of commons to adapt effectively. While institutional learning has been identified as a key element for the adaptive governance of social-ecological systems, there is still limited knowledge of what roles communities and governmental actors play in these processes. In this study, we take the case of yarshagumba (English: caterpillar fungus), a formerly non-valued product in the Himalayas, which has recently been transformed into a highly valuable resource within a short time. We compare the governance systems in collection sites in the Kailash Landscape in India and Nepal by using an analytical framework developed by Pahl-Wostl (2009). Our findings show that in these remote mountain areas, communities and communityled organizations are highly flexible in responding to immediate resource value changes by establishing communal management arrangements. At the same time, however, communities have difficulties to enforce their newly developed informal and formal arrangements. During the process of learning the link between the amendment of arrangements on community-level and the revision of formal policies and frames at the state or national level is only partly established. Against this background, we argue that in the context of rapid change, adaptive governance requires the concerted interaction of actors at the local and the national levels in order to enable the sustainable use of common pool natural resources.
\end{abstract}

Key words: adaptive governance of commons, learning, access rights, ophiocordyceps sinensis, Himalaya

\footnotetext{
${ }^{7}$ As lead author I conducted the primarily research for the manuscript and contributed the majority of the content, with some theoretical and editorial inputs by the other authors.
} 


\subsection{Introduction: yarshagumba - a highly valuable resource}

Let them [the authorities] say whatever they say, we are going for collection (Woman from Pangla, India, April 2017 - English translation, original language Hindi).

Most of the high alpine grasslands in the Himalayas of Nepal and India are still used as summer pastures for livestock grazing (Bauer 2004). Traditionally, these pastures have been common properties governed by communities through local committees, guided by social norms, common beliefs and socially and culturally shared understandings (Herrera et al. 2014; Pandey et al. 2017). In the late 1990s, Ophiocordyceps sinensis (English: caterpillar fungus; locally known as yarshagumba ${ }^{8}$ ), a highly valuable product, was discovered on these grasslands at altitudes between 3000 and 5200 m (Shrestha and Bawa 2013; 2014; Winkler 2009). Caterpillar fungus is collected by hundreds of thousands of people in the Himalayas of India, Nepal and Bhutan each year and traded by middlemen as a medicinal product, mainly to China (Baral et al. 2015; Shrestha and Bawa 2013).

In the late 1990s the demand on the Chinese market for yarshagumba transformed fundamentally, leading to a tremendous rise in prices (Winkler 2008; Yeh and Lama 2013). The high prices for yarshagumba and the perceived easy cash income opportunity for locals triggered a 'gold rush' in the Himalayan Mountains. The sudden run of collectors to the yarshagumba collection sites led to conflicts about access and uncontrolled usage of the resource (Negi et al. 2006; Shrestha and Bawa 2013). Especially collectors from distant villages, hereafter called "distant collectors," have exacerbated the pressures on the socialecological systems (Pant et al. 2017). Over the last decades the governance systems in these high alpine areas where yarshagumba is collected, have struggled to adapt to these changes and to set up and enforce management mechanisms for its sustainable collection (Baral et al. 2015; Cannon et al. 2009; Childs and Choedup 2014; Negi et al. 2006; Weckerle et al. 2010; Winkler 2009). Today, the collection is influenced by governance systems consisting of both formal governmental institutions and informal communal management arrangements (Cannon et al. 2009; Caplins 2016; Childs and Choedup 2014; Negi et al. 2015; Pant et al. 2017; Weckerle et al. 2010).

This development in the Himalayan Mountains brings up the question of how actors and institutions in remote areas govern commons when rapid changes in the social-ecological system occur. Over the last decade scientists identified adaptive governance and learning processes as essential elements for governing social-ecological systems during periods of abrupt change (Dietz et al. 2003; Folke et al. 2005; Karpouzoglou et al. 2016; Pahl-Wostl 2009; Plummer et al. 2013). However, they note, "our knowledge about resource governance systems

\footnotetext{
8 In Tibetan language yarshagumba is called yartsa gunbu, which means 'winter worm - summer grass' (Winkler 2008). Yarshagumba is an endoparasitic complex formed by the fungus ophiocordyceps sinensis and the host larva of different moth species (Negi et al. 2016). For more details on the biology and usage of yarshagumba see Winkler (2008) and Negi et al. (2016).
} 
and how they change [to deal with present and future challenges] is [still] quite limited" (PahlWostl 2009: 254).

Contributing to this on-going research area, we focus our analysis on the adaptive capacity and learning processes of resource governance systems in remote mountain areas using the case of yarshagumba collection. We compare resource governance systems in the collection sites of two settings in the Kailash Landscape ${ }^{9}$ : in the Kumaon region of Uttarakhand State in India and in the adjacent protected area of the Api Nampa Conservation Area (ANCA) in Nepal. These two regions differ in terms of both legal and social context. In India, the commercial collection of yarshagumba is legal only in community forests managed by van panchayats (community forest councils) with the approval of the State Forest Department (Uttarakhand Biodiversity Board 2017). However, collectors harvest yarshagumba wherever possible - within state forests or protected areas - regardless of property rights and legal status (Negi et al. 2016). In Nepal, in contrast, yarshagumba collection and sale in all community forests and conservation areas is legal (MoFSC 2017), but conflicts regarding access between villagers and distant collectors are common (ICIMOD 2015; Pant et al. 2017).

While comparing different resource governance systems we aim to understand how these systems respond to a rapid increase in the economic value of an available resource. The two types of systems we compare are (1) formal governmental institutions and (2) communal management arrangements, which consist of both formal committees composed of community members, and informal arrangements based on a variety of norms, and both of which are essentially community-led. Further, we ask what strategies governments and communities use to protect or gain access to these resources. We focus our case study on the following research questions: What developments can be identified in the institutional settings and the management mechanism in areas where yarshagumba is collected? What are the learning process of governmental actors, communities and formal and informal institutions, and how do these influence each other in the process of adapting to rapid changes in the high alpine grasslands of India and Nepal? Based on these questions we formulate the following hypothesis: When the economic value of a common resource in a remote mountain area increases and other changes are subsequently triggered, communities are relatively more flexible in adapting their management of the common resource than government authorities, irrespective of the legal setting of the area.

We apply the analytical framework of Pahl-Wostl (2009) for analysing the adaptive capacity and learning processes in resource governance systems, which is further elaborated in section 2. Section 3 provides details about the study area and the data collection and analysis. The analysis of the changes in the governance systems in India and Nepal where yarshagumba is

\footnotetext{
${ }^{9}$ The Kailash Landscape comprises a transboundary region of Uttarakhand State, India, Pulan County, China and parts of far western Nepal. The landscape is part of an initiative steered and implemented by the governments of China, India and Nepal and the International Centre for Integrated Mountain Development (ICIMOD).
} 
collected, namely, the formal and informal institutions, the involved state and non-state actors and the multi-level interactions and integration is presented in section 4. Further, in section 5 and 6, we analyse and discuss the roles of governments and communities during learning processes for adapting to rapidly changing conditions and, finally, draw our conclusions.

\subsection{Conceptual framework}

Most natural resources, like forests and grazing grounds, are common pool resources (Acheson 2006). Common pool resources, like yarshagumba, are subtractable, which means the resource consumed by one person cannot be used by another. Secondly, it can be difficult to exclude other people from using the resource (Ostrom 1990). It is rational for everyone to free ride on the efforts and costs of others when incentives for sustainable usage are lacking (Agrawal 2003; Ostrom 1990; Ostrom 2005). This collective-action problem applies also to the collection of yarshagumba in the high alpine grasslands. The solution to sustainably managing such a common pool resource is to establish rules curtailing the resource access and use (Acheson 2006; Dietz et al. 2003).

Social-ecological systems are dynamic. Changes within or outside social-ecological systems demand constant adaptation and proper responses by actors and institutions (Young 2009). Sudden changes can be triggered by external factors, such as changes in market demands or the emergence of new actors, as well as internal factors, such as a change of power relations between actors or overlapping institutions (Anderies et al. 2004). Often changes trigger other changes or reinforce each other (Young 2009). In our case the price increase of yarshagumba in the Himalayas has modified access demands of governmental actors, community members and distant collectors, which has further triggered power struggles and conflicts between actors.

The search for the governance system best suited to maintaining the sustainability of resources within dynamic social-ecological systems has been under discussion for many years, whether local-level management, government regulations or private property rights (Acheson 2006; Baland and Platteau 1996; Dietz et al. 2003; Folke et al. 2005; Hardin 1968; Ostrom 1990; Pahl-Wostl 2009). Governmental actors, especially in remote areas, are likely to face challenges regarding the enforcement of regulations due to limited human and financial resources or resentments by holders of customary rights (Acheson 2006). Private property does not play a role in our case study. Dietz et al. (2003) argue that local communities could manage common pool resources effectively, but they usually have challenges when sudden changes occur. Often, the change in demand and increased value of local resources overstrain the ability of local institutions to regulate the resource use in a sustainable way. Communities usually have difficulties applying sanctions and enforcing communal arrangements outside their closed community structure (Ostrom 2010).

In the last decades, researchers have argued for more complex governance systems such as 'adaptive co-management' and 'adaptive governance' (Dietz et al. 2003; Folke et al. 2005; 
Karpouzoglou et al. 2016; Olsson et al. 2006; Plummer et al. 2013), 'polycentric institutions' (Ostrom 2005) or 'hybrid institutions' (German and Keeler 2010). These approaches have in common the idea that, for governance to be effective, it "should employ mixtures of institutional types that employ a variety of decision rules to change incentives, increase information, monitor use and induce compliance" (Dietz et al. 2003: 1910). They differ in terms of setting the priorities of governance structures and in the criteria they use to evaluate the performance of governance systems for sustainability of commons (Agrawal 2003; Karpouzoglou et al. 2016; Sharma-Wallace et al. 2018).

Governance systems that negotiate and share rights, responsibilities and power among different levels and sectors of government and civil society are assumed to encourage innovation, learning, adaptation and cooperation among actors to deal with unexpected changes (Folke et al. 2005; Huitema et al. 2009; Ostrom 2010; Pahl-Wostl 2009; Pahl-Wostl et al. 2013; Sharma-Wallace et al. 2018; Young 2009). Adaptive capacity is defined as the "ability of a resource governance system to first alter processes and if required convert structural elements as a response to experienced or expected changes in the societal or natural environment" (Pahl-Wostl 2009: 355). Learning is considered to be "an exploratory, stepwise search process where actors experiment with innovation until they meet constraints and new boundaries" (Pahl-Wostl 2009: 358). The adaptive capacity of governance systems determines the learning processes and developments of institutions when sudden changes occur.

Pahl-Wostl (2009) developed an analytical framework to analyse different stages of societal learning in resource governance systems. Different from other analytical frameworks related to resource governance, such as the Institutional Analysis and Development Framework (Binder et al. 2013; McGinnis 2011), Pahl-Wostl (2009) focuses specifically on the adaptive capacity and learning processes in resource governance systems in response to changes. Her framework helps to analyse developments and learning processes within systems over time. Therefore, her approach will be used to analyse and compare resource governance systems and the associated learning processes in our study.

These multi-level and multi-loop learning processes range from incremental learning (singleloop learning) to structural change (triple-loop learning). Single-loop learning refers to a gradual improvement of actions towards a strategic goal without questioning the underlying assumptions. Double-loop learning refers to a reflection of assumptions, for example about cause-effect relationships within a value-normative framework. In triple-loop learning, one begins to reconsider underlying values and beliefs to transform the context within which the governance system is embedded. Triple-loop learning implies a transformation by changing the strategic goals and regulatory frameworks rather than optimizing adaptation strategies. Adaptive change remains largely within the reigning paradigm and structural context set by the formal policy process. Thus, adaptive change processes are within single and double-loop learning (Pahl-Wostl et al. 2013).

Pahl-Wostl (2009) has identified elements of governance systems that are key for these learning processes including institutions and actors, the relationship of state and non-state 
actors, the multi-level interactions across administrative boundaries and vertical integration, and the governance modes distinguishing bureaucratic hierarchies, networks and markets. The interplay of these elements determines the adaptive capacity of governance systems to alter processes and structures (Pahl-Wostl et al. 2013). This leads us to a comparative analysis of roles of communities and governmental actors in learning processes when sudden changes occur, using the case of yarshagumba collection in remote Himalayan regions of India and Nepal.

\subsection{Study sites and methods}

\subsubsection{Study sites}

The Kailash Landscape is one of the main areas of Nepal and India from which yarshagumba is collected. According to official national data, the conservation area ANCA in Nepal provides amounts of between 629 and $954 \mathrm{~kg}$ of yarshagumba annually (ANCA 2018 unpublished). The total harvest in the adjacent Kumaon Region, Uttarakhand State, India, amounts to around 350 to $600 \mathrm{~kg}$ per year (Negi et al. 2016). The study area map (Figure 4) shows the potential habitat of yarshagumba in the Kailash Landscape (total area approximately 1129 square metres) ${ }^{10}$.

\footnotetext{
${ }^{10}$ We calculated the potential habitat for yarshagumba in the Kailash Landscape using as basis the land cover layer of high alpine grasslands of the Kailash Sacred Landscape vegetation map (ICIMOD 2017), adding the criteria of precipitation ( 250 to $450 \mathrm{~mm}$ ), slope degree ( 0 to 15 degrees) and height ( 3200 to 5000 masl) referring to the listed criteria for determining yarshagumba growth in Negi et al. (2015). Inaccuracy of data is possible.
} 
CHAPTER 5: Governing the yarshagumba 'gold rush': A comparative study ...

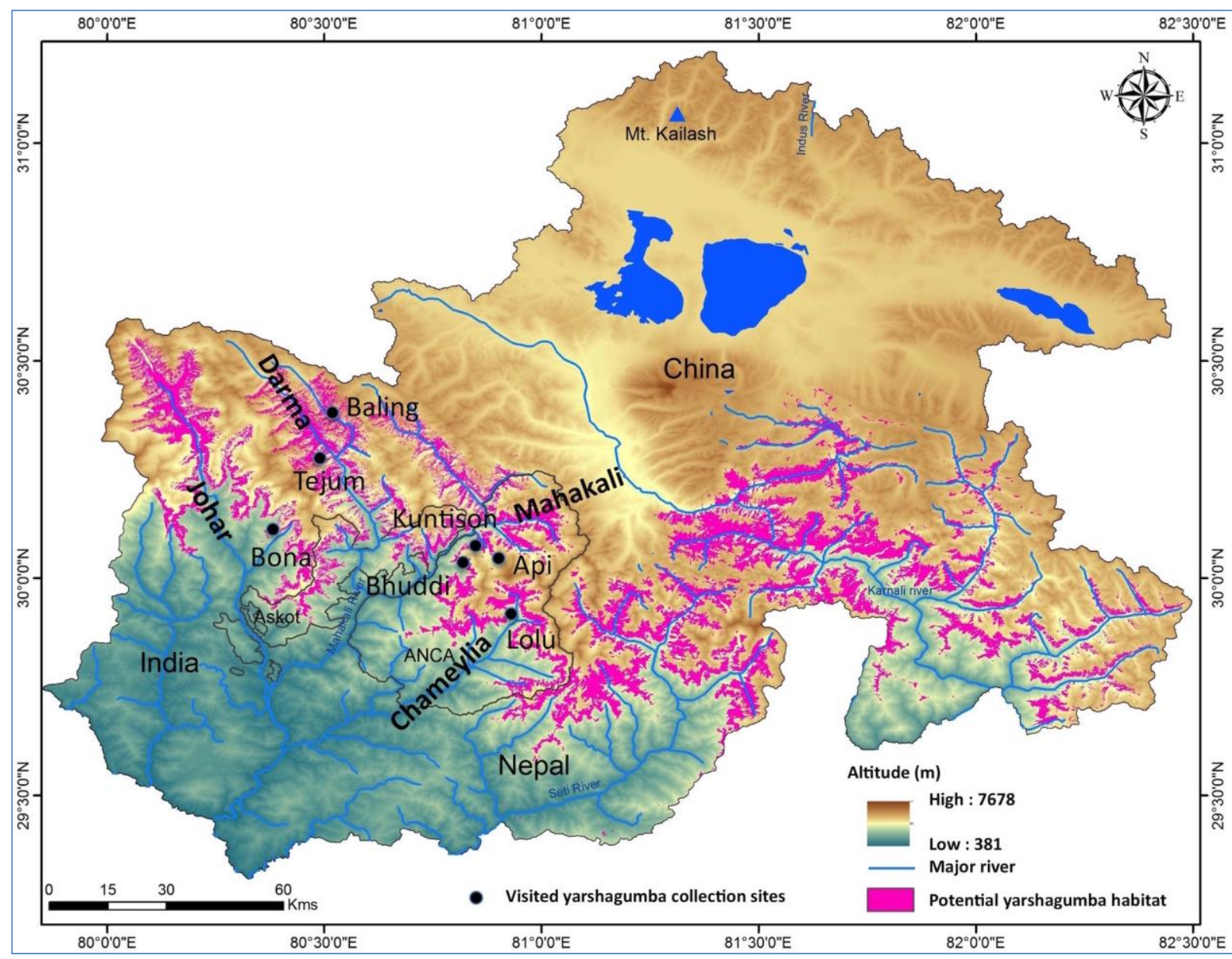

Figure 4: Map of study area and potential yarshagumba habitat (own source, based on ICIMOD (2017))

In the Kailash Landscape, two ethnic groups are predominant: the Rang community, who in Nepal are known as the Shauka, located in the upper parts of the Johar, Darma (India) and Mahakali valley (Nepal), and the Hindu community, located in the Chameylia valley (Nepal) and in the lower parts of Darma valley (India). The Rang/Shauka community traditionally practices transhumance. Over centuries, they have established strict customary laws to regulate access to and usage of their pasture areas (Hoon 1996; Leder 2003), which are now yarshagumba collection sites.

Over the last decade, the rising market price of yarshagumba has influenced and changed the livelihood strategies of the majority of communities in the high Himalayan Mountains (Childs and Choedup 2014; Shrestha and Bawa 2014; Shrestha et al. 2017). Today, according to a recent study in ANCA (Nepal) the "average household cash income from 0 . sinensis is USD $2174[\ldots]$ confirming the dominant role of $O$. sinensis in cash generation" (Pouliot et al. 2018: $65)$.

The empirical fieldwork was conducted in four valleys of the Kailash Landscape: in two valleys in the Kumaon Region (India) - Darma and Johar valleys - and two valleys of ANCA (Nepal) Mahakali and Chameylia valleys, (see figure 4). The selection of the study areas is based on 
different existing institutional settings, property rights and management systems in the yarshagumba collection sites. Individual sites are very remote, therefore the accessibility of the sites additionally had to be considered. Using these criteria we chose seven collection sites in four valleys for our case study: Bona, Baling and Tejum in India and Api, Buddhi, Kuntison and Lolu in Nepal (see Table 3 for details about the characteristics of each site).

Table 3: Characteristics of the collection sites

\begin{tabular}{|c|c|c|}
\hline \multicolumn{2}{|c|}{ Location } & Key characteristics of the collection site \\
\hline \multirow{3}{*}{$\stackrel{\underline{\pi}}{\underline{\underline{\sigma}}}$} & $\begin{array}{l}\text { Bona - } \\
\text { Johar valley }\end{array}$ & $\begin{array}{l}\text { - Site located within state forest } \\
\text { - Traditional grazing institutions } \\
\text { - Closed site - access exclusively for selected community } \\
\text { members (Rang community) }\end{array}$ \\
\hline & $\begin{array}{l}\text { Baling - } \\
\text { upper Darma valley }\end{array}$ & $\begin{array}{l}\text { - Site located within community managed forest } \\
\text { - } \quad \text { Traditional grazing institutions } \\
\text { - Closed site - access exclusively for selected community } \\
\text { members (Rang community) }\end{array}$ \\
\hline & $\begin{array}{l}\text { Tejum - } \\
\text { lower Darma valley }\end{array}$ & $\begin{array}{l}\text { - Site located within state forest } \\
\text { - } \quad \text { Closed site -access exclusively for selected community } \\
\text { members (mixed community of Hindus and Rang) }\end{array}$ \\
\hline \multirow{4}{*}{$\frac{\pi}{\frac{0}{0}}$} & $\begin{array}{l}\text { Api - } \\
\text { upper Mahakali valley }\end{array}$ & $\begin{array}{l}\text { - Site located within community managed forest and protected } \\
\text { area ANCA } \\
\text { - Traditional grazing institutions } \\
\text { - Closed site - access exclusively for selected community } \\
\text { members (Shauka community) }\end{array}$ \\
\hline & $\begin{array}{l}\text { Buddhi - } \\
\text { upper Mahakali valley }\end{array}$ & $\begin{array}{l}\text { - Site located within community managed forest and protected } \\
\text { area ANCA } \\
\text { - Open site - access not restricted (mainly Hindu community from } \\
\text { various villages) }\end{array}$ \\
\hline & $\begin{array}{l}\text { Kuntison - upper } \\
\text { Mahakali valley }\end{array}$ & $\begin{array}{l}\text { - Site located within community managed forest and protected } \\
\text { area ANCA } \\
\text { Closed site - access exclusively for selected community } \\
\text { members (Shauka community) }\end{array}$ \\
\hline & Lolu - Chameylia valley & $\begin{array}{l}\text { - Site located within protected area ANCA } \\
\text { - Open site - access not restricted (mainly Hindu community from } \\
\text { various villages) }\end{array}$ \\
\hline
\end{tabular}

\subsubsection{Data collection and analysis}

The empirical research is comprised of qualitative data collected through key informant and indepth interviews, focus group discussions and participatory field observation. The interviewees included government officials on central, state and district levels, local leaders, community members, traders, collectors from various backgrounds with different gender and age and relevant researchers from the region. In total 20 interviews with representatives of higher authorities, like national and state departments, were conducted. Additionally, 30 representatives of local authorities, like van panchayats and ANCA Conservation Committees, and 62 community members were interviewed and 13 focus group discussions with community 
members and traders were organised in 2016 and 2017 (Table 4). The interviews and focus group discussions were mainly conducted at the collection sites or in nearby villages. Both men and women come for collection to the sites. However, fewer women were interviewed because they were more reluctant to answer questions and speak with outsiders.

Table 4: Interviews and focus group discussions conducted in 2016 and 2017

\begin{tabular}{|c|c|c|c|c|c|c|}
\hline & \multicolumn{2}{|c|}{$\begin{array}{l}\text { Local authorities } \\
\text { (forest department, } \\
\text { ANCA, police) }\end{array}$} & \multicolumn{2}{|c|}{$\begin{array}{l}\text { Community members } \\
\text { (collectors, traders, villagers) }\end{array}$} & \multicolumn{2}{|c|}{$\begin{array}{l}\text { Participants of focus group } \\
\text { discussions }\end{array}$} \\
\hline & male & female & male & female & Male & female \\
\hline \multirow[t]{2}{*}{ India } & 13 & 1 & 24 & 3 & 35 & 17 \\
\hline & \multicolumn{2}{|c|}{ Total 14} & \multicolumn{2}{|c|}{ Total 27} & \multicolumn{2}{|c|}{ Total 52 (7 mixed FGD) } \\
\hline \multirow[t]{2}{*}{ Nepal } & 14 & 2 & 25 & 10 & 18 & 9 \\
\hline & \multicolumn{2}{|c|}{ Total 16} & \multicolumn{2}{|c|}{ Total 35} & \multicolumn{2}{|c|}{ Total 27 (6 mixed FGD) } \\
\hline Total & \multicolumn{2}{|c|}{30} & \multicolumn{2}{|c|}{62} & \multicolumn{2}{|c|}{13} \\
\hline
\end{tabular}

As some aspects, like negative implications of government regulations or social conflicts between different community groups, are considered sensitive and difficult to discuss openly with interviewees, participatory field observation was used as an important method for building trust between the interviewer and community members. Additionally, several policies, guidelines and directives of India and Nepal guiding natural resource management and nontimber forest product (NTFP) collection and trade were reviewed.

For the data analysis we chose the content analysis following Mayring (2015). The interviews were translated from Hindi or Nepali into English and transcribed afterwards. Field notes were taken in order to document other observations, focus group discussions and informal conversations. Following fieldwork, the texts were categorized and coded according to defined units of analysis, like formal and informal institutions, types of actors and management mechanism. Finally, the results were interpreted, compared and discussed.

\subsection{Results - Development of yarshagumba governance systems}

\subsubsection{India: Kumaon Region, Uttarakhand State}

The high alpine grasslands in the Kumaon Region are traditionally used as summer pastures and were never of great interest for the Indian state authorities (Gerwin and Bergmann 2012; Pandey et al. 2017). The State Forest Department hardly intervened in the local-level resource 
management systems for livestock grazing, although technically, all forests and grasslands in the Uttarakhand State are under their overall responsibility and supervision to manage and conserve the available resources (Singh 2016).

According to the current legislation, the collection of NTFP in the wild is illegal in India. This regulation is valid for unclassified forests, state forests and protected areas, except within community forests under the management of van panchayats. The collection of NTFPs for personal use was never restricted, but commercial collection and sale of the products was either prohibited (in the case of rare and endangered species) or permissible in van panchayats on the condition that the harvested quantity would be sold via an auction system organised by the State Forest Department (Pauls and Franz 2013; Singh 2016).

Specifically with regards to yarshagumba collection, the State Forest Department formulated a government order in 2013 to regulate its collection and sale, which falls within the remit of van panchayats. The Government Order of Uttaranchal State (former name of Uttarakhand State) Forest Department 1790/18.1.2002 authorised 20 van panchayats in Johar valley to hand out passes to community members for yarshagumba collection and provides regulations for sustainable collection and camp management.

The implementation of the Government Order has failed, however, because of the limited cooperation between the State Forest Department and local authorities. The limited support and presence of officials in the remote sites makes it difficult for van panchayat leaders to manage the available resources in accord with the regulations. Further, through the high level of bureaucracy and lack of consultations before issuing new guidelines or directives, the local leaders felt their demands were not recognised and valued by the state authorities, as the following two statements of community members highlight:

There was a new directive that we [van panchayat leaders] have the permission to give out passes to villagers for collection of yarshagumba. But nobody was authorised to buy it directly. It did not make sense. They did not even consult us beforehand (van panchayat leader in Munsyari, India, April 2017 - English translation, original language Hindi).

I think, it [the policy] doesn't matter. The foresters are not present on the ground anyway. For good management it needs strong community structures (Community leader in Dharchula, India, January 2017 - English translation, original language Hindi).

De-facto, irrespective of policies and governmental regulations, people in the Kumaon region - including both community members and distant collectors - collect in all possible locations where yarshagumba can be found, and sell it through their own systems (Negi et al. 2016). See annex 1 for some photographs of yarshagumba collection in the Kailash Landscape.

The governmental institutions are weak in controlling the collectors and resource extraction. However, the local communities have a strong interest in gaining or protecting access to sites where yarshagumba is found and limiting its collection. For that they have built up communal management arrangements specific to the conditions of each site. In the following we present different examples of management arrangements that have been set up by the communities 
and community-led organizations as a response to the rapid changes in the high alpine grasslands due to the high value of yarshagumba (refer also to Table 1 in section 3 for details about the key characteristics of each collection site in India and Nepal).

In Baling, upper Darma valley, the villagers are solely from the Rang/Shauka community and the local yarshagumba collection site lies with the boundaries of the van panchayat of Baling. The van panchayat plays a crucial role in regulating and managing the natural resources required on a daily basis by its community members. Their rights consist of excluding outsiders, extracting fodder and timber for personal usage, regulating grazing of livestock and formulating local management rules (Agrawal and Ostrom 2001; Singh 2016). The communities make use of these rights to regulate yarshagumba collection by excluding distant users and only enabling collection for community members from that village (closed site). The van panchayat of Baling has limited the collection period and set rules for managing the campsites. Also on specific religious and cultural days collection is prohibited, as the statement of a community member describes:

On the next day is a puja [religious ceremony] in the village. So, all people, who are up in the collection site will come down for that afternoon. Not everyone agrees to that, especially the youth, but there is no other option (Community member from Baling, India, June 2017 - English translation, original language Hindi).

In contrast, another example shows that social norms and beliefs also change over time and some are not accepted by all community members anymore:

All these mountains are sacred to the [Rang] people. One of these beliefs is that women, especially during their period but even in general, are not allowed to go to the high mountain areas. But nowadays people do not support that belief anymore. Women and children are also collecting (Researcher C.S. Negi, Pithoragarh, India, August 2016).

Consequently, according to the interviewee, more community members - men, women and children - go for yarshagumba collection each year and the competition between collectors therefore increases. Although the economic impact of yarshagumba has influenced and in some cases transformed local traditions, the existence of common social norms and beliefs facilitates designing, enforcing and monitoring rules as well as sanctioning collectors for violations, as the rules are socially accepted by the whole community.

Other communal management arrangements for yarshagumba collection, like in Bona, Johar valley, are built on traditional grazing rights. For centuries, local institutions have effectively regulated the limited resources in the grazing grounds (Herrera et al. 2014). The grazing system included well-defined boundaries, payments for resource usage and graduated sanctions for violations, which has historically ensured a sustainable usage of the limited resources (Negi et al. 2015). The same system is used to regulate the yarshagumba collection in Bona. The community has transferred traditional grazing rights to yarshagumba collection. Additionally, the community has designed rules limiting the collection period and area, as well as 
implemented entrance fees and fines for violations. They use the pre-established traditional systems and adapt them to the changing conditions.

In collection sites that are not within the official boundaries of van panchayats, but lie within state forests, or are not traditional grazing grounds, like in Tejum, lower Darma valley, local leaders negotiated access to a yarshagumba collection site with neighbouring communities as soon the run for yarshagumba collection started. Each community got access to one specific site. As the community leaders are socially accepted and respected by community members, these arrangements are legitimized in these communities, and therefore enforced. This has ensured that all nearby communities have access to a site, which has reduced disputes and conflicts related to it.

In addition to the State Forest Department, new governmental actors for natural resource management have emerged on state and local levels in recent years: the State Biodiversity Board and Biodiversity Management Committees (BMCs). Comparing the rights and functions of the actors on village level, the functions of the BMC overlap with rights of the van panchayats, especially regarding the regulation of access to resources by community members. The BMCs are legalised through the national Biodiversity Conservation Act (2002). So far 14 BMCs have been established in the region, but are not yet fully functional, nor fully socially accepted and integrated into the existing local natural resource governance systems. Currently, our data show that the van panchayats are more influential on local level, the van panchayat leaders are better recognised and their decisions and actions are legitimated by the community members. However, in future, the van panchayats might be replaced by the BMCs in the communities, if BMCs receive more financial resources and governmental support and therefore accumulate more authority and power.

\subsubsection{Nepal: Api Nampa Conservation Area (ANCA), Darchula District}

According to national policies in Nepal collection and sale of NTFPs including yarshagumba is legal, but the yearly total quantity of collected yarshagumba for a protected area is restricted by the Department of National Parks and Wildlife Conservation (DNPWC). In 2017, $690 \mathrm{~kg}$ was the fixed amount for ANCA (ANCA 2018 unpublished). The ANCA authority collects royalties for yarshagumba collection, which currently amounts to 25.000 NPR per kg (250 USD) (MoFSC 2015). Subsequently, ANCA makes approx. 17.3 Mio NPR (173.000 USD) in revenue per year only from yarshagumba collection.

Similar to India, in Nepal community-led organizations also play a key role in the management of high alpine grasslands. Since the 1990s, the Forest Department has handed over patches of government-owned forests surrounding the villages to communities who established community-forest user groups (CFUG) for the management of the forests. CFUGs are allowed to set up rules and regulations to manage their resources. They are allowed to restrict the number of users and the usage of resources, to collect fees for the extraction of timber and 
NTFPs and, in contrast to van panchayats in India, to sell their resources in the open market (Agrawal and Ostrom 2001).

In 2010, ANCA was established in Darchula District under the DNPWC. The establishment of ANCA and its community-led committees shifted most of the functions and rights of over 100 CFUGs in the area to newly formed ANCA Conservation Committees. The CFUGs were not dissolved, but new bodies were created and ANCA office with its communal committees emerged as new player in the region. Some community members raised concerns in relation to these developments:

The establishment of the ANCA committees is a good progress, because people can raise their voice through the committees to officials in Darchula. But in the end all decisions are made in Darchula by committee leaders and ANCA, without any involvement of the community (Community member, Dumblin, Nepal, May 2017 - English translation, original language Nepali).

As this statement emphasizes, according to community members, the power relation has not changed much following the designation of ANCA, as in many local committees, community members have just switched 'seats' and power is still concentrated in the main town of Darchula.

The formation of ANCA has also altered the perception and legal status of access rights to resources for community members within ANCA. Yarshagumba is found in the five high mountain villages of Byash, Rapla, Khandeswori, Ghusa and Chitola. Before the ANCA was established, the CFUGs of these five villages both enabled and constrained the access to the yarshagumba collection sites. Nowadays, community members from all 21 villages within ANCA have the same rights under the umbrella of ANCA, according to ANCA policies. Therefore, members from lower villages should also have the same access rights to yarshagumba collection sites and benefit from revenues in the same way as the five high mountain villages. Consequently, the five villages are reluctant to follow the new ANCA policies. The de-facto scenario is that in some sites, like in Api and Kuntison, communities still restrict access for members of other communities (closed sites). The sites Api and Kuntison lie within a community forest of the Shauka community and the communal arrangements are similar to the ones in Bona and Baling, India, like regulating access, fines and the collection period.

The collection site in Lolu, Chameylia valley, is different, as traditional grazing and community forest management systems did not exist in the site before yarshagumba collection began. Additionally, the collectors coming to Lolu are from different communities and ethnic groups with different social norms. The enforcement of access rights and management regulations is challenging for the local community, as the ANCA Conservation Committee is not yet fully functional and local arrangements are often not socially accepted by all collectors and therefore not followed. Conflicts are the consequence.

A locally developed guideline for the management of yarshagumba collection in ANCA in 2016 tried to address these different conflicts and power struggles by negotiating rights and responsibilities between the local communities and distant collectors. The guideline increased 
the transparency regarding the rights and responsibilities of the ANCA Conservation Committees, clarified access, entrance fee collection and distribution of revenues and regulated the management of campsites. In the collection season of 2016, the committees in cooperation with ANCA authorities started its implementation. However, the higher authority, the DNPWC, did not approve this ANCA-specific guideline. Instead more general national directives for yarshagumba management in protected areas were developed in 2017 (MoFSC 2017). According to this latest national directive, it is the responsibility and right of the government authority in protected areas to control the access to yarshagumba collection sites, to distribute entrance permits, to collect entrance fees and to manage the campsites. This has shifted rights to control the access to the sites from local committees to government authorities without previous consultations and consideration of the local context. The ANCA government representatives appreciate these developments as emphasized by the quote:

We think it is better that ANCA collects the entrance fees for the moment until the system works better. Than we can hand over to the community (ANCA warden, Darchula, Nepal, May 2017 English translation, original language Nepali).

In the protected area, these changes raised tensions between local leaders and governmental actors, hindered cooperation and hampered an effective implementation of the directives in the collection season of 2017.

Nevertheless, the partly implementation of both formalised guidelines, the local one in 2016 and the national one in 2017, has already improved the transparency of fee collection and accountability through the involvement of a formal institution. Since 2016, each collector pays a fixed amount of 500 NPR (5 USD), 1000 NPR (10 USD) or 3000 NPR (30 USD) depending on his/her origin (MoFSC 2017). Beforehand, the collection of entrance fees from collectors was a very informal local arrangement made by the nearby communities. This sometimes led to threats, bribery and fraud as well as non-transparent usage of the collected fees (ICIMOD 2015). The guideline also sets up an equal distribution mechanism to all 21 communities within ANCA, but at the same time reduces the direct benefit for and the responsibility and customary rights of communities living next to the yarshagumba collection sites. A community representative of ANCA states his concerns about the latest developments:

I am not happy about the new directive. It is fine when ANCA [government authority] collects the money, but the responsibilities should be discussed and agreed between ANCA and the local committees. Monitoring will be difficult for ANCA. They are not in the sites. We can easily implement regulations (ANCA Committee leader, Darchula, Nepal, May 2017 - English translation, original language Nepali).

As the statement shows, local leaders fear that management mechanisms in the collection sites cannot be sufficiently implemented by ANCA government authorities. They request cooperation and sharing of rights and responsibilities among the community-led organizations and government authorities in future for effective governance of yarshagumba collection. 


\subsection{Discussion - Governance systems and their learning processes}

Analysing the resource governance systems in different yarshagumba collection sites using the framework created by Pahl-Wostl (2009), our findings show that in both countries, the resource governance systems in high alpine grasslands have become more complex since yarshagumba collection started. Additional actors have appeared, power relations and interactions have changed, new institutions have been formed and others neglected. Some actors, like the distant collector, have emerged directly due to the rapidly increasing value of yarshagumba. Other actors and related institutions, like ANCA in Nepal, or the BMC in India, developed due to decisions and policy changes on national and state levels for natural resource management. All actors have an interest in benefitting from the increased resource value and, therefore, have influenced the governance systems in the high alpine grasslands. Further, all actors and institutions interact on multiple levels, but hardly harmonize or complement each other. Bureaucratic hierarchy is still the predominant governance mode in both countries.

In both countries, several institutional and societal multi-level learning processes were initiated, which altered the structures of existing resource governance systems and consequently triggered new learning processes. In the early years of the 2000s when the 'gold rush' started, communities set up access and management rules. This can be identified as single-loop learning that changed actions to improve established routines (Pahl-Wostl 2009). In some cases these rules solved conflicts between collectors and clarified terms of resource extraction; in other cases they raised more tensions. We identify four practices of communities to legitimate these arrangements in our case study: transfer of formal institutions from one resource to another one (example: Baling), consistent strong leadership of community heads (example: Tejum), maintenance of a shared sense of community in a site (examples: Baling and Api) and retention of established customary rights and responsibilities (example: Bona). The arrangements have enabled these communities to retain most benefits for their own community and to control users and resource extraction when the design of governmental institutions is weak, as is the case in India, or when the governmental institutions override customary rights and practices, as it is the case in Nepal.

These established communal management arrangements are not necessarily legally sanctioned by law, especially in India. They are recognized as legitimate by the involved community members (c.f. Scott 1999). However in some cases, communities have difficulties to enforce these informal regulations, especially towards distant collectors. Distant collectors often do not know or neglect these informal arrangements and, therefore, do not legitimate them. Additionally, members from within the community are not always willing to respect certain traditions, as the example of women collecting yarshagumba shows. By comparing the dynamics in the different sites, we deduce that the more the local site arrangements are linked to formal community-led organizations, like van panchayats in India or CFUG and the ANCA Conservation Committees in Nepal, the more the collection of yarshagumba is regulated and the better regulations can be enforced by the community under both community members and distant collectors. 
In India, the State Forest Department is characterised by strong bureaucratic hierarchies and limited interaction with local leaders (Singh 2016). On the one hand, the remoteness and inaccessibility of the collection sites as well as the limited human and financial resources of the State Forest Department hamper the implementation of the existing polices. On the other hand, government authorities have not yet responded to the changing situation in the high alpine grasslands with major policy revisions. Although local representatives of the State Forest Department are aware of their limitations and have an interest in further legalising the collection and sale of yarshagumba in order to collect revenues and control the access to the resource, at the time of writing, the decision about legalisation was still pending on state level.

On local and national level, the Nepali government has responded to the yarshagumba 'gold rush' only recently, when conflicts between actors increased. The local yarshagumba management guidelines for ANCA developed in 2016 were an attempt to involve state and nonstate actors on a local level equally to negotiate and share rights and responsibilities, as well as to increase their overall cooperation. However, it lacked the acceptance of higher government authorities on the central level. The formulation of national directives a year later shows that although decentralised community-based programmes have been part of government schemes since the late 1990s (Agrawal and Ostrom 2001), power and decisionmaking is still situated on national level. Therefore, the vertical integration between local and national actors and institutions remains weak. Nevertheless, the local 2016 yarshagumba management guideline for ANCA provides a good example of revising the institutional frame of the governance system by integrating informal and innovative approaches as well as local knowledge of communities in formal processes. This approach linked the single-loop learning process (improvements of local actions) with double-loop learning (revisions of the governance frame).

Referring to triple-loop learning (Pahl-Wostl 2009), to date, neither state nor non-state actors in India and Nepal are tackling the communities' strong dependency on yarshagumba collection. Governmental programmes could provide incentives to reduce the communities' dependency on NTFP collection and to identify comparable income options to reduce the pressure on these natural resources. This could transform the overall socio-economic context in the high Himalayan Mountains and would contribute towards greater sustainability of natural resources.

Subsequently, referring to our hypothesis, our findings show that in comparison to government authorities, communities adapted more flexibly to protect or gain access to a common pool resource when the value of this resource increased. Irrespective of the legal status of yarshagumba collection, the resource governance systems in both countries in our case study have adapted to the abrupt changes in the high alpine grasslands. The pressures on this resource triggered innovative approaches on a community level to protect or gain access to collection sites. Following the example in Nepal, the establishment of communal management arrangements needs to be followed by and strongly linked with the revision and implementation of governmental institutions. This can stabilize and legitimate the adaptive changes in the 
governance systems, especially when the communities respond in ways that fall outside the bounds of formal institutions.

Going beyond this case study, we elaborate that stages of multi-level learning have to build on each other to be able to move from changing actions (single-loop learning) to revising the frame by government authorities with the cooperation of communities (double-loop learning) and, finally, to transforming the context (triple-loop learning). Therefore, we argue that institutionallymixed resource governance systems constituted by multi-level interaction as well as shared responsibilities and rights among different institutions and actors can better handle sudden resource value changes and other changes triggered subsequently by enabling adaptive and transformative learning processes in the governance systems.

Currently, the limited recognition of the local context in recent policies in India and Nepal, as well as the overlapping of institutional rights, such as for van panchayats and BMCs in India and ANCA Conservation committees and CFUGs in Nepal, has led to limited vertical and horizontal integration between state and non-state actors. This could become even more severe in Nepal when the newly established administrative units, gaun palikas (villages) and nagar palikas (municipalities), empowered through the new Nepal Constitution of September 2015, demand their rights to manage natural resources at the local level. This will most likely bring a new dynamic into the existing governance structure with outcomes, which so far cannot be predicted. A similar situation could occur in India once BMCs on local level and the State Biodiversity Board receive more human and financial resources and become more strongly socially accepted. As yarshagumba is currently the local resource with the highest value found in the Himalayan Mountains (Negi et al. 2016), struggles on state and local level between State Forest Department and State Biodiversity Board to benefit from the resource are likely. However, the new situations in Nepal and India can also provide opportunities to reflect on general questions about equity, power and authority, resource distribution and livelihood dependencies in the context of NTFP collection and sale in remote mountain villages to encourage transformative change.

\subsection{Conclusion}

Our comparative case study reveals communities' and governments' capacities to adapt to resource value changes in the high alpine grasslands of the Kailash Landscape. We conclude that neither government nor communities alone can ensure effective governance in remote mountain areas when resource values rapidly increase. During learning processes the link between the amendment of actions (single-loop learning), in our case initiated by communities, and the revision of the formal policies and the frame (double-loop learning) is essential to ensure that innovative approaches reach the policy level (vertical integration) and can spread across administrative boundaries (horizontal interaction). A complex and complementary resource governance system consisting of governmental institutions and communal 
management arrangements is required to adapt adequately and to ensure that learning processes are innovative, context-specific, legally sanctioned and enforced.

Building on this insight we conclude that other common pool resources in the Himalayas face similar governance challenges. For example demand and prices for medicinal and aromatic plants have increased over the last decades (Pauls and Franz 2013). The majority of them, just like yarshagumba, are not cultivated, but harvested wild in remote areas by communities (Uprety et al. 2016). Referring to our findings, this will most likely trigger similar power struggles, adaptation and learning processes.

We recommend that the affected regions establish common platforms for actors from different levels and sectors, including the government, relevant research facilities and communities. Joint meetings could encourage exchange and understanding, create awareness and provide the opportunity to share local and scientific knowledge among relevant actors. This would also close the gap between the communal and governmental efforts for adaption and encourage transformation towards sustainable resource management.

\section{References}

Acheson, J.M. 2006. "Institutional Failure in Resource Management." Annual Review of Anthropology 35: 117-34. doi:10.1146/annurev.anthro.35.081705.123238.

Agrawal, A. 2003. "Sustainable Governance of Common Pool Resources: Context, Methods, and Politics." Annual Review of Anthropology 32: 243-62. doi:10.1146/annurev.anthro.32.061002.093112.

Agrawal, A. and Ostrom, E. 2001. "Collective Action, Property Rights and Decentralization in Resource Use in India and Nepal." Politics and Society 29, no. 4: 485-514. doi:10.1177/ 0032329201029004002.

Anderies, J. Janssen, M. and Ostrom E. 2004. „A framework to analyze the robustness of socialecological systems from an institutional perspective." Ecology and Society 9, no. 1: 18.

Api Nampa Conservation Area (ANCA). 2018.Biodiversity Profile of Api Nampa Conservation Area, Kailash Sacred Landscape Nepal. $2^{\text {nd }}$ draft prepared January 2018. Kathmandu. unpublished.

Baland J. M. and Platteau J.P. 1996. Halting Degradation of Natural Resources: Is There a Role for Rural Communities? Oxford, UK: Clarendon.

Baral, B., Shrestha, B. and Teixeira da Silva, J.A. 2015. "A review of Chinese Cordyceps with special reference to Nepal, focusing on conservation." Environmental and Experimental Biology 13: 6173.

Bauer, K.M. 2004. High Frontiers, Dolpo and the Changing Wold of Himalayan Pastoralists. New York: Columbia University Press.

Binder, C. R., Hinkel, J., Bots, P.W. and Pahl-Wostl. C. 2013. „Comparison of frameworks for analyzing social-ecological systems“. Ecology and Society 18, no. 4: 26.

Cannon, P.F., Hywel-Jones, N.L. Maczey, N., Norbu, L., Tshitila, Samdup, T. and Lhendup, P. 2009. "Steps towards sustainable harvest of Ophiocordyceps sinensis in Bhutan." Biodiversity Conservation 18: 2263-81. doi:10.1007/s10531-009-9587-5.

Caplins, L. B. 2016. Political ecology of cordyceps in the Garhwal Himalaya of Northern India. Graduate Student Theses, Dissertations, \& Professional Papers. 10913. https://scholarworks.umt.edu/etd/10913. 
Childs, G. and Choedup, N. 2014. "Indigenous Management Strategies and Socioeconomic Impacts of Yartsa Gunbu (Ophiocordyceps sinensis) Harvesting in Nubri and Tsum, Nepal." Himalaya. 34, no. 1.

Dietz, T., Ostrom, E. and Stern, P.C. 2003. "The struggle to govern the commons." Science 302: 190712. doi:10.1126/science.1091015.

Folke, C., Hahn, T., Olsson, P. and Norberg, J. 2005. "Adaptive governance of social-ecological systems." Annual Review Environmental Resources 30: 441-73. doi:10.1146/annurev.energy.30.050504.144511.

German, L.A. and Keeler, A. 2010. "Hybrid institutions: applications of common property theory beyond discrete property regimes." International Journal of the Commons 4, no. 1: 571-96. doi:10.18352/ijc.108.

Gerwin, M. and Bergmann, C. 2012. "Geopolitical Relations and Regional Restructuring: the Case of the Kumaon Himalaya, India." Erdkunde 66, no. 2: 91-107. doi:10.3112/erdkunde.2012.02.01.

Hardin, G. 1968. "The Tragedy of the Commons." Science 162: 1243-48.

Herrera, P. M., Davies, J. and Manzano, P. 2014. Governance of Rangelands: Collective Action for Sustainable Pastoralism. New York: Taylor \& Francis.

Hoon, V. 1996. Living on the Move: Bhotiyas of the Kumaon Himalaya. New Delhi: Sage Publications.

Huitema, D., Mostert, H., Egas, W., Moellenkamp, S., Pahl-Wostl, C. and Yalcin. R. 2009. „Adaptive water governance: assessing the institutional prescriptions of adaptive (co-) management from a governance perspective and defining a research agenda." Ecology and Society 14, no. 1: 26.

ICIMOD. 2015. Across the Mahakali. video. http://lib.icimod.org/record/32086. accessed on: 28.2.2018. Kathmandu: ICIMOD.

ICIMOD. 2017. Vegetation Type and Land Cover Map of Kailash Sacred Landscape. Map. Kathmandu: ICIMOD.

Karpouzoglou, T., Dewulf, A., Clark, J., 2016. "Advancing adaptive governance of social- ecological systems through theoretical multiplicity."Environmental Science and Policy 57: 1-9. Doi:10.1016/j.envsci.2015.11.011.

Leder, S. 2003. Zu einer Zeit, als Bäume und Gräser noch sprechen konnten.... Frankfurt am Main: Peter Lang Europäischer Verlag der Wissenschaften.

Mayring, P. 2015. Qualitative Inhaltsanalyse. Grundlagen und Techniken. Weinheim: Beltz.

McGinnis, M. D. 2011. "An Introduction to IAD and the Language of the Ostrom Workshop: A Simple Guide to a Complex Framework." Policy Studies Journal 39, no. 1. doi:10.1111/j.15410072.2010.00401.x.

Ministry of Forest and Soil Conservation (MoFSC). 2015. "Forest regulation 1995." Government Gazette 65, no. 26, part 3. Kathmandu: Government of Nepal. accessed on 20.02.2018. http://www.mfsc.gov.np/downloadfile/aanusuchif_1446967075.pdf.

Ministry of Forest and Soil Conservation (MoFSC). 2017. Yartsagumba management: Collection and transportation directive. Kathmandu: Government of Nepal.

Negi, C. S., Koranga, P.R. and Ghinga, H.S. 2006. "Yartsagumba (Cordycepssinensis): A call for its sustainable exploitation." International Journal of Sustainable Development \& World Ecology 13: 1-8. doi:10.1080/13504500609469669.

Negi, C.S., Joshi, P. and Bohra, S. 2015. "Rapid Vulnerability Assessment of Yartsa Gunbu (Ophiocordyceps sinensis [Berk.] G.H. Sung et al) in Pithoragarh District, Uttarakhand State, India." in: Mountain Research and Development 35, no. 4: 382-91. doi:10.1659/MRDJOURNAL-D-14-00005.1.

Negi, C.S., Pant, M., Joshi, P. and Bohra, S. 2016. "Conserving the caterpillar fungus [Ophiocordycepssinensis (Berk.) G.H. Sung et al.]: A case study of habitat ecology and sustainability in district Pithoragarh, Western Himalaya, India." International Journal of Biodiversity and Conservation. doi:10.5897/JJBC2014.0742. 
Olsson, P. Gunderson, H., Carpenter, S., Ryan, P., Lebel, L., Folke, C. and Holling, C.S. 2006. „Shooting the rapids: navigating transitions to adaptive governance of social-ecological systems." Ecology and Society 11, no. 1: 18.

Ostrom, E. 1990. Governing the Commons: The Evolution of Institutions for Collective Action. Cambridge: Cambridge University Press.

Ostrom, E. 2005. Understanding Institutional Diversity. Princeton and Oxford, Princeton University Press.

Ostrom, E. 2010. "Polycentric systems for coping with collective action and global environmental change." Global Environmental Change 20, no. 4: 550-557. Doi:10.1016/j.gloenvcha.2010.07.004.

Pahl-Wostl, C. 2009. "A conceptual framework for analysing adaptive capacity and multi-level learning processes in resource governance regimes." Global Environmental Change 19: 354-365. doi:10.1016/j.gloenvcha.2009.06.001.

Pahl-Wostl, C., Becker, G., Knieper, C., Sendzimir, J., 2013. "How multilevel societal learning processes facilitate transformative change: a comparative case study analysis on flood management." Ecology and Society 18, no.4. doi:10.5751/es-05779- 180458.

Pandey, A., Pradhan, N., Chaudhari, S. and Ghate, R. 2017. "Withering of traditional institutions? An institutional analysis of the decline of migratory pastoralism in the rangelands of the Kailash Sacred Landscape, western Himalayas." Environmental Sociology 3, no. 1: 87-100. doi:10.1080/23251042.2016.1272179.

Pant, B., Rai, R., Wallrapp, C., Ghate, R. and Shrestha, U.B. 2017. "Horizontal integration of multiple institutions: Solutions for Yarshagumba related Conflict in the Himalayan Region of Nepal?" International Journal of the Commons 11, no. 1: 464-86. doi:10.18352/ijc.717.

Pauls, T. and Franz, M. 2013. "Trading in the dark - The medicinal plan production network in Uttarakhand." Singapore Journal of Tropical Geography 34: 229-243. doi:10.1111/sjtg.12026.

Plummer, R., Armitage, D.R., de Loë, R.C., 2013. "Adaptive comanagement and its relationship to environmental governance." Ecology and Society 18, no. 1. Doi:10.5751/ES-05383-180121.

Pouliot, M., Pyakurel, D., and Smith-Hall, C., 2018. "High altitude organic gold: The production network for Ophiocordyceps sinensis from far-western Nepal." Journal for Ethnopharmacology 218: 5968. doi:10.1016/j.jep.2018.02.028.

Scott, R. 1999. Institutions and Organisations. Sage Publications.

Sharma-Wallace, L., Velarde, S. and Wreford, A. 2018. „Adaptive governance good practice: Show me the evidence!" Journal of Environmental Management 222: 174-188. Doi:10.1016/j.jenvman.2018.05.067.

Shrestha, U., Dhital, K. R., and Gautam, A.P. 2017. „Economic Dependence of Mountain Communities on Chinese Caterpillar Fungus Ophiocordyceps Sinensis (Yarsagumba): A Case from Western Nepal." Oryx. Cambridge University Press: 1-9. doi.org/10.1017/S0030605317000461.

Shrestha, U.B. and Bawa, K.S. 2013. "Trade, harvest and conservation of Caterpillar Fungus (Ophiocordyceps sinensis)." Biological Conservation 159: 514-520. doi:10.1016/j.biocon.2012.10.032.

Shrestha, U.B. and Bawa, K.S. 2014. "Economic contribution of Chinese caterpillar fungus to the livelihoods of mountain communities in Nepal." Biological Conservation 177: 194-202. doi:10.1016/j.biocon.2014.06.019.

Singh, S. 2016. The Local Governance: Politics, Decentralization and Environment. New Delhi: Oxford University Press.

Uprety, Y., Poudel, R.C, Gurung, J., Chettri, N. and Chaudhary R. P. 2016. „Traditional use and management of NTFPs in Kangchenjunga Landscape: implications for conservation and livelihoods." Journal of Ethnobiology and Ethnomedicine 12, no. 19. Doi:10.1186/s13002-0160089-8.

Uttarakhand Biodiversity Board. 2017. Study on "Science-Policy Interface" focussing on Access \& Benefit Sharing (ABS) and Trans-boundary issues, Kailash Sacred Landscape Conservation and Development Initiative. Dehradun: Uttarakhand Biodiversity Board. 
Weckerle, C., Yang, Y., Huber, F.K. and Li, Q. 2010. "People, money, and protected areas: the collection of the caterpillar mushroom Ophiocordyceps sinensis in the Baima Xueshan Nature Reserve, Southwest China." Biodiversity Conservation 19: 2685-98. doi:10.1007/s10531-010-9867-0.

Winkler, D. 2008. "Yartsa Gunbu (Cordyceps sinensis) and the Fungal Commodification of Tibet's Rural Economy." Economic Botany 62, no. 3: 291-305.

Winkler, D. 2009. "Caterpillar Fungus (Ophiocordyceps sinensis), Production and Sustainability on the Tibetan Plateau and in the Himalayas." Asian Medicine 5: 291-316. doi: $10.1163 / 157342109 \times 568829$.

Yeh, E. and Lama, K. T. 2013. "Following the caterpillar fungus: nature, commodity chains and the place of Tibet in China's uneven geographies." Social and Cultural Geography 14, no. 3: 318 - 340. doi:10.1080/14649365.2013.765025.

Young, O.R. 2009. „Institutional dynamics: Resilience, vulnerability and adaptation in environmental and resource regimes. "Global Environmental Change. doi:10.1016/j.gloenvcha.2009.10.001.

Acknowledgement: We would like to thank the informants for their hospitality and time, and the information they provided during the interviews. We are also thankful to Dr. Rajan Kotru (ICIMOD), Dr. Tashi Dorji (ICIMOD), Dr. R.S. Rawal (GBPNIHESD), Ms. Eileen Lemke, Mrs. Kristin Cain, the Central Himalayan Environment Association (CHEA) and the Api Nampa Conservation Area (ANCA). We acknowledge the support of Dr. Vishwas Chitale (ICIMOD) for his work on the study area map and Mr. Ashish Chaudary for his constant assistance in the field. We thank the Deutsches Bundesministerium für Wirtschaftliche Zusammenarbeit und Entwicklung (German Federal Ministry for Economic Cooperation and Development) / Deutsche Gesellschaft für Internationale Zusammenarbeit (GIZ) GmbH (German Development Cooperation) for financially supporting the data collection. 


\title{
6 Production networks and borderlands: cross-border yarsagumba trade in the Kailash Landscape
}

\author{
Corresponding publication: \\ Wallrapp, C., Faust, H. and Keck, M. (2019): Production networks and borderlands: cross-border
} yarsagumba trade in the Kailash Landscape. In: Journal of Rural Studies 66: 67-76. ${ }^{11}$

\begin{abstract}
To date, the role of borderlands in global production networks is an under-researched topic. In this study, we take the production network of the highly valuable non-timber forest product ophiocordyceps sinensis (yarsagumba) as a case to study the trans-border connectivities of state and non-state actors in the borderland of India, Nepal and China located within the rural Kailash Landscape. We present the results of an in-depth qualitative study on the informal trade networks through which non-state actors transport yarsagumba from India to Nepali markets, and on the related governmental marketing mechanisms for non-timber forest products in India and Nepal. By looking through the lens of borderland studies we focus our analysis on the power and embeddedness of state authorities and non-state actors on both sides of the border within these legal and illegal trade networks and relate the findings to the function of borders as both material and institutional demarcation lines. Our case study shows that state authorities and non-state actors are closely enmeshed with each other, using or bypassing state regulations for their own benefits. This reproduces a 'licit' but illegal cross-border trade system. Besides economic interdependencies, social relations between actors are crucial for building trust between business partners who deal with high product values and cash flows outside formal regulatory spaces or between different regulatory spaces across state borders. We conclude that the power and embeddedness of actors in the production networks enable a network dynamic that undermines the function of the border as a line of separation.
\end{abstract}

Keywords: Global production networks, borderland studies, informal trade, ophiocordyceps sinensis, Himalaya

${ }_{11}$ As lead author I conducted the primarily research for the publication and contributed the majority of the content, with some theoretical and editorial inputs by the other authors. 


\subsection{Introduction}

In the remote border region of the Kailash Landscape in India and Nepal, the local population is highly dependent on the collection and trade of ophiocordyceps sinensis, locally known as yarsagumba or keera ghaas ${ }^{12}$, as a source of income (Negi et al., 2016). Yarsagumba is currently the most valuable non-timber forest product (NTFP) in the region with prices ranging from 8,000 to 14,000 USD per kg on the local market (Pant et al., 2017; Pouliot et al., 2018). It is found in the high alpine grasslands and used in traditional Chinese and Tibetan medicine (Winkler, 2008). In ayurvedic and other types of traditional medicine in Nepal and India, in contrast, yarsagumba is hardly known or utilized, and therefore not in high demand (Negi et al., 2016). Consequently, the product is traded from the Himalayan Mountains in India and Nepal to China.

In the late 1990s the demand in China for yarsagumba increased tremendously, which led to an enormous rise in prices (Linke, 2017; Winkler, 2008; Yeh and Lama, 2013). This price trend triggered a 'gold rush' in the Himalaya, which led to an unprecedented upsurge in the number of collectors (Cannon et al., 2009; Shrestha and Bawa, 2014; Winkler, 2009). The sudden run of collectors on the yarsagumba collection sites led to uncontrolled collection and to conflicts about access (Pant et al., 2017; Wallrapp et al., forthcoming). At the same time, a wellorganized trade network developed, consisting of several levels of intermediaries linking the remote mountain areas of India and Nepal to the global market (Shrestha and Bawa, 2013). The network builds on existing kinship, cultural, social and economic relations across the region, which have been established over centuries (Bergmann, 2016; Shneiderman, 2013).

In terms of quantities, Pouliot et al. (2018: 65) calculated that around $384.1 \mathrm{~kg}^{13}$ of yarsagumba was collected in the collection sites of Darchula District, Nepal, in the 2014-15 season, with a local value of approx. 4.7 million USD. However, the official amount of traded yarsagumba in Darchula District registered through the official state authority, Api Nampa Conservation Area (ANCA), was $850 \mathrm{~kg}$ in 2015 (DNPWC et al., 2018). How does this apparent surplus come about? Negi et al. (2016) show that an estimated production of 350 to $600 \mathrm{~kg}$ of yarsagumba per year takes place in the Kumaon Region in India, just across the border. This surplus can therefore be explained by the local population in the Kumaon Region's preference for a trade network through Nepal to sell their yarsagumba harvest. Thus, yarsagumba collected both from within ANCA, Nepal and from the Kumaon Region, India is traded in Nepal. Why is this the case? And what role does the border play in this regard?

In this study, we take the global production network (GPN) concept and link it to concepts from the emerging field of borderlands studies (Van Schendel and Abraham, 2005; Gellner, 2013;

12 In Tibetan language yarsagumba is called yartsa gunbu, which means 'winter worm - summer grass' (Winkler 2008). Yarsagumba is an endoparasitic complex formed by the fungus ophiocordyceps sinensis and the host larva of different moth species (Negi et al. 2016).

${ }^{13}$ There is an uncertainty of several $\mathrm{kg}$ in the calculated and estimated figures (see Pouliot et al., 2018). 
Ghosh, 2011; Goodhand, 2005; Grillot, 2016; Harris, 2013; Nordstrom, 2000; Shneiderman, 2013; Titeca and Flynn, 2014). To be more precise, we take a non-state-centric perspective (Gellner, 2013; Scott, 2009) studying the cross-border trade from both sides of the state border (Baud and Van Schendel, 1997). We further analyse the cross-border interactions 'from below' by focusing on the perspectives of the local population and of relevant local state actors (cf. Doevenspeck, 2011; Korf and Raeymaekers, 2013; Jones, 2012).

While yarsagumba is traded from the Himalayan Mountains of India and Nepal via several towns and cities into China, in our case study, we focus only on the production network in the rural Kailash Landscape. The production network consists of three processes interrelated with each other. Firstly, the governmental marketing system for NTFPs in India is legal, but disadvantageous, for Indian collectors and traders. Secondly, their preferred informal trade route to sell their yarsagumba harvest runs from India through Nepal, and is discussed in depth here. Thirdly, the legalization process through the Nepali governmental mechanism is used for yarsagumba harvested both in India and Nepal. We analyse in detail the power and embeddedness of state authorities and non-state actors on both sides of the border within these processes and relate the findings to the function of a border as line of separation. We argue that actors in borderlands question, negotiate, subvert and re-enforce borders. At the same time, borders influence the configuration of production networks in borderlands. With this indepth case study we show the importance of linking the concept of GPN with findings from borderland studies to better understand micro-level power structures and the embeddedness of actors in production networks in borderlands.

\subsection{Conceptual framework}

Over the last two decades two main approaches to analysing the relationships between production, trade and consumption of products have developed: the global value chain (GVC) approach by Gereffi et al. (2005) and the GPN approach by Hendersen et al. (2002). The GVC approach primarily follows a linear understanding of production networks and puts the main emphasis on the analysis of power relations between companies in their respective institutional contexts (Coe et al., 2008; Pauls and Franz, 2013). In comparison, the GPN approach expands beyond the linearity of the GVC approach to understand international production and trade as a highly complex and dynamic process, incorporating all kinds of network configurations as well as formal and informal arrangements. In this study, we apply the GPN concept.

Hendersen et al. (2002) distinguish three analytical categories: value, embeddedness, and power. Aspects of the value of yarsagumba are dealt with in other studies on the region (Pouliot et al., 2018; Pyakurel et al., 2018; Shrestha and Bawa, 2013) and therefore will not play a role in our study. Embeddedness and power relations, in contrast, are the focus of our work. We understand actors' embeddedness in GPNs as being characterized by their personal relationships to other network actors, their opportunities to gain access to resources via theses relations as well as their related personal obligations and dependencies (Keck, 2016; Li, 2007). 
We take power to describe the ability of actors to influence other actors in their doings as well as to define, enforce and revoke the prevalent system of rules and regulations (Hendersen et al., 2002; Neilson et al., 2014).

As the GPN approach underlines, production and trade networks are bound by and take place within institutional settings that together build regulatory spaces determining the socioeconomic situation of the involved actors. Regulatory spaces may be either generated by states as governmental institutions or may be socially produced through customary rights, social norms, belief systems or culturally shared understandings. These regulatory spaces determine actors' daily routines, their enabled or constrained access to resources, and their in- or exclusion in the community and markets. While the 'state' as sovereign is crucial in shaping these regulatory spaces, other actors play an important role as well (cf. Pauls and Franz, 2013). Jones argues that "rather than understanding sovereignty as unitary and all-encompassing, it is better conceptualized as multifaceted, partial and conflicted" (2012: 3). Despite the expansion of the sovereign state over the past century, there are many loosely administered places within a state territory, where the authority of the state is weak or non-existent. Even at the borders of a state, where the performances of sovereign authority are often the most conspicuous, the territorial control of sovereigns is incomplete leading to informal networks and activities, for example in our case, the yarsagumba trade. State laws are constantly questioned, negotiated, subverted and re-enforced by state and non-state actors on the margins of the state, particularly in borderlands (Ghosh, 2011; Goodhand, 2005).

To date, the role of borders in GPNs has been an under-researched topic. Borders demarcate the state's sovereign territory. They can be seen as political divides that gradually emerged worldwide with the onset of modern statehood (Van Schendel and Abraham, 2005). Borders are key elements in the maintenance of territoriality and the boundary of state sovereignty, the principle through which people and resources are controlled and governed (Paasi, 1999). They are separation lines between 'us' and 'them' and 'here' and 'there' (Newman, 2006). Yet, while many people conceive borders as static and impervious, borderland studies have presented plenty of evidence that borders are rather highly fluid, permeable, and in part even connectional entities (Gellner, 2013; Paasi, 1999). Borders are constructed through the action of state authorities and non-state actors on both sides of the border (Newman, 2006). They "create political, social and cultural distinctions, but simultaneously imply the existence of (new) networks and systems of interaction across them" (Baud and Van Schendel, 1997: 216).

Against this background, we introduce the term 'borderlands' to describe these spaces at the margin of states (Scott, 2009). Borderlands are social, economic and geographical spaces on both sides of a border defined by the creation of opportunities and constraints during interactions across borders (Chan and Womack, 2016). In our case the borderland of the Kailash Landscape is formed by the triangle where India, Nepal and China meet. People living in borderlands are often acquainted with different institutional settings, and may be skilled users of more than one language and currency for daily interaction and exchange. They can be active 'border-crossers' who make use of such skills to either challenge or comply with given rules of 
a particular regulatory space and respect or ignore state sovereignty, whichever is more profitable for them in order to improve their livelihoods (Chan and Womack, 2016; Doevenspeck, 2011).

From a non-state perspective, people involved in cross-border networks often consider certain activities to be legitimate, though the state deems these same acts illegal. These activities are accepted in the eyes of the 'border-crossers' - a common phenomenon, for which Van Schendel and Abraham use the term 'licit' (2005: 4). Especially in borderlands, legal restrictions are often accompanied by socially sanctioned practices such as smuggling. While this may have the effect of driving these practices into illegality, it does not eliminate them nor does it necessarily force them into obscurity. Hence, informal networks develop, which often build on patterns of mobility, trade and exchange as well as on cultural and kinship networks that have been in existence for centuries (Van Schendel and Abraham, 2005). They are often based on specific codes of conduct, opaque power relations, and rules that are orally passed on. Trustworthiness, credibility and reputation are key in these informal networks (Keck, 2016; Nordstrom, 2000), especially when it comes to trade across borders (cf. Grillot, 2016; Tong, 2014).

In borderland studies, scholars highlight the multi-functional role of state actors in cross-border networks. Nordstrom emphasizes the interweaving of state and non-state actors across borders by introducing the term 'extra-state,' which she uses

to underscore the fact that while these networks are not comprised by states themselves, neither are they entirely distinct from, or opposite to states - they work both through and around formal state representatives and institutions. States and these networks exist simultaneously ... each presenting different forms of authority and politico-economic organisation (2000: 36).

By taking up this notion of the 'extra-state,' we include in our analysis the informal as well as legal processes for marketing NTFPs in India and Nepal to understand the different hats state authorities wear within the cross-border network of yarsagumba. Yet, clear distinctions between legal and illegal, between state and non-state, and local and international often are not possible to draw in borderlands (Korf and Raeymaekers, 2013). State and non-state actors have several roles and are interlocked and enmeshed with one another, which forms specific configurations of production networks in borderlands.

Taking findings from borderland studies into consideration, we use the concept of GPN as our main analytical tool to understand the role that the border - both as a material and institutional demarcation line - plays for the production network configuration and its actors in the borderland of the Kailash Landscape. 


\subsection{Study area and data collection}

\subsubsection{Study area}

The Kailash Landscape encompasses the border region of Darchula District in Nepal, the Kumaon Region, Uttarakhand State in India and Pulan County, Tibet Autonomous Region (TAR) in China. The mountainous area is geopolitically sensitive and disputed borders have led to high military presence in India and China and to restrictions on movement of people and goods over the last decades. The area has long been characterised by great economic, social and cultural interactions across the borders, which are declining more and more due to political and socio-economic changes (Bergmann, 2016; Harris, 2013; Shneiderman, 2013). In former times, the Rang community - known as Shauka in Nepal - had the exclusive rights for the trans-Himalayan trade through the Kailash Landscape via the mountain valleys from the Gangetic plains to the Tibetan Plateau (Bergmann, 2016). With the increase of Chinese dominance on the Tibetan plateau in the 1950s and the Indo-China war in 1962, their customary rights for transhumance and movement of goods and people were restricted, the Indo-Chinese high mountain passes closed, and trade reduced (Bergmann, 2016) (figure 5).

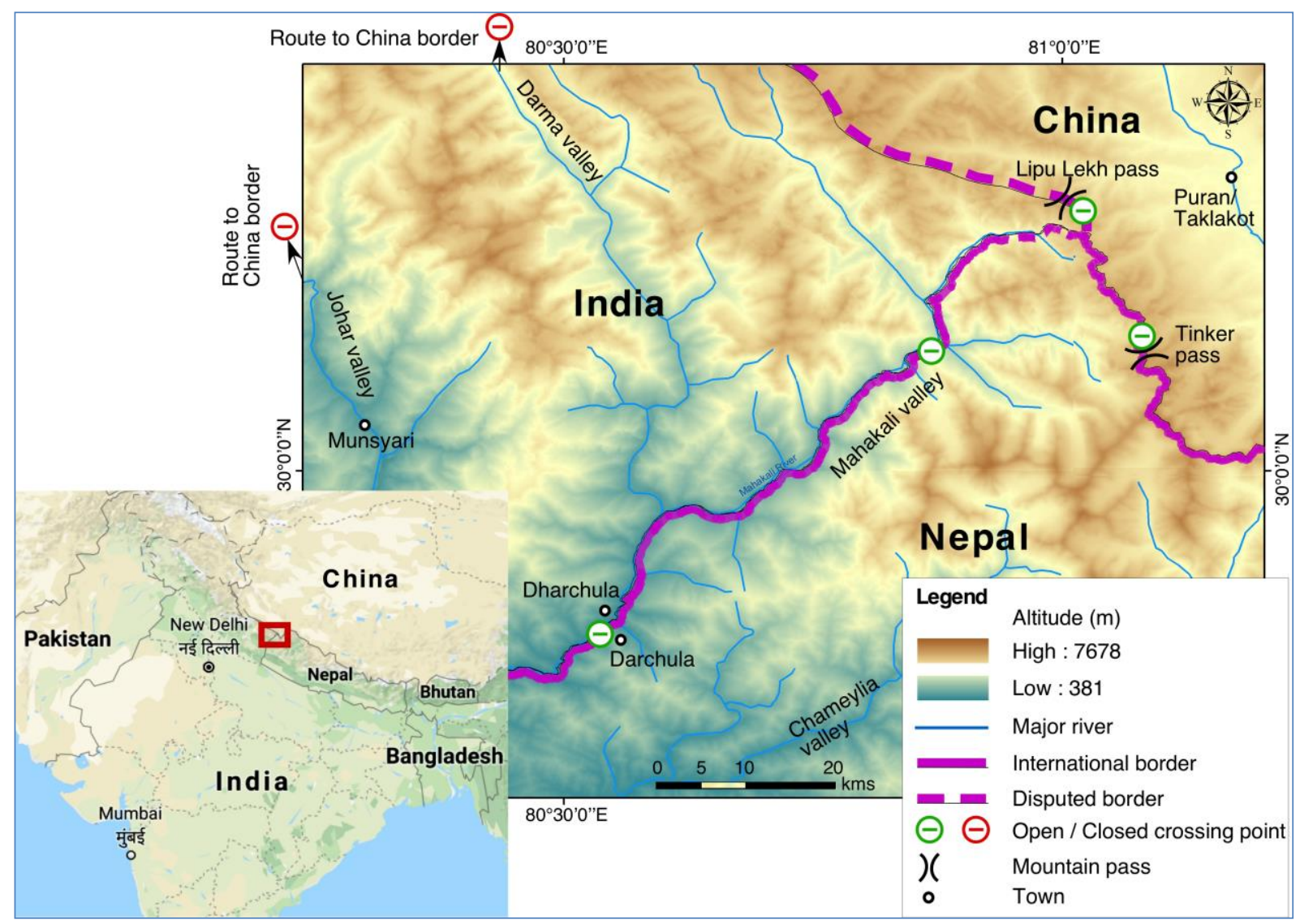

Figure 5: Map of the borderland of India, Nepal and China in the Kailash Landscape (detailed map: own source; overview map: map data 2018 google) 
Between China and Nepal, the Tinker pass remained open. The Lipu Lekh pass in India reopened in 1992 as an important pilgrimage route to holy Mount Kailash in the TAR, China and for limited commodity trade. Currently, trade to China is allowed up to $30 \mathrm{~km}$ into Chinese territory, to the next market town, Puran/Taklakot in Pulan County. In the last years, more and more regulations have been drawn up for this traditional border market limiting the flow of commodities and volume of trade (He et al., 2018).

In contrast, the border between India and Nepal is described as an 'open' border (Gellner, 2013). People and everyday goods can move freely in small quantities without formalities across this border. Several treaties have legalised these activities and have regulated customs duties and state border controls over the last decades (Kansakar, 2001). Apart from the political borders between the countries, physical boundaries such as the Mahakali River between Nepal and India or high mountain passes between India and Nepal and the TAR in China, have always presented obstacles to the movement of goods and people across the region. This has channelled the 'border-crossers,' but never halted these activities.

The closure of trading routes from India to the Tibetan plateau in the 1960s has changed the economic status of Indian communities in this region tremendously over the last decades. In both India and Nepal, out-migration of young people and whole families has led to barren agricultural fields and the extinction of entire villages in the high mountain ranges (Bergmann, 2016). Over the last decades, the collection of NTFPs, especially yarsagumba, has become one of the key income sources for most of the households in these valleys (Negi et al., 2016; Pouliot et al., 2018).

\subsubsection{Data collection}

The empirical fieldwork was conducted in four valleys of the Kailash Landscape: two valleys of ANCA in Nepal - Mahakali and Chameylia valleys - and two valleys in the Kumaon Region of India - Darma and Johar valleys. The empirical research mainly comprises qualitative data collected through key informant and in-depth interviews and focus group discussions between 2014 and 2017. The interviewees included government officials on the central, state and district levels, local leaders, community members, traders and collectors from various backgrounds with different gender and age. In total 13 focus group discussions with community members and traders were organised in 2016 and 2017, 30 representatives of local authorities and 62 community members were interviewed, and 20 interviews with representatives of higher state authorities and regional experts were conducted. Due to the sensitive content of the interviews in an internationally disputed border region, no further details on the backgrounds of the interviewees are provided.

As some aspects of the study were difficult to discuss openly with stakeholders, participatory field observation was conducted as an important complementary source of information. Additionally, for both India and Nepal, relevant policies, guidelines and directives were studied and reviewed with stakeholders. 
For the data analysis we chose the content analysis following Mayring (2015). The interviews were translated from Hindi or Nepali into English and transcribed afterwards. Field notes were taken in order to document other observations, focus group discussions and informal conversations. Following fieldwork, the texts were categorized and coded according to defined units of analysis. The results are interpreted and discussed in the following.

\subsection{Results}

The collection and trade of NTFP, particularly of yarsagumba, is the main livelihood source for the people in this region and dominates all socio-economic systems in the borderland. Although some parts of the cross-border network activities are illegal according to Indian and Nepali law, all participants within the system, including state and non-state actors, know the 'rules of the game' and are interwoven within the wider network.

We trace the product flow of yarsagumba from the Indian collectors to the international wholesalers in Kathmandu, Nepal. The Indian governmental marketing mechanism is not the preference for Indian collectors and traders to sell their harvest. Instead, the informal trade network and the subsequent legalization process in Nepal offer Indian actors better prices with fewer bureaucratic struggles. The borderland context enables a lucrative and well-functioning informal trade network formed by strong dependencies and economic and social relations between state and non-state actors across the border.

We present our findings in three sections according to the main processes in the production network: (1) the Indian governmental marketing mechanism relevant for all NTFPs in India, (2) the informal trade network between India and Nepal, and (3) the legalization process of yarsagumba on the Nepali side. The fourth section presents less utilized trading routes for yarsagumba in the region. Figure 6 summarizes our findings regarding the legal/illegal product flow, the relevant actors and the dominant and subordinate trading routes in the borderland of the Kailash Landscape. 


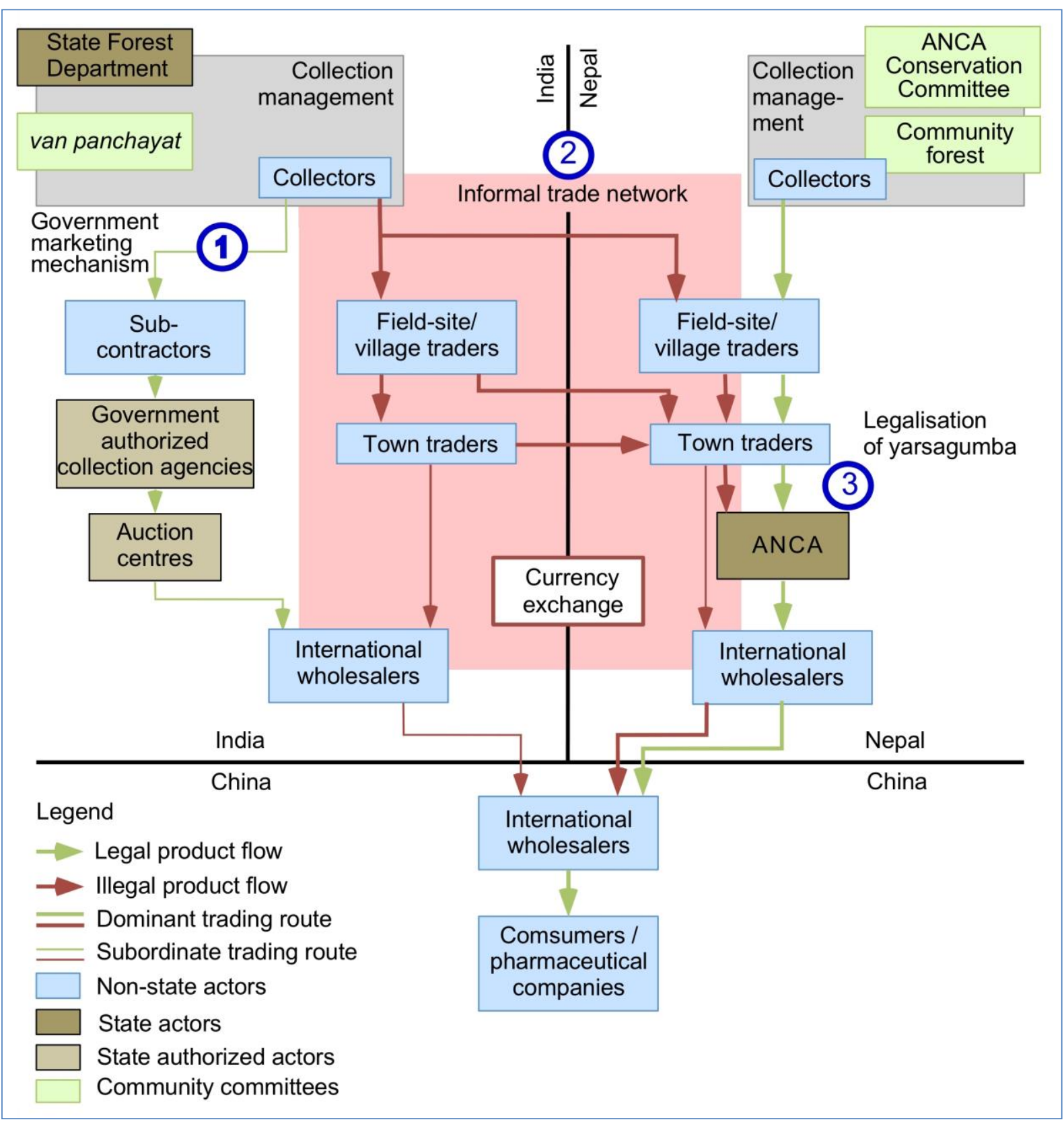

Figure 6: Trade network of illegal (red) and legal (green) product flows of yarsagumba in the Indian/Nepali borderland with relevant state and non-state actors. No. 1 (left) outlines the product flow of yarsagumba using the governmental marketing mechanism in India, no. 2 (middle) the informal trade network from India to Nepal and no. 3 (right) the legalization process in Nepal. The thick arrows show the dominant, the thin arrows the subordinate trading routes.

\subsubsection{The governmental marketing system for yarsagumba in India (no. 1 in figure 6)}

The governmental marketing mechanism for NTFPs and medicinal and aromatic plants in Uttarakhand State, India, is regulated by the State Forest Department (SFD) of Uttarakhand (Pauls and Franz, 2013). In order to sell any cultivated or collected NTFP or medicinal and aromatic plants, the SFD authorizes agencies, like the Kumaon Mandal Vikas Nigam and the Bhesaj Sangh, to function as intermediaries between local harvesters, government authorities 
and traders. These agencies ensure the documentation with the van panchayats (local forest management committees) and control the product quality. After completing the required process, the products are sold at SFD-organised auctions to registered companies or wholesalers. The prices are fixed in advance by the SFD based on the quality of the products and market prices. This system is applied to all cultivated and collected NTFPs and medicinal and aromatic plants in the state authorized for sale. ${ }^{14}$ Yet, Indian collectors of yarsagumba do not usually trade their collected products via these channels (Negi et al., 2016). Only up to 8 $\mathrm{kg}$ of yarsagumba were auctioned in the years between 2008 and 2012 (CHEA, 2015).

Although governmental regulations are in place for the sale of NTFPs, there are gaps in the regulatory system for the collection and trade of yarsagumba in India (Caplins, 2016; Negi et al., 2016; Wallrapp et al., forthcoming). In India, commercial collection of yarsagumba is legally permissible only in van panchayats, however, collectors harvest yarsagumba wherever possible - within state forests or protected areas - regardless of property rights and legal status (Negi et al., 2016). But even for yarsagumba collected within van panchayats, the sale and marketing mechanisms are not clearly drawn up. A forester from the region stated:

To catch them [yarsagumba collectors and traders] under which act? We can't do anything. I requested my senior to give a clear answer but that was not possible (Interview April 2017 - English translation, original language Hindi).

On the one hand these unclear regulations leave room for interpretation for SFD representatives as well as for the collectors and traders. On the other hand, this gives state authorities power over local collectors and traders. This power to enforce regulations is demonstrated by sporadic arrests when yarsagumba is sold openly (Interview with a trader in India, May 2017). Consequently, to avoid arrests and for the personal benefit of state and nonstate actors, payment of bribes and requests for personal favours are common practices.

Due to pressure by influential local leaders, the SFD has made several attempts to improve the marketing system for yarsagumba in the last years by authorizing van panchayat leaders to hand out certificates of origin for collected yarsagumba and thereby to allow the sale of yarsagumba from specific collection sites via the auction system. Nevertheless, this system has provoked critique:

... the government always offers lower prices, so why should somebody sell for that amount? Nobody was interested in selling for that amount. And the other system is well established (Interview with community member in Munsyari, India, January 2017 - English translation, original language Hind $া$ ).

As this quote indicates, the local population considers the bureaucracy of the marketing system, the low prices and the time-consuming procedures to be too complicated and inappropriate. They criticize their own inability and lack of power to influence the governmental system and

${ }^{14}$ For more details on the governmental marketing system in Uttarakhand State, India, see Pauls and Franz (2013) and Caplins (2016). 
the unwillingness of state authorities to address their concerns. The dominant role of the SFD and the governmental marketing system, which is disadvantageous for the local population, force them to look for alternative ways to sell their products. The availability of the Nepali NTFP trading system across the border displays such an alternative for the sale of yarsagumba collected in India.

\subsubsection{The informal trade network across the border from India to Nepal (no. 2 in figure 6)}

\subsubsection{The product flow of yarsagumba from India to Nepal}

Indian yarsagumba collectors usually sell their harvest to traders when they return to their villages. Each village in the upper Kumaon Region in India has a specific site in the high mountainous area where they collect yarsagumba during the collection season. Governance systems consisting of government institutions and communal norms regulate the access to and management of the yarsagumba collection sites. ${ }^{15}$ The Indian collectors mainly meet the yarsagumba traders when they return to their villages from the collection site, and less often in the site itself or in other trading hubs. During and after the collection season, village traders either from India or Nepal visit the villages frequently to negotiate prices with the collectors and to check the available quantities. After the purchase of products, they cross the border to Nepal (see figure 6, no. 2, dominant trading route).

Yarsagumba traders from India and Nepal prefer unofficial border crossing points instead of the official one between the towns of Dharchula, India, and Darchula, Nepal (figure 5). A bridge across the Mahakali River, which forms the border between India and Nepal, connects the two towns. Police and customs clearance points on both sides control the movement of goods and people. A bit further up the river from Dharchula along the border, several 'rope bridges' are installed to enable the local people to cross the river (see figure 7 and 8). These are unofficial border crossing points.

\footnotetext{
${ }^{15}$ For more details about the governance systems for collection of yarsagumba in the Kailash Landscape see Wallrapp et al. (forthcoming) and Pant et al. (2017).
} 


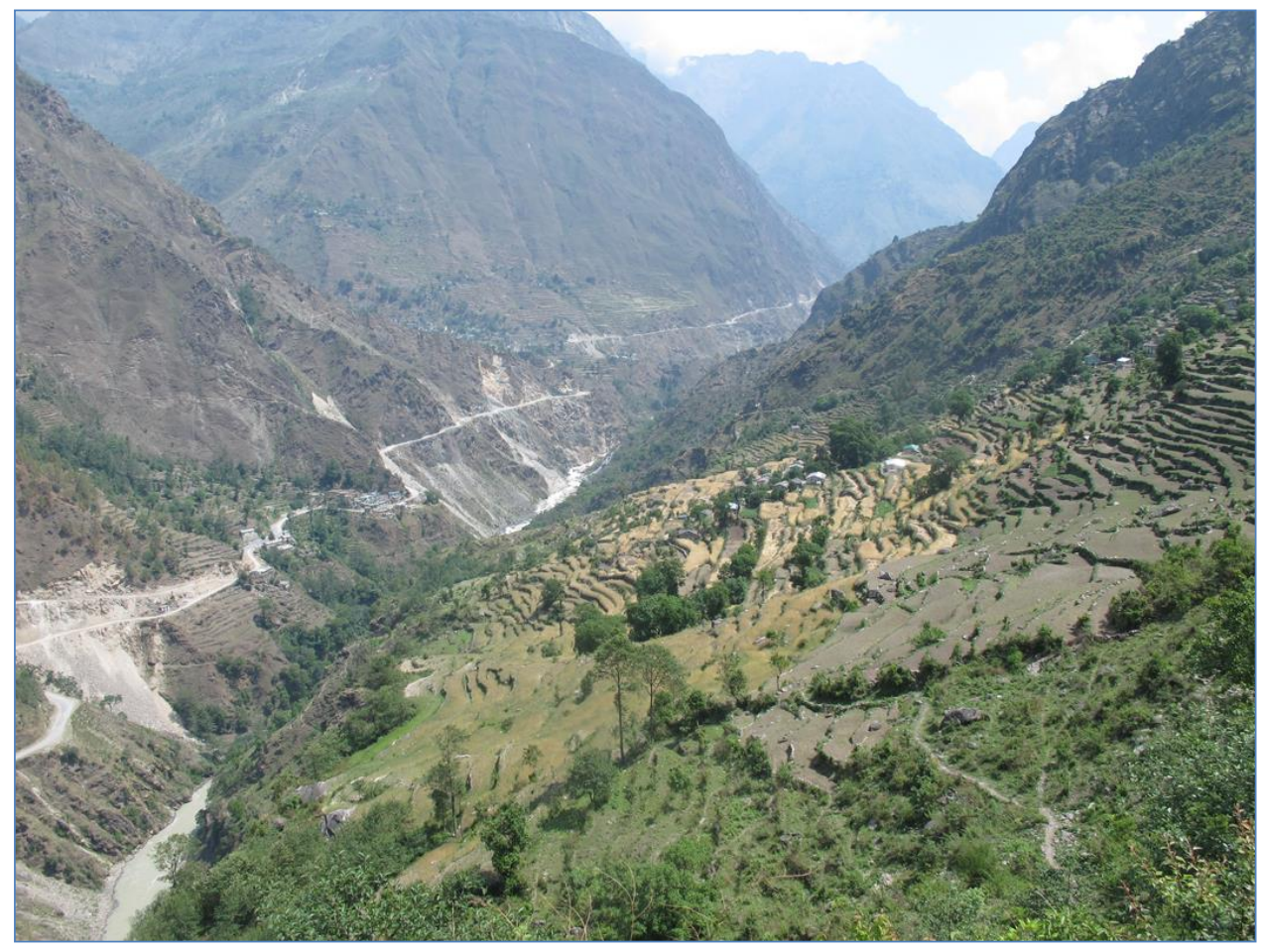

Figure 7: The Kailash Landscape with the Mahakali river as the border between India and Nepal (own source May 2017)

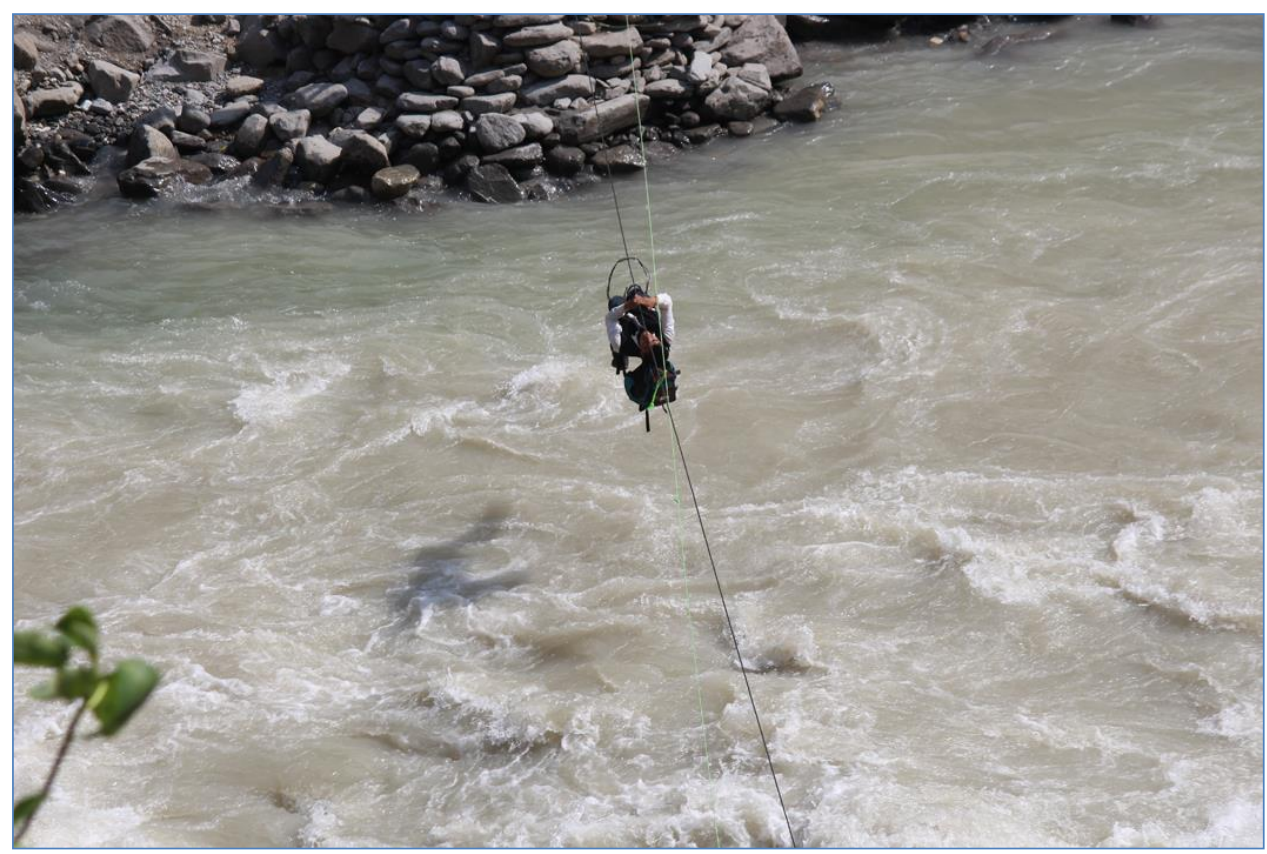

Figure 8: A 'rope bridge' over the Mahakali River (own source May 2017)

According to the treaties signed between the two countries, the free movement of people and commodities in small quantities is legal. Only commodities moving across the border in bigger bulk, including medicinal aromatic plants and NTFPs, require legal documents and customs 
declarations (Kansakar, 2001). Community members from both sides use 'rope bridges' frequently for daily activities, such as getting to markets, having easier access to road infrastructure and transportation, visiting family members or cutting fodder for animals. As 'rope bridges' are used for everyday activities, police and border control units from both states do not regularly check the movement of people and commodities across them. People in the region are active 'border-crossers' aware of the conditions, regulations and ways around these. As a trader from the region states:

If herbs are transported, people do not have papers. But, they do not transport them in large bulk. They carry them in small packages and try not to get caught [by police or border controls] (Interview with trader from Nepal, April 2017 - English translation, original language Hindi).

On the Nepali side, some teashops along the border function as trading hubs during the yarsagumba collection season. There, village traders from India and Nepal meet Nepali 'town traders' and exchange their products and cash. Some town traders are registered in the governmental ANCA office for the collection of yarsagumba. There, they are issued legal documents for transportation of yarsagumba within Nepal. Afterwards, town traders transport the sealed and cleared yarsagumba packages to Kathmandu. In Kathmandu the packages are resold to international wholesalers for export to China. On the Chinese side, the main trading hubs for yarsagumba from Nepal are Shigatse and Lhasa, or yarsagumba is flown directly from Kathmandu to Guangzhou and other major Chinese cities (He et al., 2018; Linke, 2017; Yeh and Lama, 2013).

One additional challenge for the cross-border network is the currency exchange from Nepalese Rupees (NPR) to Indian Rupees (INR), as most of the money comes from international wholesalers from Kathmandu in cash in NPR. Withdrawing large amounts of cash is difficult in India, especially after the demonetisation of all INR 500 and INR 1000 banknotes in November 2016. The Government of India declared the banknotes invalid, aiming to curtail the shadow economy and counterfeit cash being used to fund illegal activities. In 2017, however, the informal cross-border exchange and cash payments related to yarsagumba trade continued as before. The currency exchange between NPR and INR is organised through different traders and a separate system, which will not be further addressed in this article.

\subsubsection{Embeddedness and power of the actors in the informal trade network}

Collectors, village traders, town traders, international wholesalers and state authorities from both countries are all relevant actors in the informal trade network from India to Nepal. In our analysis, we have identified different aspects regarding the embeddedness and power of actors in the network: the network structure, the time-delayed cash transfer in relation to the product flow, the social ties and business relations between actors and the local knowledge of actors. These aspects are interrelated with each other.

The network structure of the yarsagumba trade in the borderland becomes increasingly condensed along the product flow, as the number of people involved in trade becomes less while the volume of yarsagumba grows. While several thousand collectors collect hundreds of 
pieces of yarsagumba in different collection sites in India and Nepal, only a few village traders per village or valley buy the products, pool them together and transport them in packages to town. Then, the product flow is channelled through the hands of only a few town traders in Darchula, Nepal. Along the product flow, the product can easily change ownership three to five times on the way from the collection site until it is transported to Kathmandu.

In every village and valley one or a handful of traders control and dominate the trade of yarsagumba. Traders are usually focused on a certain valley or village depending on kinship and existing personal relationships with community members and collectors. In certain areas, they demand commission for allowing other traders to get involved in the yarsagumba business. This is often combined with the fact that these traders have several functions in the communities: they often play the role of moneylenders, shop owners, local politicians and community representatives. Poorer households in India and Nepal often sell their future yarsagumba stock by taking advances or loaning money from businessmen in the villages between collection seasons. In these situations, the two parties agree orally on a certain price for the future stock. The relationship between trader and collector and the economic situation of each collector determine the bargaining power between the collector and village trader. However, poorer collectors in particular can be vulnerable to these dependencies, which may lead to distress deals allowing traders to bargain lower prices. It can lock the poor into a patronclient relationship with local traders (cf. Goodhand, 2005). But for Indian collectors, the prices are still higher than the ones offered in the governmental marketing system in India. Traders, in contrast, use their dominant position in the communities to bargain prices, concentrate the market and block competing traders.

The power structures and economic embeddedness of actors in the network depend on the timing of the product flow in relation to the cash flow. The town traders of India and Nepal are mostly located in the trading hubs or towns, but have several village traders working for them who buy yarsagumba in the villages and collection sites. Before the season starts, the town traders usually receive advances from other businessmen or international wholesalers from Kathmandu. After receiving it, the town traders distribute the cash further to village traders, who either use it to pay advances to collectors or directly to buy quantities of yarsagumba during the collection season. In this way, the town traders ensure that certain quantities are reserved for them and that village traders are bound to them. But it also means that they are bound to certain buyers, which limits their bargaining power in return. Although advances for yarsagumba are distributed within the system between the different actors, the collectors often have to wait for weeks or even months for the actual payment for their products. Only after the actual payment is made by the international wholesaler, either in Kathmandu or even in China, is the pending amount of money settled within the trade network. The cash flow does not take place at the same time as the product flow. It creates mutual dependencies between the different levels of traders and between the village traders and collectors and influences the power of actors to negotiate prices. They are entangled in the network, which determines their economic embeddedness. These dependencies are not only established during the 
yarsagumba collection season (end of April until end of June) in one national regulatory space, but persist over the whole year across the Indian, Nepali, and even Chinese borders.

Although the international wholesalers determine the cash flow, town traders have a crucial role in the network structure. International wholesalers have the function of investors in the system without having sound local knowledge or relationships with relevant local state and nonstate actors. They depend on the town traders to buy the quantities they want. Town traders have good knowledge of the region and good connections to village traders. In addition, they have well-established relations to local politicians, local government officials, police, other businessmen, traders' associations and traders from both sides of the border. As only Nepali traders are allowed to be issued the legalization documents, they play a dominant role in the network.

In India the unclear governmental regulations about the collection and trade of yarsagumba make Indian actors vulnerable. They fear sporadic arrests and confrontations with state representatives from the SFD or police if they sell yarsagumba openly. State authorities are present in towns and at road-junctions, but hardly come to the remote villages. Therefore, the collectors feel safe enough in their villages to sell their harvest directly to village traders there, instead of bringing their products down to the trading hubs. Trust between the different levels of traders and between the traders and collectors is crucial for the functioning of this informal cross-border network, where collectors and traders cannot rely on governmental law enforcement and are vulnerable to arbitrary behaviour by state and non-state actors.

Traders use social relations and social codes of conduct to manage risks for their business activities in this informal setting (cf. Linke, 2017). The Rang/Shauka community (52 villages) is located in the Kailash Landscape on both sides of the border in India and Nepal and are organised in the Rung Kalyan Sanstha (Rang Welfare Society). Yearly meetings of the Rang Welfare Society provide an open platform to share and discuss issues, develop a common understanding and resolve conflicts within the community. Coming from the same village, being from the same community or being related with each other supports the economic relations between actors in the trade network. These social relations provide the actors possibilities for building pressure within the community and for sanctioning violations against social codes of conduct through community measures.

Besides social relations between actors, the credibility and reputation of a person is important in order to be perceived as trustworthy in this kind of business. A village trader stated:

The relation has nothing to do with being Rang or not. It is about trust and business. It is about connection, friendship and knowing a person to build up trust and to make these deals with big money (Interview with village trader in Dharchula, India May 2017 - English translation, original language Hindi).

As the statement shows, business partners in the yarsagumba trade do not necessarily have to come from the same community, but knowing a person is crucial. Although, traders take a 
number of measures to manage the risks, this lucrative business is regularly affected by fraud and betrayal:

I agreed with some Nepali trader to sell keera ghaas [yarsagumba]. We met in a hotel. I exchanged the stock, but did not receive the money immediately, and the guy disappeared. He left his clothes on the balcony, so everyone thought that he was still in the room, but he had disappeared with the stock. I lost a lot of money that day (Interview with trader in Dharchula, India, April 2017 - English translation, original language Hindi).

The story of this trader indicates that, although traders build up their business relationships on the basis of social networks and the reputation and credibility of their partners, there still remains a great risk of getting cheated. According to traders, it takes several years of trustbuilding before a town trader is seen as trustworthy enough to be given advances by international wholesalers. The same is true for advances to village traders and collectors or exchanges of products and cash.

State actors on both sides of the border are aware of the informal cross-border trade. They restrict it and at the same time, they are part of it. According to traders, the state authorities in Nepal and India are reluctant to intervene in the yarsagumba trade, likely due to the personal benefits they receive from it. Arrests and confiscations of yarsagumba are rare and interlocutors suggested that they might be more related to personal power struggles between traders and government representatives than strategic state interventions to restrict the cross-border network. Joint patrolling and information exchange between state authorities in India and Nepal are regularly conducted to enforce the border and to limit illegal cross-border activities, but this has not yet hampered the cross-border yarsagumba trade network.

\subsubsection{Legalization of yarsagumba in Nepal (no. 3 in figure 6)}

The collection and sale of yarsagumba is legal within Nepal and does not require documents until the products are transported across district boundaries. Only then does the trader need several permits and royalties need to be paid to state authorities, in our case to the ANCA office. Firstly, to be able to engage in trade, the trader must have a company registered in the district that is specialized in trading NTFPs. Secondly, the trader needs to apply at the ANCA office for permission to collect yarsagumba in the conservation area. Thirdly, after the collection season the trader pays a royalty for the collected yarsagumba at the ANCA office (in 2017 this was 25,000 NPR or 250 USD per $\mathrm{kg}$ ). There, the trader also requests a transportation permit. The yarsagumba is then packed, sealed and legalised as a Nepali product.

The ANCA office regulates the trade volume of yarsagumba by limiting the harvested quantity per year. In addition, ANCA restricts the number of permitted traders in the conservation area (in 2017, there were 50 traders). The limitation of traders enforces the concentration of the yarsagumba market and forces other non-registered traders from India and Nepal to cooperate with the registered ones to trade their products. In this way ANCA and the dominant town 
traders can jointly influence the selection process of registered traders and channel the product flow from India and Nepal.

Since the approval of the national yarsagumba management policy by the Ministry of Forests and Soil Conservation in Kathmandu in 2017, ANCA additionally requests certificates of origin filled out by the collectors from the registered traders (MoFSC, 2017). An ANCA representative stated:

In the national directive is the point of 'certificate of origin'. That will have an effect on the Indian traders, because you need to have the certificate cards from collectors from Nepal to be able to get the transportation approval by the government (Interview ANCA representative, Darchula, Nepal, May 2017 - original language English).

An Indian trader responded to the same question about the certificates of origin in Nepal:

About the new rules in Nepal? Yes, I know about that certificate. I need cards to get the documents, but no problem. I will get around that (Interview Indian trader, Dharchula, India, May 2017 - English translation, original language Hindi).

The statement of the Indian trader shows that the Nepali governmental regulations increase the obstacles for informal network actors, but do not hinder them from continuing to use the same Nepali route. Actors in the network are adaptive (cf. Keck, 2016).

From the perspective of the Nepali state representatives the informal cross-border trade system has the advantage that the state earns revenues from the trade of yarsagumba without exploiting its own resources. Additionally, personal benefits for individual state representatives are common. Adhikari (2015) describes common corruption practices in the forestry sector in Nepal, like the payment of royalties for a certain weight of a package, while the actual weight is higher. These practices are also found in the yarsagumba trade system. The embeddedness of the state actors in the established formal and informal parts of the network enables and ensures a smooth operation of informal trade across the India-Nepal border despite the formulation of additional regulations.

In general, traders from Nepal and India accept the formal and informal process for legalization of their products through ANCA. They prefer a legalised product to reduce their risks of being arrested by state authorities in Nepal. Another reason is that the prices in Kathmandu are higher for legal products and the sealed yarsagumba packages are in higher demand by international wholesalers than illegally transported yarsagumba (interview with trader from Nepal, August 2017).

\subsubsection{Alternative trading routes for yarsagumba from India to China (no. 2 in figure 6)}

The limited availability of alternative trading routes makes the legalization of yarsagumba in Nepal via ANCA even more attractive for Indian traders (see study area map in figure 5). Possible alternative yarsagumba trading routes such as via the closed remote Himalayan 
passes (Johar and Darma valleys) or via the re-opened Lipu Lekh pass from India to the TAR, China, are too risky because of the high presence of army and border police (interviews in Dharchula, India, January 2017) (figure 6, no. 2, subordinate trading route). The trading route from the Indian collection sites in the mountains through Indian territory to Delhi and further to China is not well established either. How much is actually transported from India directly to the TAR, China, cannot be assessed.

Another option, the route via the Tinker pass in the northern part of the Kailash Landscape from Nepal to the border market town Puran/Taklakot in the TAR, China, is only used for smaller amounts of yarsagumba. According to the ANCA warden approximately 20 to $30 \mathrm{~kg}$ of yarsagumba were transported via this route in 2016 (Interview in Darchula, Nepal, May 2017). Traders describe the route as being difficult due to poor infrastructure and increased border controls on the Chinese side. The perceived 'easiest way' for Indian and Nepali traders to market the collected yarsagumba from the Indian Kumaon region is currently via ANCA in Nepal.

\subsection{Discussion}

From a state-centric perspective, the Kailash Landscape is considered to be a peripheral borderland at the margins of three states: India, Nepal and China. By tracing the informal trade network of yarsagumba in this borderland we see that the region is not disconnected from, but highly integrated into and stimulated by processes associated with globalisation. The remote mountainous villages and people of India and Nepal are highly connected to international markets and depend on global demands, especially for NTFPs. The yarsagumba collection alone has an approximate yearly turnover of 10.5 million USD for the $850 \mathrm{~kg}$ yarsagumba collected in this region, according to the official figure of ANCA (DNPWC et al., 2018). With this high turnover and very limited other income-generating alternatives in this borderland, it is not surprising that state and non-state actors have an interest to get and stay involved in this very lucrative and functional production network.

The existence of different regulatory spaces in India and Nepal, such as the different policies for marketing of NTFPs, stimulates the informal cross-border trade network in the Kailash Landscape. The unattractive governmental marketing system in India encourages Indian collectors and traders to look for alternatives. The perceived 'easy way' of legalization of yarsagumba products in Nepal provides them an opportunity to sell their products for a better price and with fewer bureaucratic obstacles. On the one hand, some local people, for example traders, are skilled in navigating these different policies and can therefore take advantage of this situation. Non-state actors constantly adapt to multiple forms of national and local regulations in order not to be excluded from the production network (cf. Harris, 2013). Examples from our case are the demonetarisation process in India in 2016 and the introduction of certificates of origin for collected yarsagumba in Nepal. On the other hand, non-state actors, like in our case the Indian collectors, feel powerless to influence their own state authorities to 
revise regulations and reform institutions to better suit their demands. As such, they command adaptive capacities, but only limited transformative ones (cf. Keck, 2016).

Along the product flow, yarsagumba transforms from an illegally collected and traded product in India into a packaged and sealed legal product fit for transport from Nepal to China. The local population of the borderland and to some degree also the local authorities see the cross-border trade between India and Nepal as licit. They are aware that they are violating the governmental regulations, but these activities have a routine character and seem normal enough to participate in. The trade is socially accepted by collectors and traders and therefore legitimised by them (Scott, 1999).

State authorities in India and Nepal play several roles in the network dynamic and configuration. On the one hand, state authorities enforce regulations according to sovereign power through border controls and patrols, military presence and implementation of policies regulating the NTFP collection and cross-border trade. On the other hand, state authorities are also highly embedded in the cross-border network. They may interfere sporadically. Within a few hours or days, after the payment of a suitable official or unofficial fine, the violator is free again and life goes on as before. Following the arguments of Jones (2012), borderlands are territories with incomplete sovereign power. Often state actors use their power to allow themselves to operate outside the laws of the state, undermining the state's goals of regulations and order. In our case study, state authorities have not prevented or hindered the informal yarsagumba trade across the border, but rather have used it for their own personal gain.

Our findings show that in this informal setting with exchanges of high cash amounts where traders and collectors cannot rely on governmental institutions, social ties between actors are not only favourable, but even essential for non-state actors to build up their economic relations and dependencies between actors. As our two examples of Indian town traders demonstrate, actors are economically and socially embedded in the trade network. The behaviour of the actors in this formal and informal institutional, economic and social setting determines the trader's reputation and credibility as a business partner. Actors have to balance between profit, credibility and reputation to manage their own risks of fraud and betrayal by business partners, as well as of arrests by government representatives. They must also do this successfully to be considered trustworthy for their partners for future deals.

Due to their deep social and economic embeddedness in the cross-border trade network on the local level, town traders make transactions and resource flows possible. These traders mediate simultaneously between the centre and periphery, state and non-state actors and between actors across the borders. In contrast, international traders have the economic resources, but usually lack the social embeddedness and local knowledge that would enable them to be the dominant actors in the network. As such, the network relations are not spontaneous interactions, but all actors have clearly defined roles and functions and depend on each other, creating a well-established, organised and lucrative trade network operating across the border (Cf. Nordstrom, 2000). 
As our case study shows, borderlands are determined by global production networks that develop through the interconnectedness across the border. Certainly, the 'open' border between India and Nepal facilitates the cross-border network. The alternative trading routes crossing the highly militarized border between India and China are perceived by traders as more difficult for smuggling and therefore are currently not preferred. However, even then, cross-border networks develop if the demand for the smuggled products and expected profits are high (cf. Doevenspeck, 2011; Van Schendel and Abraham, 2005), as other studies from the neighbouring Garhwal region in India show (Caplins, 2016; Mathur, 2013). Governments have several options for reacting to these informal production networks. Either they 'close' the border further, which usually has limited success (cf. Doevenspeck, 2011; Gellner, 2013; Jones, 2012), they restrict the illegal activities (cf. Goodhand, 2005), or they revise policies to provide opportunities to transform the informal network activities into formal ones. ${ }^{16}$ However, due to these well-established lucrative networks and the adaptive capacities of actors, policy revisions might not achieve what policy-makers intend them to.

\subsection{Conclusion}

By linking the concept of global production networks with key findings from borderland studies, our case study on the yarsagumba trade in the rural Kailash Landscape provides in-depth findings about the power and embeddedness of state authorities and non-state actors in the yarsagumba cross-border network. The configuration of the production network enables a network dynamic that undermines the function of the border as line of separation. The dichotomies of legal/illegal and formal/informal become blurred and regulatory spaces are reinterpreted. Actors are constrained and limited by the border, but at the same time the border provides them with new opportunities to improve their livelihoods. State authorities and nonstate actors are closely socially and economically enmeshed with each other across the border, forming 'extra-state' configurations by using or bypassing state regulations for their own benefits. We conclude that these dynamics enable configurations of global production networks in borderlands, which constantly question, negotiate and subvert, but also re-enforce the border and with it the sovereignty of the state. Thus, the border has a clear effect on production networks and their immanent power relations, while at the same time production networks in borderlands strengthen the element of connectivity that characterizes borderlands.

\footnotetext{
16 In October 2018 the Uttarakhand State Forest Department in India approved a new regulation for yarsagumba allowing its marketing through registered traders independent from the state-organised auction system. This will reduce the power and embeddedness of Nepali traders in the GPN and strengthen the Indian collectors and traders to market their products via Indian middlemen to China directly. Yet, it is difficult to predict if traders will prefer the well-established route via Nepal or develop further alternative routes directly to China, and therefore the impacts on the current cross-border trade network remain to be seen.
} 
Although the concept of GPN is very comprehensive including formal and informal arrangements, different types of actors and their embeddedness and power relations within the network, our case study shows that linking the concept of GPN with considerations of borderland studies differentiates the analysis of production networks further in terms of in-depth understanding of spatial, institutional and socio-economic dynamics in borderlands. As an outlook for further research on GPN we suggest considering the specific dynamics of borderlands as a peripheral area with demarcated territories and different regulatory spaces, but with high connectivity across borders and linkages to and dependencies on global markets. Thus, a borderland should be considered as one production and trade region including both sides of the border with different regulatory spaces.

\section{References}

Adhikari, K., 2015. Perception or reality? A case study of corrupt practices in the forestry sector in Nepal. European Bulletin of Himalayan Research 46, pp. 9-34.

Baud, M., and Van Schendel, W., 1997. Toward a Comparative History of Borderlands. Journal of World History 8, 2 (fall), pp. 211-242. doi: 10.1353/jwh.2005.0061

Bergmann, C. 2016. The Himalayan Border Region - Trade, Identity and Mobility in Kumaon, India. Springer International Publishing Switzerland.

Cannon, P.F., Hywel-Jones, N.L., Maczey, N., Norbu, L., Tshitila, Samdup, T., and Lhendup, P., 2009. Steps towards sustainable harvest of Ophiocordyceps sinensis in Bhutan. Biodiversity Conservation 18, pp. 2263-81. doi:10.1007/s10531-009-9587-5

Caplins, L. B., 2016. Political ecology of cordyceps in the Garhwal Himalaya of Northern India. Graduate Student Theses, Dissertations, \& Professional Papers. 10913. https://scholarworks.umt.edu/etd/10913

Central Himalayan Environment Association (CHEA). 2015. Workshop report on keera jadi (cordypus sinensis) at Munsyari, Pithoragarh. Nainital, Uttarakhand, unpublished.

Chan, Y. W., and Womack, B., 2016. Not merely a border: borderland governance, development and transborder relations in Asia. Asian Anthropology 15, 2, pp. 95-103. doi: 10.1080/1683478X.2016.1214352

Coe, N. M., Dicken, P., and Hess, M., 2008. Global production networks: realizing the potential. Journal of Economic Geography 8, 3, pp. 271-295. doi: 10.1093/jeg/lbn002

DNPWC, ICIMOD \& RECAST. 2018. Biodiversity Profile of Api Nampa Conservation Area, Kailash Sacred Landscape, Nepal. Department of National Parks and Wildlife Conservation, International Centre for Integrated Mountain Development, and Research Centre for Applied Science and Technology, Kathmandu, Nepal.

Doevenspeck, M., 2011. Constructing the border from below: Narratives from the Congolese-Rwandan state boundary. Political Geography 30, pp. 129-42. doi:10.1016/J.polgeo.2011.03.003

Gellner, D. 2013. Borderland Lives in Northern South Asia. Duke University Press, Durham and London.

Gereffi, J., Humphrey J., and Sturgeon, T., 2005. The governance of global value chains. Review of International Political Economy 12, 1, pp. 78-2014. doi: 10.1080/09692290500049805

Ghosh, S., 2011. Cross-border activities in everyday life: the Bengal borderland. Contemporary South Asia 19, 1 (March), pp. 49-60. doi: 10.1080/09584935. 2010.544718

Goodhand, J., 2005. Frontiers and Wars: The Opium Economy in Afghanistan. Journal of Agrarian Change 5, 2, pp. 191-216. doi: 10.1111/j.1471-0366.2005.00099.x 
Grillot, C., 2016. "Trust facilitates business, but may also ruin it": the hazardous facets of SinoVietnamese border trade. Asian Anthropology 15, 2, pp. 169-85. doi:10.1080/1683478X.2016.1216281

Harris, T., 2013. Trading places: New economic geographies across Himalayan borderlands. Political Geography 35, pp. 60-68. doi: 10.1016/j.polgeo.2012.12.002

He, J., Yang, B., Dong, M., and Wang, Y., 2018. Crossing the roof of the world: Trade in medicinal plants from Nepal to China. Journal of Ethnopharmacology 224, pp. 100-110. doi: 10.1016/j.jep.2018.04.034

Hendersen, J., Dicken, P., Hess, M., Coe, N., and Yueng, H. W., 2002. Global production networks and the analysis of economic development. Review of International Political Economy 9, 3, pp. 436 464. doi: $10.1080 / 09692290210150842$

Jones, R., 2012. Spaces of Refusal: Rethinking Sovereign Power and Resistance at the Border. Annals of the Association of American Geographers 102, pp. 1-15. doi:10.1080/00045608.2011.600193

Kansakar, V.B.S., 2001. Nepal-India Open Border: Prospects, Problems and Challenges. Nepal Democracy, Friedrich Ebert Stiftung, Nepal Office. Accessed on $13^{\text {th }}$ July 2018: http://www.nepaldemocracy.org/documents/treaties_agreements/nep_india_open_border.htm

Keck, M., 2016. Navigating real markets. The economic resilience of food wholesale traders in Dhaka, Bangladesh. Franz Steiner, Stuttgart.

Korf, B. and Raeymaekers, T., 2013. Violence on the Margins: States, Conflict, and Borderlands. Palgrave Macmillan.

Li, P., 2007. Social ties, social capital, and social behaviour: toward an integrative model of informal exchange. Asian Pacific Journal of Management 24, 2, pp. 227-246.

Linke, J., 2017. Market Positions of Tibetans in Qinghai: The Rush For Caterpillar Fungi. In: Gruschke, A., and Breuer I., 2017. Tibetan Pastoralists and Development - Negotiating the Future of Grassland Livelihoods. Reichert Verlag, Wiesbaden.

Mathur, N., 2013. Naturalizing the Himalaya as Border in Uttarakhand. In: Gellner, D., 2013. Borderland Lives in Northern South Asia. Duke University Press, Durham and London.

Mayring, P., 2015. Qualitative Inhaltsanalyse. Grundlagen und Techniken. Weinheim: Beltz.

Ministry of Forest and Soil Conservation (MoFSC). 2017. Yartsagumba management: Collection and transportation directive. Kathmandu: Government of Nepal.

Negi, C.S., Pant, M., Joshi, P. and Bohra, S., 2016. Conserving the caterpillar fungus [Ophiocordyceps sinensis (Berk.) G.H. Sung et al.]: A case study of habitat ecology and sustainability in district Pithoragarh, Western Himalaya, India. International Journal of Biodiversity and Conservation. doi:10.5897/JJBC2014.0742

Neilson, J., Pritchard, B., and Yeung, H. W., 2014. Global value chains and global production networks in the changing international economy: An introduction. Review of International Political Economy 21, 1, pp. 1-8. doi: 10.1080/09692290.2013.873369

Newman, D., 2006. The lines that continue to separate us: borders in our 'borderless' world. The Progress in Human Geography 30, pp. 1-19. Doi: 10.1191/0309132506ph599xx

Nordstrom, C., 2000. Shadows and Sovereigns. Theory, Culture \& Society 17, 4, pp. 35-54. doi: $10.1177 / 02632760022051301$

Paasi, A., 1999. Boundaries as Social Processes: Territoriality in the World of Flows. Geopolitics 3, 1, pp. 1-26. doi: 10.1080/14650049808407608

Pant, B., Rai, R., Wallrapp, C., Ghate, R., and Shrestha, U.B., 2017. Horizontal integration of multiple institutions: Solutions for Yarsagumba related Conflict in the Himalayan Region of Nepal? International Journal of the Commons 11, 1, pp. 464-86. doi:10.18352/ijc.717

Pauls, T., and Franz, M., 2013. Trading in the dark - The medicinal plant production network in Uttarakhand. Singapore Journal of Tropical Geography 34, pp. 229-243. doi:10.1111/sjtg.12026 
Pouliot, M., Pyakurel, D., and Smith-Hall, C., 2018. High altitude organic gold: The production network for Ophiocordyceps sinensis from far-western Nepal. Journal for Ethnopharmacology 218, pp. 59-68. doi:10.1016/j.jep.2018.02.028

Pyakurel, D., Bhattarai Sharma, I., and Smith-Hall, C., 2018. Patterns of change: the dynamics of medicinal plant trade in far-western Nepal. Journal of Ethnopharmacology 224, pp. 323-334. doi: 10.1016/j.jep.2018.06.004

Scott, J., 2009. The Art of Not Being Governed - An Anarchist History of Upland Southeast Asia. Yale University Press.

Scott, R., 1999. Institutions and Organisations. Sage Publications.

Shneiderman, S.B., 2013. Himalayan border citizens: Sovereignty and mobility in the Nepal - Tibetan Autonomous Region (TAR) of China border zone. Political Geography 35, pp. 25-36. doi: 10.1016/j.polgeo.2013.04.001

Shrestha, U.B., and Bawa, K.S., 2013. Trade, harvest and conservation of Caterpillar Fungus (Ophiocordyceps sinensis). Biological Conservation 159, pp. 514-520. doi:10.1016/j.biocon.2012.10.032

Shrestha, U.B., and Bawa, K.S., 2014. Economic contribution of Chinese caterpillar fungus to the livelihoods of mountain communities in Nepal. Biological Conservation 177, pp. 194-202. doi:10.1016/j.biocon.2014.06.019

Titeca, K., and Flynn, R., 2014. "Hybrid Governance," Legitimacy, and (II)legality in the Informal CrossBorder Trade in Panyimur, Northwest Uganda. African Studies Review 57, 1, pp. 71-91. doi:10.1017/asr.2014.6

Tong, C. K., 2014. Rethinking Chinese Business. In: Chee Kiong Tong, C.T., 2014. Chinese Business. Rethinking Guanxi and Trust in Chinese Business Networks. Springer, Singapore.

Van Schendel, W., and Abraham, I., 2005. Illicit Flows and Criminal Things. Indian University Press, Bloomington.

Wallrapp, C., Keck, M., and Faust, H., Governing the yarshagumba 'gold rush': A comparative study of governance systems in the Kailash Landscape in India and Nepal. forthcoming.

Winkler, D., 2008. Yartsa Gunbu (Cordyceps sinensis) and the Fungal Commodification of Tibet's Rural Economy. Economic Botany 62, 3, pp. 291-305.

Winkler, D., 2009. Caterpillar Fungus (Ophiocordyceps sinensis), Production and Sustainability on the Tibetan Plateau and in the Himalayas. Asian Medicine 5, pp. 291-316. doi: $10.1163 / 157342109 \times 568829$

Yeh, E., and Lama, K. T., 2013. Following the caterpillar fungus: nature, commodity chains and the place of Tibet in China's uneven geographies. Social and Cultural Geography 14, 3, pp. $318-340$. doi:10.1080/14649365.2013.765025

Acknowledgements: We would like to thank the informants for their hospitality and time, and for the information they provided during the interviews. We are also thankful to the team of the Kailash Sacred Landscape Conservation and Development Initiative (KSLCDI), the support of Dr. Vishwas Chitale (ICIMOD) for his work on the study area map, Eileen Lemke and Kristin Cain for editing and proof-reading, and Ashish Chaudary for his constant assistance in the field. We thank the Deutsches Bundesministerium für Wirtschaftliche Zusammenarbeit und Entwicklung (German Federal Ministry for Economic Cooperation and Development) / Deutsche Gesellschaft für Internationale Zusammenarbeit (GIZ) GmbH (German Development Cooperation) for financially supporting the data collection. 
CHAPTER 6: Production networks and borderlands ... 


\section{Discussion}

This section returns to the central questions of the study presented in the introduction section 1.2.2:

- How do actors adapt governance systems regulating commercial collection and trade of the resource in response to changes in relation to the resource, like an increased resource value?

- What kinds of production networks emerge in borderlands?

- What roles do state and non-state actors play in the negotiation processes shaping governance systems that control access to and benefit from commercial NTFP collection and trade in borderlands?

In the following two sections I discuss the answers to these questions in detail.

\subsection{Governance systems and networks are more than institutions}

Through the increased demand for yarshagumba on the Chinese market over the last 20 years, this natural product growing in the high alpine grasslands of the Himalayas transformed into a highly valued tradable commodity commercially collected by the local people. Its high value and the risk of its overexploitation forced and encouraged state authorities and local communities to adapt governance systems in order to secure or gain access to the resource and to benefit from the trade through informal and formal channels. These governance systems and networks on the ground are diverse, adaptive and complex including rights, institutions, power structures, and social and economic relations between actors.

This study shows that both yarshagumba and the high alpine grasslands are resources produced through social, economic and political dimensions. This transformation of a natural product into a resource is a dynamic process and not static. It is possible that tomorrow, another plant or product will be hyped by Chinese society for its medicinal use and replace yarshagumba. Or the Nepali government may declare yarshagumba an endangered species and put a ban on yarshagumba collection and export. The resource is thus socially constructed by market demands, governmental interventions, governance systems, contemporary discourses on property right regimes for conservation and natural resource management, as well as in this specific case, on medicinal practices. These features can change at any time, which will influence the governance system of the resource and vice versa.

Through the commercialisation of yarshagumba, our findings show that the production network of yarshagumba has become complex in this trans-boundary region and triggered different developments. In response, more actors have appeared who demand access to the resource, 
the dependency of the local communities on the resource as an income source has increased, signs of habitat degradation have become visible and the risk of overexploitation of yarshagumba has risen (cf. Pant et al. 2017; Shrestha et al. 2017). Global market demands and political and economic decisions of state authorities and powerful non-state actors - like traders and consumers - influence the behaviour of local collectors and push them further into dependency on the resource and on other actors' decisions (cf. Caplins 2016; Stewart 2014). This therefore leads to degradation of the habitats through intensified collection and more pressure on the governance systems to regulate access and resource extraction. Following the understanding of political ecology, dependency on resources and environmental changes reinforce each other. As a result, local communities are vulnerable to other actors' demands, to environmental changes in the habitats, changes within the market structure of the resource, and changes in property rights or rules for collection and trading due to governmental interventions. However, marginalisation is only one side of the yarshagumba phenomenon, which is happening in the study area.

At the same time, in both parts of my case study - the collection and the trade of yarshagumba - the results show that the local people are vulnerable to some extent as they depend on the demands of the global market and are exposed to governmental regulations, but they are not passive players in the collection and trading systems. They are active participants along with the state authorities in shaping governance systems and trading networks suitable and appropriate to their demands and interests. The in-depth analysis of the local situation shows that state and non-state actors have reacted to the changing conditions through the use of their own agency. They have formed new institutions, established networks using opportunities across the national borders and adapted regulations for resource extraction and trade securing their own benefits. In this regard, systems regulating access to NTFP collection and the related trading networks are complex, linking multiple scales, actors and dimensions.

These established resource governance systems and networks are the outcomes of negotiation processes between state and non-state actors. Every collection site of yarshagumba has an individually-designed governance system consisting of governmental regulations and local communal arrangements, which are either complementary to or replace governmental regulations. Rather than formal rules and regulations, negotiation processes between actors play a key role to determine who has access to the resource and who benefits from the trade network. Thus, governance systems and networks in relation to commercial collection of resources are complex constellations. They are an interplay of rights, institutions, power structures, and social and economic relations between actors adapting to changing conditions. They are dynamic and differ from resource to resource and from location to location.

\subsection{Negotiation processes between state and non-state actors}

As discussed above, in the first part of the thesis about the collection of yarshagumba, the findings show that the negotiation processes between state authorities and communities 
formed complex governance systems in each collection site to regulate access to the common pool resource yarshagumba. Since yarshagumba collection started, additional actors have appeared and power relations and interactions have changed. Collectors from distant villages demanded access to the collection sites, putting the local communities under pressure to share their locally available resources with them. Communities reacted immediately by setting up their own communal management arrangements to regulate access and extraction of yarshagumba in their collection sites, appropriate to each specific location. They justify their claims on the basis of customary rights and have re-enforced them; in other words, they have formed new institutions on the basis of governmental regulations or have effectively replaced these regulations according to their demands and interests. Further, they have legitimated these arrangements within their community and social group, not necessarily through formal property right regimes, but instead through, for example, traditional grazing rights and through social dimensions, like strong leadership. Thus, informal institutions and social dimensions play a key role in claiming and protecting access to common resources.

The state authorities, responsible for natural resource management in the high-alpine mountains, hardly intervene in these local systems. As governmental authorities are far from the collection sites and have limited human and financial resources, they are often powerless to implement and enforce governmental regulations. However, recently, in both countries, governments have revised their policies regarding yarshagumba, regardless of the community management arrangements in the sites and without involving the local community in the policyprocess. With these revisions, the government authorities want to ensure their involvement within the lucrative yarshagumba business. The findings of the case study demonstrate the power game between the state and non-state actors about profiting from the lucrative locally available resources through designing and establishing governance systems in the collection sites that serve their own advantage and goals.

Who wins and who loses in the negotiation processes about the control of the locally available resources? From the findings it is apparent that, on the one hand, the governments of Nepal and India have designed new or revised existing policies relevant for yarshagumba collection, but on the other hand, they have not restricted the local communal management systems, although communities regularly violate current state law. State authorities sometimes intervene on the Indian side when the product is sold. However, rather than strategic enforcement of governmental law, this more strongly appeared to be a demonstration of power by individual state representatives. In this regard, in the collection sites the implementation of the newly designed policies from the governments of India and Nepal remains to be seen. Most likely, on the basis of earlier experiences, once they do so, the local actors will again be creative and adapt accordingly. The power game and the negotiation processes continue.

The negotiation process between state and non-state actors about access to the collection sites shows that communities have power and capacities to adapt to the changing conditions and situations on the local level. However, so far they are excluded from the process of transforming and revising governmental regulations. Out of necessity, communities are forced 
to set up their own systems to secure or gain access to a collection site, due to their high dependency on the resource. This leads to natural resource governance systems that are often accepted by the nearby communities, but not sanctioned by law. Therefore, their process of negotiation with state actors is a continuous process and power game that will last until either the communal management arrangements are formalised or their dependency on this one resource is reduced.

Both the communal management arrangements and the revised governmental regulations in India and Nepal are 'immediate' actions to adapt to the changing situation and changing conditions, rather than long-term strategic natural resource management interventions. Longer term strategic interventions would involve seeing the current challenges related to the commercial collection of yarshagumba on a bigger scale linking the yarshagumba collection with the property rights regimes in the high-alpine grasslands, with contemporary discourses and governmental strategies on conservation of flora and fauna in remote high mountain regions and, last but not least, with the dependency of the communities on one resource as their main income source. If these different aspects are not addressed and considered in negotiation processes between state and non-state actors, it is unlikely that sustainable income for the local people and the sustainable management of the resource and the habitats will be ensured.

In the second part of the thesis about the trade of yarshagumba within the Kailash Landscape, the findings show that also in the trading system, state and non-state actors are closely enmeshed in the informal trading network across the Indian-Nepali border. Similarly to the negotiation processes between actors regulating the collection of yarshagumba, the governance system and networks for trading are a mixture of governmental regulations and informal arrangements, which are built on social and economic embeddedness of actors and power games between the different state and non-state actors. Both state representatives and non-state actors, like collectors, village traders and town traders, are closely enmeshed with each other forming these networks, in which actors utilise, bypass or neglect governmental regulations where they find it appropriate, and set up their own arrangements and 'rules of the game'.

State and non-state actors either question or enforce sovereign power in borderlands, depending on what is more suitable for them. State authorities are either directly involved and enmeshed with the traders or do not intervene strategically and thoroughly. As shown in the case study in chapter 6 , state actors have several roles, which enables non-state actors to negotiate a trading system with state representatives. These systems enable a functioning trading network in the borderland, in which all actors involved benefit from the locally available resources.

The network configurations are not formally institutionalised. Ensuring the functioning of the networks, actors know the 'rules of the game'. They are embedded in the network based on social and economic dimensions. These networks are built on trust, credibility and reputation of actors as key features to limit the risks of various forms of abuse that can occur without 
formal contracts and reliance on legal tools (cf. Grillot 2016; Nordstrom 2000). Additionally, trading routes and network configurations are built on social cohesion, like between the Nepali and Indian collectors and traders and state authorities, but are also influenced by issues related to state stability and security on the state-level. In the case study, the continuous tensions between India and China as well as the tensions within TAR related to the occupation of Tibet by the Chinese in the 1950s influence perceptions of local people. Although the actual disputes lie a long time in the past, the unsolved historical issues affect the border area and the decisions of the traders themselves.

As in the case of yarshagumba, local people can be pushed into illegal activities, which in this case is especially the illegal sale of yarshagumba in India and the subsequent informal trade across the border to Nepal. However, in contrast to the understanding of Scott (2009), who speaks about resistance of local people to government authorities in the margins of states, my detailed analysis of the trading network in the borderlands of India and Nepal shows that local people do not resist governments, but are active participants in the governance systems and networks, although not all practices are considered legal by law. Thus, local people are not resisting sovereign power, but out of necessity, negotiate spaces jointly with state representatives from both sides of the border enabling the informal cross-border trade network.

Borderlands are regions with opportunities producing cross-border social and economic spaces through trans-border connectivities and cross-border networks. There, territoriality, sovereign power and the border are continuously negotiated and reinforced by state and non-state actors. Governance systems of NTFP commercially collected and traded in borderlands are formed by negotiation processes between state authorities and non-state actors from both sides of the border, rather than purely based on governmental regulations and sovereign power of the state. 


\section{Conclusion}

The thesis provides an in-depth understanding of the negotiation processes between state authorities and non-state actors to shape governance systems and networks for commercial NTFP collection and trade in border regions. The thesis uses the case of the resource yarshagumba in the remote high Himalaya of the Nepal-India trans-boundary region within the Kailash Landscape to explore this topic. The negotiation processes between actors within the case study are triggered through increased prices of the resource on the global market, through new actors demanding access to the resource, and through state and non-state actors' interests in securing or gaining access to the resource and in benefitting from its trade. The product is collected in the high alpine grasslands of the Himalaya of India and Nepal, informally traded from India and Nepal and legalised through the Nepali governmental marketing system. In this regard, political ecology provided an important basis to critically scrutinize the political, social and economical dimensions of the trans-boundary production network of the natural resource yarshagumba.

As a result of these negotiation processes between actors, I conclude that, in the margins of states, governance systems and networks for commercial collection and trade of NTFP move in and out of legality and use or bypass governmental regulations; the transitions are fluid. These governance systems and networks on the ground are complex constellations. Both state authorities and non-state actors are closely socially and economically enmeshed in these formal and informal governance and network structures. State authorities play different roles and can have several functions, using, neglecting or misusing their sovereign power. The trade flow does not stop at borders and actors in borderlands do not restrict themselves to one territory and regulatory space. Negotiation processes beyond borders form the governance systems, rather than governmental regulations. Thus, governance systems are more than institutions. They are an interplay of rights, institutions, power structures and social and economic relations between actors. Therefore, the narratives of the local state authorities and non-state actors are essential in the process of negotiating. The configuration and thus functioning of production networks in borderlands is continuously negotiated by actors to ensure their access to the locally available resources, and their participation in the profitable trade network. Any changes in the conditions of the networks and regulatory spaces can shift the power and embeddedness of actors and require adaptation.

Production networks and governance systems in borderlands are specific and complex and need appropriate and adjusted analysis and perspectives in order to capture all formal and informal as well as all political, social and economic dimensions. Looking at the case study and the results of the thesis, I conclude that a non-state centric perspective has enabled me an indepth analysis of the complexity of the commercialisation of NTFP, especially when collected and traded in borderlands. 
Building on the recommendation of chapter 5 and 6 , as an outlook for further research on governance systems of commons in margins of states, I suggest to consider a non-state centric perspective, looking beyond governmental regulations and sovereign power, but taking a realistic point of view on governance systems regulating resource access, extraction and trade. Using these perspectives enables an understanding of various actors and dimensions on multiple scales, as well as of the different practices, dependencies, power structures and behaviours of non-state actors as well as state representatives. I make a similar suggestion for further research on the concept of GPN. Considering the borderland as one production and trade region including both sides from the border does not limit the study to one territory and sovereign power, but enables a comprehensive analysis of local realities and power and embeddedness of actors within a production network beyond borders.

\subsection{Is yarshagumba a curse or good fortune?}

It is certain that yarshagumba has incorporated the local population in India and Nepal more tightly into the cash economy. In one way, this simultaneously marginalises them, making them highly vulnerable to international traders and finally to Chinese consumers. Traditional or other livelihood options are limited. In general, local people are optimistic: "When yarshagumba vanishes, another resource will come" (interview with collector in Nepal, May 2017). At the same time, as I show in this study, local people are active participants and central in the commercialisation process of resources by shaping the governance systems and networks controlling access and trade of the locally available resources.

Although the collection and trade of yarshagumba is partly informal, it is the main income source of the local population and it is currently central for the economic development of the mountainous border region in the Kailash Landscape. The borderlands within the Kailash Landscape are remote margins of three states, India, Nepal and China, far from the capital cities. The states, especially China and India, mainly invest in infrastructural development related to militarization and protection of the borders. The local economic development is mainly built on trade of NTFP and other products. Yarshagumba collection alone has an approximate yearly turnover of 10.5 million USD (based on $850 \mathrm{~kg}$ of collected yarshagumba) in the Kailash Landscape. Additionally, other NTFP and products are traded via similar networks between the three countries. Therefore, the partly informal production networks of locally available resources are not marginal, but central to the cash economy on the individual household level and for the development of the region in India and Nepal.

The governments, especially the Nepali authorities, also profit significantly from the yarshagumba trade. ANCA, the Nepali government authority in the border region, which is responsible for the legalisation of yarshagumba in Nepal, earns official revenues of up to 212,000 USD per year (MoFSC 2015). Additionally, as shown in the study, state actors on both sides, India and Nepal, are highly involved and enmeshed in the informal Indian-Nepali trade network, profiting through bribes and other requests for personal favours. 
Consequently, the transformation of yarshagumba into a highly valuable resource demanded on the global market is both a good fortune and a curse for the local people, the region and the respective governments. Further, we should see the phenomenon of yarshagumba as an example of commercialisation of NTFP. The resource yarshagumba might vanish over the coming years, but it is likely that another natural resource will appear with high commercial demands triggering similar effects in the region.

\subsection{Recommendations for policy-making processes}

The findings of this thesis point to a handful of recommendations for international and national development agencies, which support policy-making processes related to natural resource management and especially to NTFP collection and trade in the Himalayan region. The recommendations are formulated based on the resource yarshagumba from the case study, but most of them can be easily transferred to any other locally available natural resource collected or harvested in remote areas of a state.

Encourage state actors to recognize and to formalize the communities' efforts for natural resource management: As seen in my analysis of the collection and trade of yarshagumba in India and Nepal, local communities are the key stakeholders in the collection process and natural resource management in the high alpine grasslands. They are the custodians of the high mountainous regions and have a high interest in and concern for sustainable management of yarshagumba collection to ensure their future income. Through the different established communal management arrangements in the collection sites, first steps are taken towards regulating access rights and sustainably managing the collection sites. Although some of these arrangements are not legal by law, the state should recognize these efforts and support a process to formalize them. These arrangements are socially accepted by community members, are adjusted to the local context and contribute towards sustainability of the resource.

Encourage state actors to engage multiple actors in decision-making processes: In the collection and trade of yarshagumba, several actors are involved with several functions within the collection and trading system, leading to complementary or overlapping institutions and actions, as well as sometimes to neglect. As seen in the case study, especially in regions at the margin of states like borderlands, state authorities and representatives can be closely enmeshed in trading networks across borders. This requires policy-makers to take a perspective that looks beyond technical and managerial questions in relation to natural resource extraction and trade. Instead, policy-makers should be aware of political, social and economic dimensions within resource production networks and should consider these dimensions in the process of policy design and its implementation. Further, this requires state authorities to be more reflective regarding their own regulations and processes of decisionmaking, as well as about their behaviours and formal and informal involvement in natural resource management and trading networks. Open dialogues between state and non-state actors would be a first step to create a common understanding of the local realities, build up 
trust between community members and state authorities and identify appropriate solutions, which meet the different demands and interests.

Support research and exchange on the effectiveness of communal management arrangements and regulations in the collection sites: There is a need to assess these diverse and emerging efforts at the grass roots level, to monitor their effectiveness and help develop sustainable collection arrangements. This activity could follow a research and exchange model where those currently experimenting with different management arrangements could share with each other. Communities across the region are dealing with the same issues and trying different techniques, like limiting the time of collection, limiting the number of collectors or rotating the collection sites per season. The region is large and diverse, but some areas are having success in their collection management practices, and could offer suggestions to others. Additionally, scholars have gathered information and knowledge about sustainable management of NTFP in other areas, which could enrich the discussions about effectiveness. Communities perceive that quantities of yarshagumba are reducing, and there is therefore a high interest from their side to get support and knowledge to better regulate yarshagumba collection.

Support a delineation process of collection sites based on existing communal management arrangements: For both countries, there is a need to jointly delineate collection sites for yarshagumba in the high alpine grasslands. This needs to be a joint effort by the local communities and the respective government authorities to define collection sites for each community and clarify access rights. As recommended in the first point, this process needs to be based on existing communal management arrangements in the collection sites and customary rights in the high-alpine grasslands. Further, livelihood dependencies of communities and conservation aspects of flora and fauna should be considered to meet the different interests and demands of the actors. By involving the different actors in the process and mapping the different arrangements, interests and rights, a transparent knowledge platform for open negotiation processes between actors can be built. This will also provide the opportunity to formalize some of the communal management arrangements and to define the rights of actors for resource extraction, as well as to define their responsibilities towards resource management. The delineation process can also stimulate discussions about environmental impacts, like the location of the campsites or possibilities for introducing a rotation system for collection and camp sites or even temporarily closing some sites.

Encourage state actors to think beyond the state borders: As my case study shows, state and non-state actors especially in borderlands are innovative and flexible in making use of opportunities and building networks beyond the state border. Both state and non-state actors in the borderlands are flexible in adapting to changing conditions to ensure benefit from the lucrative trade. Seeing a border region as one unit of analysis helps to build a better understanding of the cross-border networks, the social and economic relations across borders, and possible implications of interventions. Governments must be aware that policy revisions on one side of the border have effects on the other side of the border, as well as on the cross- 
border networks. Furthermore, governments can learn from the findings of borderland studies that informal networks and illegal trade cannot be restricted only through regulations and reinforced border control. These activities will continue unless appropriate marketing mechanisms and regulations are implemented providing incentives to collectors and traders, then they might give preference to formal trading networks and marketing options.

Encourage state actors to think beyond sectors: Policy-makers and government authorities should see the region as a whole unit - as one social-ecological system - and not from the lens of one sector only. Natural resource management is not only a technical challenge for ecologists and foresters. For sustainable management of yarshagumba all social, political and economic relations within the production network, as well as the ecological relations, need to be understood and considered. In the short term, governmental programmes, which provide incentives to reduce the communities' dependency on NTFP collection and to identify comparable income options, will most likely not reduce the pressure of the collectors on the resource. The current price of yarshagumba is so high that there will always be community members who have an economic interest in continuing to collect yarshagumba. Instead, as mentioned earlier in other recommendations, enabling the adaptation and formalisation of governance systems for the collection and trade, which are built in consensus with communities, will encourage sustainability of the resource and will reduce its informality. 


\section{References (Chapter 1, 2, 3, and 7)}

Acheson, J.M, (2006): Institutional Failure in Resource Management. In: Annual Review of Anthropology 35: 117-34. doi:10.1146/annurev.anthro.35.081705.123238

Adhikari, K., (2015): Perception or reality? A case study of corrupt practices in the forestry sector in Nepal. In: European Bulletin of Himalayan Research 46: 9-34.

Agrawal, A. (2003): Sustainable Governance of Common Pool Resources: Context, Methods, and Politics. In: Annual Review of Anthropology 32: 243-62. doi:10.1146/annurev.anthro. 32.061002.093112

Agrawal, A. and Ostrom, E. (2001): Collective Action, Property Rights and Decentralization in Resource Use in India and Nepal. In: Politics and Society 29, no. 4: 485-514. doi:10.1177/ 0032329201029004002

ANCA (Api Nampa Conservation Area) (2016): Yartsa gunbu (ophiocordyceps sinensis) status, recent management practices and sustainable management options in ANCA, Kailash Landscape. Presentation by Ashok Ram and Corinna Wallrapp at the Workshop "Tracking Options for Sustainable Management and Trade of Yarshagumba in the Kailash Sacred Landscape" 812.August 2016, Paro, Bhutan.

Anderies, J. Janssen, M. and Ostrom E. (2004): A framework to analyze the robustness of socialecological systems from an institutional perspective. In: Ecology and Society 9, no. 1, 18.

Baland J. M. and Platteau J.P. (1996): Halting Degradation of Natural Resources: Is There a Role for Rural Communities? Oxford, UK: Clarendon.

Baral, B., Shrestha, B. and Teixeira da Silva, J.A. (2015): A review of Chinese Cordyceps with special reference to Nepal, focusing on conservation. In: Environmental and Experimental Biology 13: 61-73.

Baud, M., and Van Schendel, W., (1997): Toward a Comparative History of Borderlands. In: Journal of World History 8, 2 (fall): 211-242. doi: 10.1353/jwh.2005.0061

Bauer, K.M. (2004): High Frontiers, Dolpo and the Changing Wold of Himalayan Pastoralists. New York: Columbia University Press.

Bauriedl, S. (2016): Politische Ökologie: nicht-deterministische, globale und materielle Dimensionen von Natur/Gesellschaft-Verhältnissen. In: Geographica Helvetica 71: 341-351.

Belcher, B. and Schreckenberg, K. (2007): Commercialisation of non-timber forest products: a reality check. In: Development Policy Review 25, no. 3: 355-77. doi:10.1111/j.1467-7679.2007. 00374.x

Bergmann, C. (2016): The Himalayan Border Region - Trade, Identity and Mobility in Kumaon, India. Springer International Publishing Switzerland.

Blaikie, P., and H. Brookfield (1987): Land degradation and society. London: Methuen.

Bloomer, J. (2009): Using a political ecology framework to examine extra-legal livelihood strategies: a Lesotho-based case study of cultivation of and trade in cannabis. In: Journal of Political Ecology 16: 49-69. Doi: 10.2458/v16i1.21691

Bowen, G. A. (2009): Document analysis as a qualitative research method. In: Qualitative research journal 9 (2): 27-40. doi: 10.3316/QRJ0902027

Bryant R. and Bailey, B. (1997): Third World Political Ecology. New York: Routledge.

Bum, T. (2016): Guardians of Nature: Tibetan Pastoralists and the Natural World. In: Asian Highlands Perspectives 42. 
Cannon, P.F., Hywel-Jones, N.L. Maczey, N., Norbu, L., Tshitila, Samdup, T. and Lhendup, P. (2009): Steps towards sustainable harvest of Ophiocordyceps sinensis in Bhutan. In: Biodiversity Conservation 18: 2263-81. doi: 10.1007/s10531-009-9587-5.

Caplins, L. B. (2016): Political ecology of cordyceps in the Garhwal Himalaya of Northern India. Graduate Student Theses, Dissertations, \& Professional Papers. 10913. https://scholarworks.umt.edu/etd/10913.

Caplins, L., Halvorson, S.J. and Bosak, K. (2018): Beyond resistance: A political ecology of cordycepts as alpine niche product in the Garhwal, Indian Himalaya. In: Geoforum 96: 298-308.

Castree, N. (2001): Socializing Nature: Theory, Practice, and Politics. In: Social nature: theory, practice, and politics, edited by N. Castree and B. Braun. 1-21, Oxford, UK: Blackwell Publishers.

Castree, N. and Braun, B. (2001): Social nature: theory, practice and politics, Oxford, UK: Blackwell Publishers.

Chan, Y. W., and Womack, B., (2016): Not merely a border: borderland governance, development and transborder relations in Asia. In: Asian Anthropology 15, 2: 95-103. doi: 10.1080/1683478 X.2016.1214352

Childs, G. and Choedup, N. (2014): Indigenous Management Strategies and Socioeconomic Impacts of Yartsa Gunbu (Ophiocordyceps sinensis) Harvesting in Nubri and Tsum, Nepal. In: Himalaya. 34 (1).

Choudhary, D., Kala, S.P., Todaria, N.P., Dasgupta, S., Kollmair, M., (2014): Drivers of exploitation and inequity in non-timber forest products (NTFP) value chains: the case of Indian Bay Leaf in Nepal and India. In: Development Policy Revision 32: 71-87.

Cleaver, F. (2003): Reinventing institutions. Bricolage and the social embeddedness of natural resource management. In: Securing Land Rights in Africa, edited by Benjaminsen, T.A. and Lund, C., 1130. London: Frank Cass.

Demeritt, D. (2001): Being constructive about nature. In: Social nature: Theory, practice, and politics, edited by N. Castree and B. Braun. 22-40, Oxford, UK: Blackwell Publishers.

Desai, V. and Potter, R B (2006): Doing development research. London, UK: SAGE.

Dhakal, B. (2014): The Local Environmental, Economic and Social Tragedies of International Interventions on Community Based Forest Management for Global Environmental Conservation: A Critical Evaluation. In: Open Journal of Forestry 04, no.1: 58-69. Doi: 10.4236/ojf.2014.41010

Dietz, T., Ostrom, E. and Stern, P.C. (2003): The struggle to govern the commons. In: Science 302: 1907-12. doi:10.1126/science.1091015

Doevenspeck, M., (2011): Constructing the border from below: Narratives from the Congolese-Rwandan state boundary. In: Political Geography 30: 129-42. doi:10.1016/J.polgeo. 2011.03.003

Doolittle, A. (2010): Stories and Maps, Images and Archives. Multimethod Approach to the Political Ecology of Property Rights and Natural Resource Management in Sabah, Malaysia. In: Environmental Management 45, 1: 67-81.

Escobar, A. (1999): After nature: steps to an antiessentialist political ecology. In: Current anthropology 40 (1): 1-30.

Flick, U., von Kardorff, E. and Steinke, I. (2003): Qualitative Forschung, Ein Handbuch, Reinbek bei Hamburg: Rowohlt.

Folke, C. (2007): Social-ecological systems and adaptive governance of the commons. In: Ecological Research 22:14-15. Doi: 10.1007/s11284-006-0074-0

Folke, C., Hahn, T, Olsson, P. and Norberg, J. (2005): Adaptive governance of social-ecological systems. In: Annual Review Environmental Resources 30: 441-473. doi: 10.1146/annurev.energy. 30.050504.144511

Gaull K, and Hauser M. (2009): Pro-poor Commercial Management of Non-timber Forest Products in Nepal's Community Forest User Groups: Factors for Success. In: Mountain Research and Development 29 (4): 298-307. Doi: 10.1659/mrd.00051 
Gellner, D. (2013): Borderland Lives in Northern South Asia. Duke University Press, Durham and London.

German, L.A. and Keeler, A. (2010): Hybrid institutions: applications of common property theory beyond discrete property regimes. In: International Journal of the Commons 4 (1): 571-96. doi: 10.18352/ijc.108.

Ghate, R. and Chaturvedi, R. (2016): Unpacking the governance conundrum for better natural resource management. ICIMOD Working Paper 2016, no. 2, Kathmandu: ICIMOD.

Goodhand, J. (2013): Epilogue: The View from the Border. In: Violence on the Margins: States, Conflict, and Borderlands. Edited by B. Korf and T. Raeymaekers: Palgrave Macmillan.

Goodhand, J., (2005): Frontiers and Wars: The Opium Economy in Afghanistan. In: Journal of Agrarian Change 5, 2: 191-216. doi: 10.1111/j.1471-0366.2005.00099.x

Grillot, C., (2016): "Trust facilitates business, but may also ruin it": the hazardous facets of SinoVietnamese border trade. In: Asian Anthropology 15, 2: 169-85. doi:10.1080/1683478X. 2016.1216281

Hamilton, A.C., (2004): Medicinal plants, conservation and livelihoods. In: Biodiversity Conservation 13, $1477-1517$.

Hardin, G. (1968): The Tragedy of the Commons. Science 162: 1243-48.

Harris, T. (2013): Trading places: New economic geographies across Himalayan borderlands. In: Political Geography 35: 60-68. doi: 10.1016/j.polgeo.2012.12.002

Hausner, S.L. and Sharma, J.R. (2013): On the Way to India: Nepali Rituals of Border Crossing. In: Borderland Lives in Northern South Asia. Edited by D. Gellner (2013) Durham and London: Duke University Press, 94-116.

He, J., Yang, B., Dong, M., and Wang, Y. (2018): Crossing the roof of the world: Trade in medicinal plants from Nepal to China. In: Journal of Ethnopharmacology 224: 100-110. doi: 10.1016/ j.jep.2018.04.034

Heinen JT and Shrestha-Acharya R. (2011): The non-timber forest products sector in Nepal: Emerging policy issues in plant conservation and utilization for sustainable development. In: Journal of Sustainable Forestry 30, 6: 543-63.

Hendersen, J., Dicken, P., Hess, M., Coe, N., and Yueng, H. W. (2002): Global production networks and the analysis of economic development. In: Review of International Political Economy 9, 3: 436464. doi: $10.1080 / 09692290210150842$

Herrera, P. M., Davies, J. and Manzano, P. (2014): Governance of Rangelands: Collective Action for Sustainable Pastoralism. New York: Taylor \& Francis.

Hoon, V. (1996): Living on the Move: Bhotiyas of the Kumaon Himalaya. New Delhi: Sage Publications.

Hopping, K. Chignell, S. and Lambin E. (2018): The demise of caterpillar fungus in the Himalayan region due to climate change and overharvesting. In: PNAS, 1-6. Doi: 10.1073/pnas. 1811591115

Howard, T. (2015): The "Rules of Engagement": A Socio-legal Framework for Improving Community Engagement in Natural Resource Governance. In: Oñati Socio-legal Series [online], 5 (5), 12091235.

ICIMOD (2010): Kailash Sacred Landscape Conservation initiative - Target Area Delineation Report. International Centre for Integrated Mountain Development. Kathmandu: ICIMOD.

ICIMOD (2011): Kailash Sacred Landscape Conservation initiative - Feasibility assessment report. Edited by Zomer, R and Oli, KP Kathmandu: ICIMOD.

ICIMOD (2015): Across the Mahakali. video. http://lib.icimod.org/record/32086. accessed on: 28.2.2018. Kathmandu: ICIMOD.

ICIMOD (2016): Tracking Options for Sustainable Management and Trade of Yarshagumba in the Kailash Sacred Landscape. Workshop proceedings 8-12.August 2016, Paro, Bhutan, Kathmandu: ICIMOD. 
ICIMOD (2017): Vegetation Type and Land Cover Map of Kailash Sacred Landscape. Map. Kathmandu: ICIMOD.

Ives, J. and Messerli, B. (1989): The Himalayan Dilemma - Reconciling Development and Conservation. The United Nations University. London and New York: Routledge.

Jones, R. (2012): Spaces of Refusal: Rethinking Sovereign Power and Resistance at the Border. In: Annals of the Association of American Geographers 102: 1-15. doi:10.1080/00045608. 2011.600193

Kala, C.P., Dhyani, P.P. and Sajwan, B.S. (2006): Developing the medicinal plants sector in northern India: challenges and opportunities. In: Journal of Ethnobiology and Ethnomedicine 2 (32): 1-15. doi:10.1186/1746-4269-2-32

Kanel, K. R. and Kandel B. (2004): Community Forestry in Nepal: Achievements and Challenges. In: Journal of Forest and Livelihood 4, no. 1: 55-63.

Keck, M. (2016): Navigating real markets. The economic resilience of food wholesale traders in Dhaka, Bangladesh. Franz Steiner, Stuttgart.

King, N. and Horrocks, C. (2010): Interviews in qualitative research. Los Angeles: SAGE.

Korf, B. and Raeymaekers, T. (2013): Violence on the Margins: States, Conflict, and Borderlands. Palgrave Macmillan.

Kumar, A. (2006): Van Panchayats in Uttaranchal. In: Local Governance in India - Decentralization and Beyond. Edited by N.G. Jayal, A. Prakash and P. Sharma. Delhi: Oxford University Press.

Kunwar, R.M., Mahat, L., Acharya, R.P., Bussmann, R.W., (2013): Medicinal plants, traditional medicine, markets and management in far-west Nepal. In: Journal of Ethnobiology and Ethnomed. 9, 1.

Kusters, K., Achdiawan, R., Belcher, B. and Ruiz Pérez M. (2006): Balancing development and conservation? An assessment of livelihood and environmental outcomes of non-timber forest product trade in Asia, Africa, and Latin America. In: Ecology and Society 11, no. 2. doi: 10.5751/ES-01796-110220.

Lamnek, S. (2010): Qualitative Sozialforschung, 5th ed., Weinheim: Beltz (Lehrbuch).

Lange, D., (2006): International trade in medicinal and aromatic plants. In: Medicinal and Aromatic Plants edited by Bogers, R.J., Craker, L.E., Lange, D. Amsterdam: Springer.

Le Billon, P. (2001): Angola's political economy of war: The role of oil and diamonds, 1975-2000. In: African Affairs 100: 55-80.

Leder, S. (2003): Zu einer Zeit, als Bäume und Gräser noch sprechen konnten.... Frankfurt am Main: Peter Lang Europäischer Verlag der Wissenschaften.

Li, P. (2007): Social ties, social capital, and social behaviour: toward an integrative model of informal exchange. In: Asian Pacific Journal of Management 24, 2: 227-246.

Linke, J. (2017): Market Positions of Tibetans in Qinghai: The Rush For Caterpillar Fungi. In: Gruschke, A., and Breuer I., 2017. Tibetan Pastoralists and Development - Negotiating the Future of Grassland Livelihoods. Reichert Verlag, Wiesbaden.

Longhurst, R. (2010): Semi-structured interviews and focus groups. In: Key Methods in Geography, edited by N. Clifford, S. French and G. Valentine. 103-115, London, UK: SAGE.

Lund, C. (2008): Local politics and the dynamics of property in Africa. Cambridge, UK: Cambridge University Press.

Mansarowar National Daily (2017): Police to be deployed for the security of Yarsagumba collectors. Title translated from Nepali into English.In: Mansarowar National Daily. Local newspaper of Dharchula District, Nepal. Issue 139, published on baisakh 24, 2074 (7th May 2017).

Mayring, P. (2010): Qualitative Inhaltsanalyse. Grundlagen und Techniken. $11^{\text {th }}$ ed. Weinheim: Beltz.

Ministry of Forest and Soil Conservation (MoFSC) (2015): Forest regulation 1995. In: Government Gazette 65, no. 26, part 3. Kathmandu: Government of Nepal. accessed on 20.02.2018. http://www.mfsc.gov.np/downloadfile/aanusuchif_1446967075.pdf. 
Ministry of Forest and Soil Conservation (MoFSC) (2017): Yartsagumba management: Collection and transportation directive. Kathmandu: Government of Nepal.

Mung'ong'o C.G. (2009): Political ecology: a synthesis and search for relevance to today's ecosystem conservation and development. In: African Journal of Ecology 47 (Suppl. 1): 192-197. doi: 10.1111/j.1365-2028.2008.01069.x.

Negi, C. S., Koranga, P.R. and Ghinga, H.S. (2006): Yar tsa gumba (Cordyceps sinensis): A call for its sustainable exploitation. In: International Journal of Sustainable Development \& World Ecology 13: $1-8$. doi:10.1080/13504500609469669.

Negi, C.S., Joshi, P. and Bohra, S. (2015): Rapid Vulnerability Assessment of Yartsa Gunbu (Ophiocordyceps sinensis [Berk.] G.H. Sung et al) in Pithoragarh District, Uttarakhand State, India. in: Mountain Research and Development 35, no. 4: 382-91. doi:10.1659/MRD-JOURNALD-14-00005.1.

Negi, C.S., Pant, M., Joshi, P. and Bohra, S. (2016): Conserving the caterpillar fungus [Ophiocordyceps sinensis (Berk.) G.H. Sung et al.]: A case study of habitat ecology and sustainability in district Pithoragarh, Western Himalaya, India. In: International Journal of Biodiversity and Conservation. doi:10.5897/IJBC2014.0742.

Negi, V.S., Maikhuri, R.K., Phondani, P.C. and Rawat, L.S. (2010): An inventory of indigenous knowledge and cultivation practices of medicinal plants in Govind Pashu Vihar Wildlife Sanctuary, Central Himalaya, India. In: International Journal of Biodiversity Science and Ecosystem Service Management 6: 96-105.

Neilson, J., Pritchard, B., and Yeung, H. W., (2014): Global value chains and global production networks in the changing international economy: An introduction. In: Review of International Political Economy 21, 1: 1-8. doi: 10.1080/09692290.2013.873369

Neumann, R.P. and Hirsch, E., (2000): Commercialisation of Non-Timber Forest Products: Review and Analysis of Research. Bogor: ClfOR.

Newell, P. (2012): Globalization and the Environment - Capitalism, Ecology and Power. Cambridge, UK: Polity Press.

Newman, D. (2006): The lines that continue to separate us: borders in our 'borderless' world. In: The Progress in Human Geography 30: 1-19. doi: 10.1191/0309132506ph599xx

Nordstrom, C. (2000): Shadows and Sovereigns. In: Theory, Culture \& Society 17, 4: 35-54. doi: $10.1177 / 02632760022051301$

North, D. C. (1990): Institutions, Institutional Change, and Economic Performance. Cambridge: Cambridge University Press.

Olsen, C.S., (2005): Valuation of commercial Central Himalayan medicinal plants. In: Ambio 34, 607610. doi.org/10.1579/0044-7447-34.8.607

Ostrom, E. (1990): Governing the Commons: The Evolution of Institutions for Collective Action. Cambridge: Cambridge University Press.

Ostrom, E. (2005): Understanding Institutional Diversity. Princeton and Oxford: Princeton University Press.

Ostrom, E., Burger, J., Field, C.B, Norgaard, R.B. and Policansky, D. (1999): Revisiting the Commons: Local Lessons, Global Challenges. In: Science 284: 278-82, doi:10.1126/science. 284.5412.278.

Pahl-Wostl, C. (2009): A conceptual framework for analysing adaptive capacity and multi-level learning processes in resource governance regimes. In: Global Environmental Change 19: 354-365. doi:10.1016/j.gloenvcha.2009.06.001.

Pahl-Wostl, C., Becker, G., Knieper, C., Sendzimir, J. (2013): How multilevel societal learning processes facilitate transformative change: a comparative case study analysis on flood management. In: Ecology and Society 18, no.4. doi:10.5751/es-05779- 180458.

Pant, B., Rai, R., Wallrapp, C., Ghate, R. and Shrestha, U.B. (2017): Horizontal integration of multiple institutions: Solutions for Yarshagumba related Conflict in the Himalayan Region of Nepal? In: International Journal of the Commons 11, no. 1: 464-86. doi:10.18352/ijc.717. 
Pathak, S., Pant, L. and Maharjan, A. (2017): De-population Trends, Patterns and Effects in Uttarakhand, India - A Gateway to Kailash Mansarovar. ICIMOD Working Paper 2017, no. 22. Kathmandu: ICIMOD.

Paudel, M. (2004): Non-timber forest products from community forestry practices, problems and prospects for livelihood strategy in Jumla. In: Banko Janakari 17(2): 45-54.

Pauls, T. and Franz, M. (2013): Trading in the dark - The medicinal plan production network in Uttarakhand. In: Singapore Journal of Tropical Geography 34: 229-243. doi:10.1111/sjtg.12026.

Paulson S. and L.L Gezon. (2004): Political Ecology Across Spaces, Scales and Social Groups. New Brunswick, USA: Rutgers University Press.

Peet, R., P. Robbins, and M. Watts. (2011): Global nature. In: Global political ecology, edited by R. Peet, P. Robbins and M. Watts. 1-47, Milton Park: Routledge.

Plummer, R., Armitage, D.R., de Loë, R.C. (2013): Adaptive comanagement and its relationship to environmental governance. In: Ecology and Society 18, no. 1. Doi:10.5751/ES-05383-180121.

Pouliot, M. (2016): Into thin air: mapping and quantifying the national-level trade in medicinal plants from Nepal. Presentation at $5^{\text {th }}$ Conference of the Asian Borderlands Research Network: Dynamic Borderlands: Livelihoods, Communities and Flows. 12-14 December 2016. Kathmandu, Nepal.

Pouliot, M., Pyakurel, D., and Smith-Hall, C. (2018): High altitude organic gold: The production network for Ophiocordyceps sinensis from far-western Nepal. In: Journal for Ethnopharmacology 218: 59-68. doi:10.1016/j.jep.2018.02.028.

Pyakurel, D., Sharma I.B. and Smith-Hall-C. (2018): Patterns of change: The dynamics of medicinal plant trade in far-western Nepal. In: Journal of Ethnopharmacology 224: 323-334. Doi: 10.1016/j.jep.2018.06.004

Rasul, G., Choudhary, D., Pandit, B.H., Kollmair, M., (2012): Poverty and livelihoods impacts of a medicinal and aromatic plants project in India and Nepal: an assessment. In: Mountain Research and Development 32: 137-148. doi.org/10.1659/MRD-JOURNAL-D-11-00112.1

Ribot, J. C. and Peluso, N.L. (2003): A Theory of Access. In: Rural Sociology 68, no. 2: 153-81. doi:10.1111/j.1549-0831.2003.tb00133.x.

Robbins, P. (2012): Political Ecology - A Critical Introduction, Second Edition. West Sussex UK: John Wiley and Sons Ltd.

Schippmann, U., Leaman, D., Cunningham, A.B., (2006): A comparison of cultivation and wild collection of medicinal and aromatic plants under sustainability aspects. In: Medicinal and Aromatic Plants edited by Bogers, R.J., Craker, L.E., Lange, D. Amsterdam: Springer.

Scott, J. (2009): The Art of Not Being Governed - An Anarchist History of Upland Southeast Asia. Yale University Press.

Scott, R. (1999): Institutions and Organisations. Sage Publications.

Sharma-Wallace, L., Velarde, S. and Wreford, A. (2018): Adaptive governance good practice: Show me the evidence! In: Journal of Environmental Management 222: 174-188. Doi:10.1016/j.jenvman.2018.05.067.

Sharma, S. (2004): Trade of Cordyceps sinensis from high altitudes of the Indian Himalaya: Conservation and biotechnological priorities. In: Current Science 86 (12): 1614-1619.

Shneiderman, S.B. (2013): Himalayan border citizens: Sovereignty and mobility in the Nepal - Tibetan Autonomous Region (TAR) of China border zone. In: Political Geography 35: 25-36. doi: 10.1016/j.polgeo.2013.04.001

Shova, T. and Hubacek, K. (2011): Drivers of illegal resource extraction: an analysis of Bardia National Park, Nepal. In: Journal of Environmental Management 92: 156-164.

Shrestha, U., Dhital, K. R., and Gautam, A.P. (2017): Economic Dependence of Mountain Communities on Chinese Caterpillar Fungus Ophiocordyceps Sinensis (Yarsagumba): A Case from Western Nepal. In: Oryx. Cambridge University Press: 1-9. doi.org/10.1017/ S0030605317000461. 
Shrestha, U.B. and Bawa, K.S. (2013): Trade, harvest and conservation of Caterpillar Fungus (Ophiocordyceps sinensis). In: Biological Conservation 159: 514-520. doi:10.1016/j.biocon. 2012.10.032.

Shrestha, U.B. and Bawa, K.S. (2014): Economic contribution of Chinese caterpillar fungus to the livelihoods of mountain communities in Nepal. In: Biological Conservation 177: 194-202. doi:10.1016/j.biocon.2014.06.019.

Shrestha, U.B., Shrestha, S., Ghimire, S., Nepali, K., Shrestha, B.B., (2014): Chasing Chinese caterpillar fungus (OphioOphiocordyceps sinensis) harvesters in the Himalayas: harvesting practice and its conservation implications in western Nepal. In: Society and Natural Resources 27: 1242-1256. doi.org/10.1080/08941920.2014.928394

Sikor, T. and Lund, C. (2009): Access and property: a question of power and authority. In: Development and Change 40, no. 1: 1-22. doi: 10.1111/j.1467-7660.2009.01503.x.

Singh, B. P. (2017): Yarsagumba collectors say buy now, pay later. In: KathmanduPost. National newspaper from Nepal, published on 13.10.2017. file://Users/cowallrapp/Desktop/Dr.\%20 Yarsagumba/Zeitung/Kathmandu\%20Post-Oct2017Yarsagumba\%20collectors.webarchive, accessed on: 15.10.2017.

Singh, N., Pathak, R. Kathait, A.S., Rautela, D. and Dubey, A. (2010): Collection of Cordyceps sinensis (Berk.) Sacc. in the Interior Villages of Chamoli District in Garhwal Himalaya (Uttarakhand) and its Social Impacts. In: Journal of American Science 6 (6): 5-9.

Singh, S. (2016): The Local Governance: Politics, Decentralization and Environment. New Dehli: Oxford University Press.

Stewart, M.O. (2014): The Rise and Governance of 'Himalayan Gold': Transformation of the Caterpillar Fungus Commons in Tibetan Yunnan, China. PhD diss., University of Colorado, Boulder.

Subedi, A., Kunwar, B., Choi, Y., Dai, Y., van Andel, T., Chaudhary R.P., de Boer H. and Gravendeel, B. (2013): Collection and trade of wild-harvested orchids in Nepal. In: Journal of Ethnobiology and Ethnomedicine 9, 64.

Tan, G.G. (2018): Chapter 7: Caterpillar Fungus and Transforming Subjectivities. In: Pastures of Change: Contemporary Adaptations and Transformations Among Nomadic Pastoralists of Eastern Tibet edited by G.G. Tan: Springer International Publishing AG, Springer.

Thapa, B.B. Panthi, S., Rai, R.K, Shrestha, U.B. Aryal, A., Shrestha, S. and Shrestha B. (2014): An Assessment of Yarsagumba (Ophiocordyceps sinensis) Collection in Dhorpatan Hunting Reserve, Nepal. In: Journal of Mountain Science 11 (2): 555-562. Doi: 10.1007/s11629-0132692-7

The Record Nepal (2014): Police brutality on Dolpo's "black day" under investigation. In: The Record Nepal. National newspaper of Nepal, published on 05.06.2014. https://www.recordnepal.com/wire/ police-brutality-on-dolpos-black-day-under-investigation/, accessed on 14.08.2017.

Thoms, C. A. (2008): Community Control of Resources and the Challenge of Improving Local Livelihoods : A Critical Examination of Community Forestry in Nepal. In: Geoforum 39: 1452-1465. http://doi.org/10.1016/j. geoforum.2008.01.006

Tong, C. K. (2014): Rethinking Chinese Business. In: Chee Kiong Tong, C.T., 2014. Chinese Business. Rethinking Guanxi and Trust in Chinese Business Networks. Springer, Singapore.

Tsing, A. L. (2015): The Mushroom at the End of the World - On the Possibilities of Life in Capitalist Ruins. Princeton and Oxford: Princeton University Press.

Uprety, Y., Poudel, R.C, Gurung, J., Chettri, N. and Chaudhary R. P. (2016): Traditional use and management of NTFPs in Kangchenjunga Landscape: implications for conservation and livelihoods. In: Journal of Ethnobiology and Ethnomedicine 12, no. 19. Doi:10.1186/s13002-0160089-8.

Uttarakhand Biodiversity Board (2017): Study on "Science-Policy Interface" focussing on Access \& Benefit Sharing (ABS) and Trans-boundary issues, Kailash Sacred Landscape Conservation and Development Initiative. Dehradun: Uttarakhand Biodiversity Board. 
Van Schendel, W., and Abraham, I. (2005): Illicit Flows and Criminal Things. Indian University Press, Bloomington.

Vasisht, K., Sharma, N. and Karan, M., (2016): Current perspective in the international trade of medicinal plants materials: an update. In: Current Pharmaceutical Design 22: 4288-4336. doi: 10.2174/1381612822666160607070736

Wade R. 1994. Village Republics: Economic Conditions for Collective Action in South India. Oakland: ICS Press.

Wallrapp, C. Keck, M. and Faust, H. (2018): Institutional Issues, Power Struggles and Local Solutions Governance Systems of Yarshagumba Collection in India and Nepal in the Kailash Landscape. In: Aktuelle Forschungsbeiträge zu Südasien, 8.Jahrestagung des AK Südasien, 19./20. Januar 2018, Köln edited by C. Butsch, A. Follmann and Müller J. Schriftenreihe des Arbeitskreises Südasiens in der Deutschen Gesellschaft der Geographie.

Wallrapp, C., Faust, H. and Keck, M. (2019): Production networks and borderlands: cross-border yarsagumba trade in the Kailash Landscape. In: Journal of Rural Studies 66: 67-76.

Wallrapp, C., Keck, M. and Faust, H. (forthcoming): Governing the yarshagumba 'gold rush': a comparative study of governance systems in the Kailash Landscape in India and Nepal. In: International Journal of Commons, accepted for publication.

Wangchuk, K. and Wangdi J. (2015): Mountain pastoralism in transition: consequences of legalizing cordyeps collection on yak farming practices in Bhutan. In: Pastoralism: Research, policy and practice 5 (4). doi: 10.1186/s13570-015-0025-x

Wangchuk, K. Sangay, Norbu Nawang, and Sherub (2012): Impacts of Cordyceps Collection on Livelihoods and Alpine Ecosystems in Bhutan as Ascertained from Questionnaire Survey of Cordyceps Collectors. Bumthang Royal Government of Bhutan: UWICE Press.

Watts, M. (2000): Chapter 16: Political Ecology. In: A Companion to Economic Geography edited by Sheppard, E. and Barnes, T.J.

Weckerle, C., Yang, Y., Huber, F.K. and Li, Q. (2010): People, money, and protected areas: the collection of the caterpillar mushroom Ophiocordyceps sinensis in the Baima Xueshan Nature Reserve, Southwest China. In: Biodiversity Conservation 19: 2685-98. doi:10.1007/s10531-010-9867-0

Winkler, D. (2005): Cordyceps sinensis (Berk.) Sacc.: Economy, Ecology and Ethno-Mycology of Yartsa Gunbu, a Medicinal Fungus Endemic for the Tibetan Plateau. In: International Journal of Medicinal Mushrooms 7 (3): 481-482.

Winkler, D. (2009): Caterpillar Fungus (Ophiocordyceps sinensis), Production and Sustainability on the Tibetan Plateau and in the Himalayas. In: Asian Medicine 5: 291-316. doi: $10.1163 / 157342109 \times 568829$

World Health Organisation (WHO) (2002): WHO Traditional Medicine Strategy. World Health Organization, Geneva.

World Health Organisation (WHO) (2013): WHO Traditional Medicine Strategy 2014-2023. World Health Organization, Geneva.

Yeh, E. and Lama, K. T (2013): Following the caterpillar fungus: nature, commodity chains and the place of Tibet in China's uneven geographies. In: Social and Cultural Geography 14, no. 3: 318 - 340. doi:10.1080/14649365.2013.765025

Young, O.R. (2009): Institutional dynamics: Resilience, vulnerability and adaptation in environmental and resource regimes. In: Global Environmental Change. doi:10.1016/j.gloenvcha.2009. 10.001 


\section{Annex}

\section{Annex 1: Pictures of the yarshagumba collection}

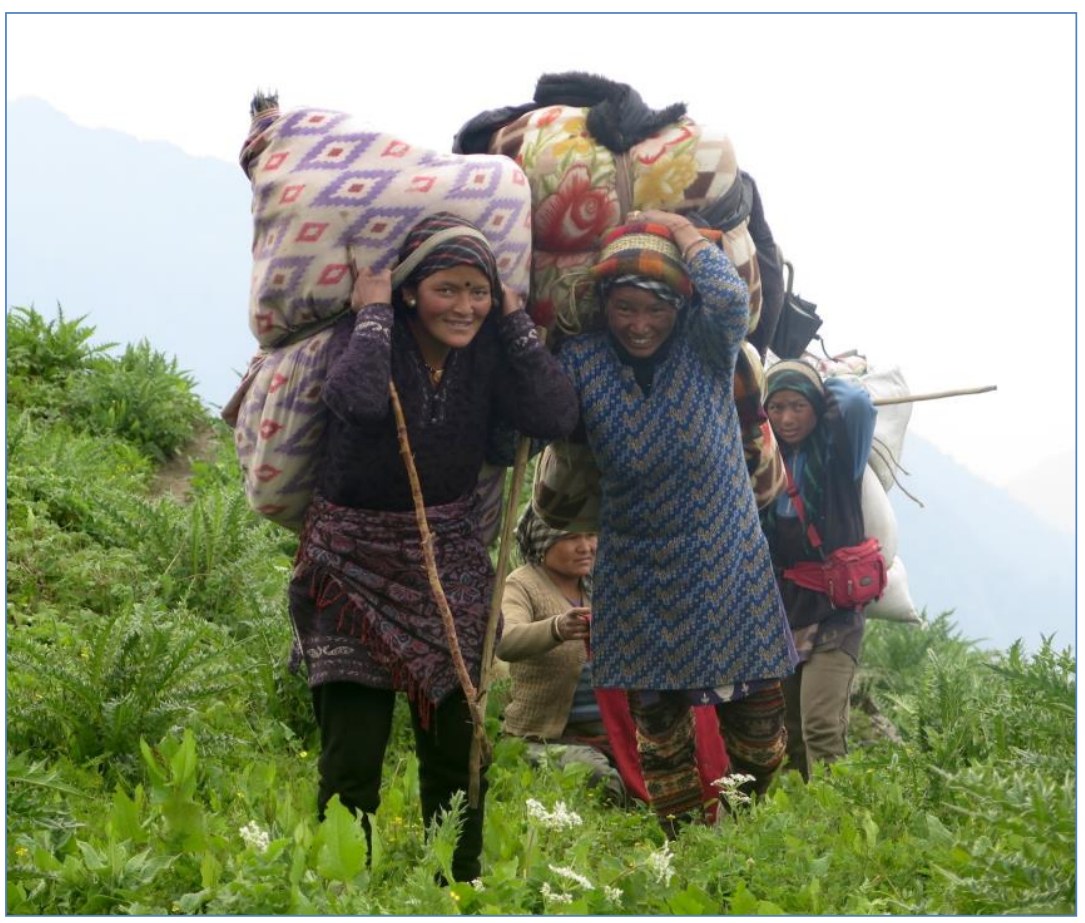

Picture 1: Collectors with camping luggage (June 2017)

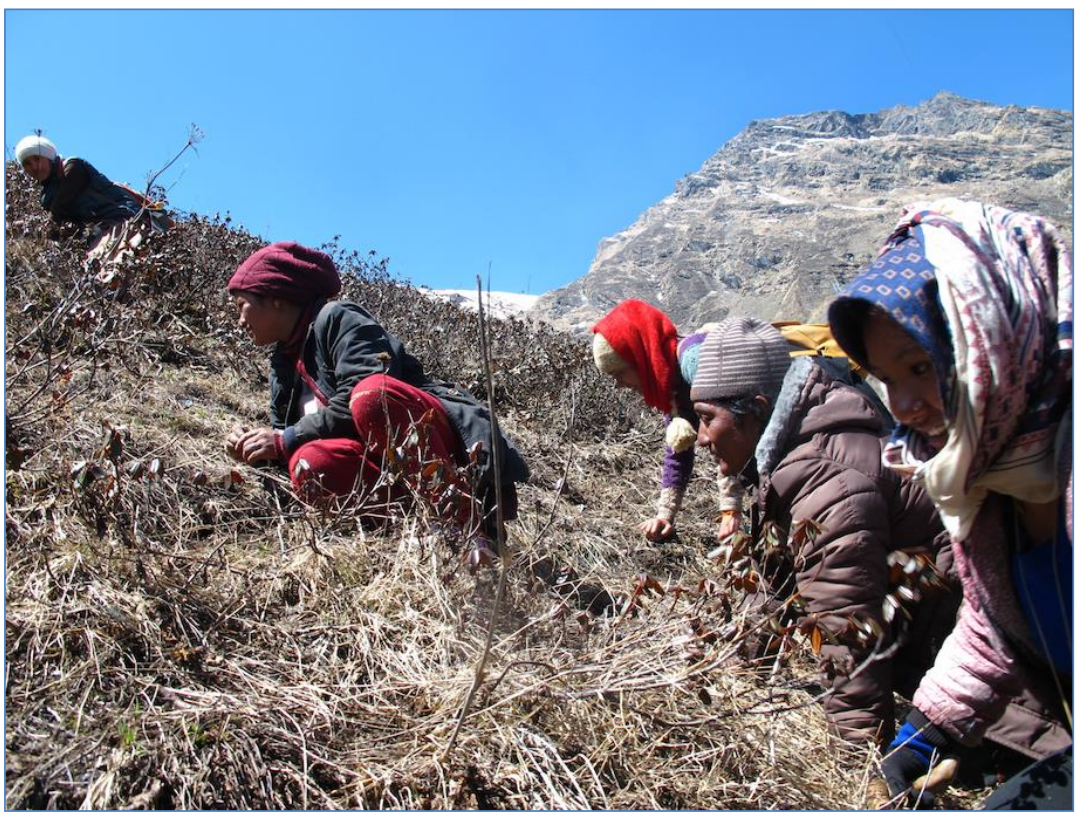

Picture 2: Collectors searching for yarshagumba (May 2017) 


\section{Curriculum Viate}

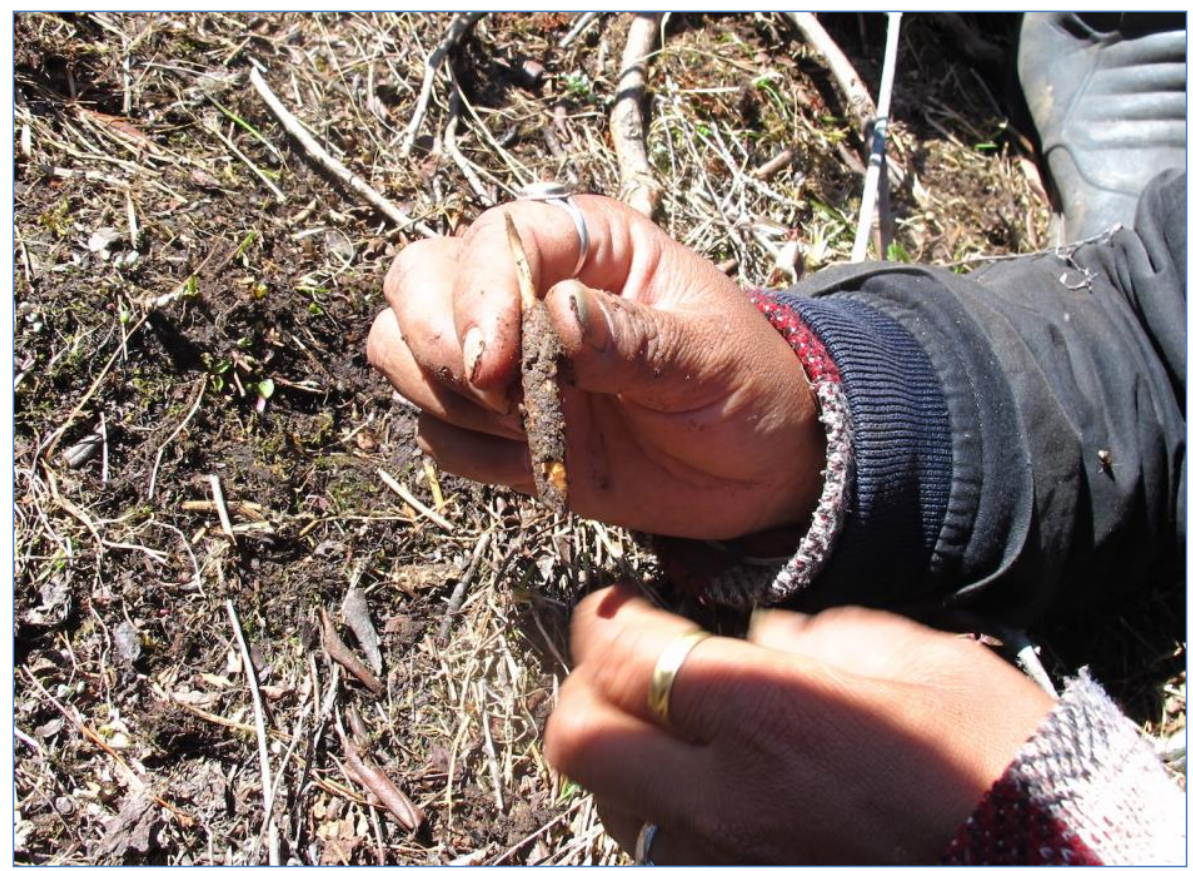

Picture 3: Yarshagumba when collected (May 2017)

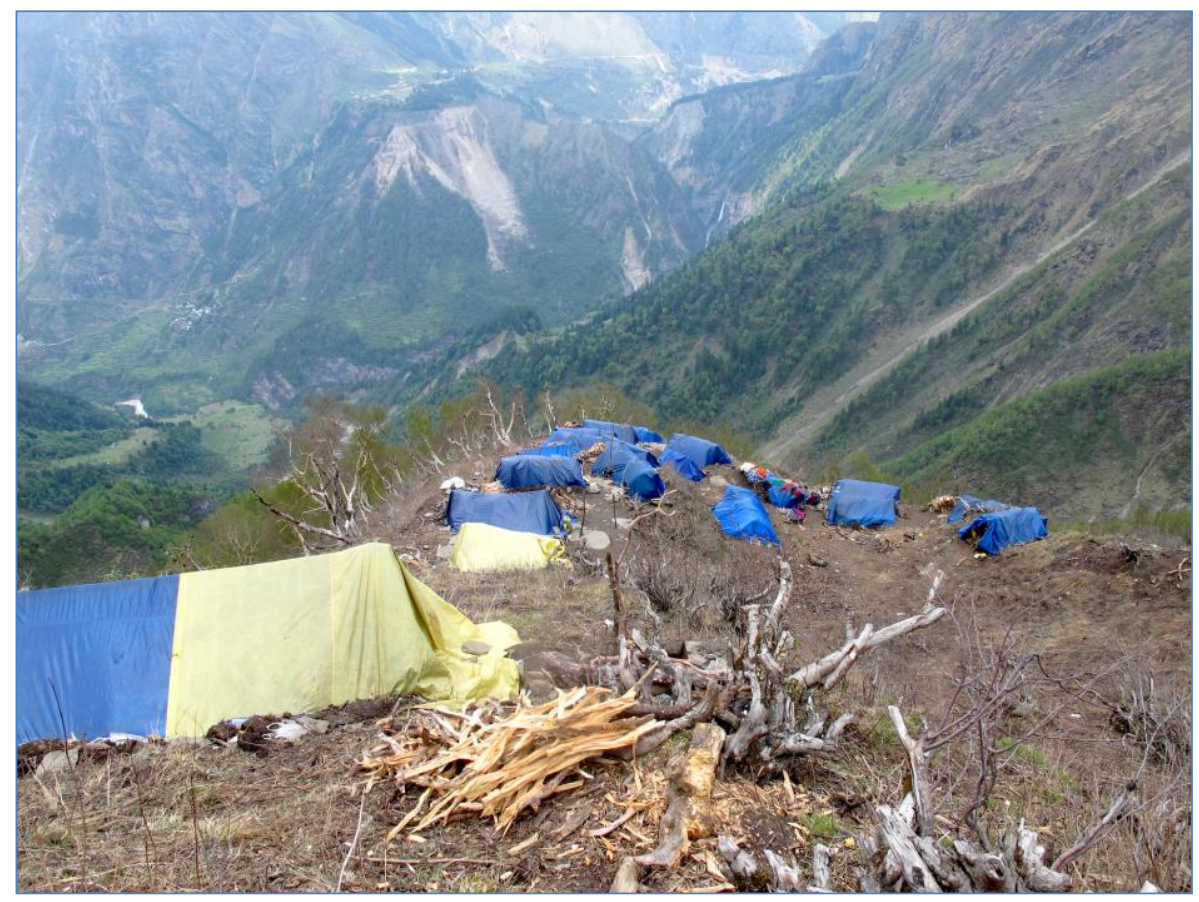

Picture 4: Campsite of collectors (May 2017) 


\section{Annex 2: Guiding questions for interviews}

\section{Questionnaire (Version: 06. April 2017) - India - Nepal}

1. Assessing governance structures for NRM and yarshagumba collection

\begin{tabular}{|c|c|}
\hline Topic & Key questions for interviews \\
\hline $\begin{array}{l}\text { General info } \\
\text { of available } \\
\text { Institutions } \\
\text { (government } \\
\text { or community } \\
\text { lead) }\end{array}$ & $\begin{array}{l}\text { What institutions regulate NRM in the valley? - FD, GP, VP, ASKOT, community } \\
\text { head (Bada), religious leaders, women groups } \\
\text { What powers/influences do the institutions have? (de jure) - decision-making, } \\
\text { planning, revenue collection, spending power, enforcement .... } \\
\text { What mandate, role, rights related to NTFP (collection and sale of timber and NTFP, } \\
\text { regulating access, ownership, management of NR) } \\
\text { What is their main interest and concern? } \\
\text { What is their capacity? } \\
\text { What structure (members, how selected, how leaders elected, decision making } \\
\text { process, Representation of different social groups (women, dalits, SC, ST, elders, } \\
\text { young..) } \\
\text { How often do they meet? Are other persons invited? } \\
\text { Have you ever participated in a meeting of the committee (GP, VP, VDC, ANCA } \\
\text { Committee) } \\
\text { Are the members in the different meetings the same, or different? } \\
\text { Who makes decisions? Jointly or by the head? } \\
\text { Coordination between different institutions? (GP, VP, District magistrate, VDC, ANCA } \\
\text { Committee) } \\
\text { Are saving groups within the community? (members, successful, how long) } \\
\text { Are these institutions recognised by authorities? } \\
\text { How are these institutions influencing yarsha management? }\end{array}$ \\
\hline $\begin{array}{l}\text { Perception of } \\
\text { people }\end{array}$ & $\begin{array}{l}\text { How do you perceive the different institutions, their work and interests? Which } \\
\text { institution powerful, which not? Why? Work appreciated? } \\
\text { Does it benefit all, or only a few? } \\
\text { Do you feel represented by the current leaders? }\end{array}$ \\
\hline $\begin{array}{l}\text { Changes in } \\
\text { NRM } \\
\text { institutions }\end{array}$ & $\begin{array}{l}\text { When were the „new“ institutions/conditions established? By whom? } \\
\text { Est. ASKOT 1986, BMC in India, ANCA } 2010 \\
\text { Who took part in the process and contributed to it? Who opposed it? } \\
\text { Did some rightsholders or stakeholders take the lead? "winners" } \\
\text { Did others feel "left out"? "losers"? } \\
\text { Who was then in charge of deciding about natural resources? } \\
\text { Was there some form of continuity? What remained of the earlier institutions and } \\
\text { arrangements? } \\
\text { How did the situation evolve? }\end{array}$ \\
\hline $\begin{array}{l}\text { Policies to } \\
\text { NRM - NTFP } \\
\text { - } \\
\text { endangered } \\
\text { species }\end{array}$ & $\begin{array}{l}\text { Knowledge about policies, government orders, regulations related to collection and } \\
\text { marketing } \\
\text { How implemented? By whom? } \\
\text { Challenges related to the policies? }\end{array}$ \\
\hline
\end{tabular}




\section{Curriculum Viate}

\begin{tabular}{|l|l|}
\hline $\begin{array}{l}\text { What other } \\
\text { institutions }\end{array}$ & $\begin{array}{l}\text { What beliefs, customs exist relevant for NRM? (sacred groves, community leader) } \\
\text { (women not allowed in high altitude pastures) } \\
\text { What role/function do they play in the community? } \\
\text { Are these institutions recognised by authorities? } \\
\text { What is their interest and concern? } \\
\text { How are these institutions influencing yarsha management? }\end{array}$ \\
\hline $\begin{array}{l}\text { Past: access } \\
\text { to alpine } \\
\text { pastures }\end{array}$ & $\begin{array}{l}\text { How was the access and usage of the alpine pastures regulated and managed before } \\
\text { yarsha collection started? Main differences to now? } \\
\text { Who had access? } \\
\text { Challenges? }\end{array}$ \\
\hline $\begin{array}{l}\text { Change of } \\
\text { institutions } \\
\text { due } \\
\text { yarshagumba }\end{array}$ & $\begin{array}{l}\text { Did institutions change due to yarshagumba collection? } \\
\text { How? Loosing of power, gaining power? Which institutions? } \\
\text { What is good about that? What bad? }\end{array}$ \\
\hline Future & $\begin{array}{l}\text { Which institution (formal and informal) should regulate more the access to the } \\
\text { collection sites, the trade? How to organise? } \\
\text { What roles do you think can communities play to manage the collection sites and } \\
\text { reduce illegal trading? }\end{array}$ \\
\hline
\end{tabular}

2. Assessing yarshagumba management - detailed

\begin{tabular}{|c|c|}
\hline Topic & \\
\hline $\begin{array}{l}\text { Access to } \\
\text { collection } \\
\text { sites }\end{array}$ & $\begin{array}{l}\text { Which community members have access to the sites? When? How long? } \\
\text { how controlled and enforced? By whom? } \\
\text { How many collectors/families do come every year? How changed over time? } \\
\text { Are tensions created between different groups? Between whom? What is the } \\
\text { perception of these tensions? } \\
\text { Have all people from the village same access to the sites? SC, ST, poor? } \\
\text { Any challenges? Weighting of challenges? }\end{array}$ \\
\hline $\begin{array}{l}\text { Usage of } \\
\text { pastures }\end{array}$ & $\begin{array}{l}\text { Besides yarsha collection how are the pastures used during the year? By whom? } \\
\text { Which animals are grazing? } \\
\text { Are the same institutions managing the pastures during the rest of the year? }\end{array}$ \\
\hline $\begin{array}{l}\text { degradation } \\
\text { of pastures / } \\
\text { sites }\end{array}$ & $\begin{array}{l}\text { Have the pastures / collection sites changed over the years? } \\
\text { Factors causing the degradation? Collectors, grazing of animals? } \\
\text { Does the degradation have an influence on the production/reduction on yarshagumba } \\
\text { collection? }\end{array}$ \\
\hline $\begin{array}{l}\text { Yarshagumba } \\
\text { harvesting }\end{array}$ & $\begin{array}{l}\text { how much yarshagumba harvested per person per season? } \\
\text { How much yarshagumba harvested in the valley/ VP/ region? Estimations? } \\
\text { How many of the families are collecting? Who is the best person collecting? Why? } \\
\text { Everyone same chances? } \\
\text { Is yarshagumba overharvested? (perception) } \\
\text { Factors that influence decline/increase? }\end{array}$ \\
\hline $\begin{array}{l}\text { Description of } \\
\text { sites and }\end{array}$ & $\begin{array}{l}\text { Who manages the site? (waste, forest management, drinking water) } \\
\text { What activity implemented? By whom? } \\
\text { How financed? How many fees are collected? By whom? }\end{array}$ \\
\hline
\end{tabular}




\begin{tabular}{|l|l|}
\hline management & How changed over time? \\
structures & Who decides what to do? How? \\
& Who participates during the meeting? (authority? Community member?) \\
& Do cultural beliefs play a role? How? \\
& How many collectors? How many tents? \\
How many vendors/tea shops? (fee? To whom to be paid?) \\
How good organised/managed according to own ranking? Any management \\
measures in place? \\
What challenges?
\end{tabular}

\section{Assessing yarshagumba trade}

\begin{tabular}{|c|c|}
\hline Topic & Key questions for interviews \\
\hline $\begin{array}{l}\text { Yarshagumba } \\
\text { trade } \\
\text { regulations }\end{array}$ & $\begin{array}{l}\text { In general who regulates the trade of NTFP/MAP? (local authorities?) } \\
\text { How does the trade of yarshagumba work? Who involved? Which route? } \\
\text { Which certificates and registrations required? How much royalty to pay - to whom? } \\
\text { How many traders involved? Registered? Indian/Nepali? District, locals? }\end{array}$ \\
\hline India & $\begin{array}{l}\text { Why do you think the government marketing mechanisms for NTFP/yarhsagumba } \\
\text { were not yet successful? } \\
\text { What needs to be done? What is your suggestion? } \\
\text { How many death cases were registered last year? }\end{array}$ \\
\hline $\begin{array}{l}\text { Nepal } \\
\text { (ANCA) }\end{array}$ & $\begin{array}{l}\text { How many trading permission do you hand out per year? } \\
\text { What is the average amount of } \mathrm{kg} \text {, which are trader deals with? } \\
\text { What criteria does a trader need to fulfil? (registration? ....) } \\
\text { How many traders involved? } \\
\text { Does the trader association have a role? What role? } \\
\text { For NTFP trade, what government institutions are involved? } \\
\text { How many death cases were registered last year? }\end{array}$ \\
\hline $\begin{array}{l}\text { Yarshagumba } \\
\text { sale by } \\
\text { collectors and } \\
\text { middlemen }\end{array}$ & $\begin{array}{l}\text { Processing and grading: before selling what do you do with the yarsha? } \\
\text { how does the yarsha value chain proceeds? Who buys, who sells? who consumes? } \\
\text { to whom do you sell? Do you have a kind of contract/arrangement with him/her? } \\
\text { Always the same? } \\
\text { When do you sell? in the site, in the village, in town? Why do you choose to do so? } \\
\text { Do you think you would earn more if you do it differently? } \\
\text { Can you change? What hinders you? } \\
\text { Where are the risks/ obstacles in that business? - price fluctuations, storage, } \\
\text { business relations, financial transactions? Advance cash? } \\
\text { How do you deal/cope with these risks? } \\
\text { How do you know about prices? From where do you receive the information? When? } \\
\text { Are they fluctuating? } \\
\text { How would you describe the relationships between the traders and local collectors } \\
\text { (amicable, debt bounding, brotherhood)? }\end{array}$ \\
\hline consumption & $\begin{array}{l}\text { Do you know where does the product go after you have sold it to the trader? } \\
\text { How to consume? } \\
\text { What medicinal use? }\end{array}$ \\
\hline
\end{tabular}




\section{Curriculum Viate}

4. Assessing borderland networks and relations

\begin{tabular}{|c|c|}
\hline Topic & Key questions for interviews \\
\hline $\begin{array}{l}\text { formal } \\
\text { institutions }\end{array}$ & $\begin{array}{l}\text { Contact with other country counterpart? } \\
\text { Any regular border meetings? What topic to discuss? How often? Who participates? } \\
\text { Do you think it is important to exchange across the border? } \\
\text { What is the challenge in cooperation? }\end{array}$ \\
\hline $\begin{array}{l}\text { Costumes } \\
\text { between } \\
\text { Nepal and } \\
\text { India }\end{array}$ & $\begin{array}{l}\text { What main items are traded between the two countries? } \\
\text { What products allowed being exported and imported? What about NTFP/MAP? } \\
\text { What certificates and papers required for China/ India/ for Nepal? Which fees to be } \\
\text { paid? For export and import? } \\
\text { Where to get the documents? } \\
\text { Established costumes point in Tinker? In Lipu Lek Pass? }\end{array}$ \\
\hline $\begin{array}{l}\text { individual } \\
\text { level } \\
\text { general } \\
\text { relation }\end{array}$ & $\begin{array}{l}\text { How do you perceive the government authorities (Indian, China, Nepal) from the other } \\
\text { country? } \\
\text { Connect with Nepalis/Indians? With whom? people from which villages? What about } \\
\text { people living in another valley? } \\
\text { How are you related to Indians/Nepalis? Through what? culture? Social relationships? } \\
\text { Economic relationships? grazing rights? } \\
\text { How are the Nepali/Indian different? Binding elements, distinguish elements? } \\
\text { What are the advantages/benefits living next to the border (India, Nepal, China) - } \\
\text { opportunities and restrictions? }\end{array}$ \\
\hline $\begin{array}{l}\text { Yarsha } \\
\text { network }\end{array}$ & $\begin{array}{l}\text { In relation to trade and yarsha, how does the network work? Did these network existed } \\
\text { before the trade started in } 2000+\text { ? } \\
\text { What was traded/exchanged earlier? } \\
\text { What are the risks related to the yarsha trade and network? Who takes the main risk? } \\
\text { Money flow? Product exchange? }\end{array}$ \\
\hline
\end{tabular}

5. Assessing socio-economic of collectors and traders

\begin{tabular}{|c|c|}
\hline Topic & Key questions for interviews \\
\hline $\begin{array}{l}\text { Yarshagumba } \\
\text { in comparison } \\
\text { to other } \\
\text { income } \\
\text { sources }\end{array}$ & $\begin{array}{l}\text { What are the other livelihood sources/options for you? } \\
\text { How did that change over the last years? } \\
\text { In comparison to other livelihood activities, yarshagumba collection more difficult and } \\
\text { hard work or less? }\end{array}$ \\
\hline $\begin{array}{l}\text { Spending of } \\
\text { yarshagumba } \\
\text { money - risk } \\
\text { of losing } \\
\text { income } \\
\text { source for } \\
\text { collectors and } \\
\text { traders }\end{array}$ & $\begin{array}{l}\text { How do you perceive the risk that yarshagumba may not be there next year or prices } \\
\text { are dropping? } \\
\text { In comparison to other livelihood sources, how risky/unreliable you would say is } \\
\text { yarshagumba collection and trade? Why? } \\
\text { What changes do you foresee? (future scenario?)? } \\
\text { Do you have an alternative, if you would not be able collect/trade yarshagumba } \\
\text { anymore? }\end{array}$ \\
\hline
\end{tabular}




\begin{tabular}{|l|l|}
\hline $\begin{array}{l}\text { Development } \\
\text { of region }\end{array}$ & $\begin{array}{l}\text { Do you think 'yarshagumba' contributed to the development of the region? To out- } \\
\text { migration? In what way? And to what extent? } \\
\text { What other economy did arise due to yarshagumba income (tea shops, alcohol } \\
\text { shops, restaurants, along the way and in the bigger towns, hotels) in your valley? } \\
\text { Was the investment coming from yarshagumba money? } \\
\text { How do you see the future of the villages? Of the valley? }\end{array}$ \\
\hline $\begin{array}{l}\text { Major } \\
\text { government } \\
\text { schemes }\end{array}$ & $\begin{array}{l}\text { Any affirmative action policies (scheduled tribes) by state, region, national - Bhothias } \\
\text { are recognised ST since 1967. } \\
\text { What are major government schemes in the landscape? BRCLIP by FD, JFM, ANCA } \\
\text { Access to rations and funds? }\end{array}$ \\
\hline
\end{tabular}

6. Assessing the context of the landscape

\begin{tabular}{|l|l|}
\hline Topic & Key questions for interviews \\
\hline $\begin{array}{l}\text { Socio- } \\
\text { economic } \\
\text { situation in } \\
\text { landscape }\end{array}$ & $\begin{array}{l}\text { Access to basic infrastructure (communication, road, health care, school, market for } \\
\text { other commodities) } \\
\text { Access to financial institutions } \\
\text { Actually and perceived by different groups } \\
\text { Economic developments? Poverty rate? } \\
\text { Nepal: why so many Shauka in high positions on district level? (political party leaders, } \\
\text { ANCA chairman, economic powerful traders) }\end{array}$ \\
\hline $\begin{array}{l}\text { Description } \\
\text { of } \\
\text { ethnic/social } \\
\text { groups }\end{array}$ & $\begin{array}{l}\text { What are the different groups (social, religious, ethnical) in the landscape } \\
\text { How do they see themselves? } \\
\text { Livelihood sources: Agricultural production declining? Out-migration? What are the new } \\
\text { livelihood sources? } \\
\text { Migratory pastoralism declining? } \\
\text { Solidarity between the groups? Families? - social boundaries? }\end{array}$ \\
\hline
\end{tabular}

\section{Annex 3: List of interview partners}

\section{A) Nepal - community level}

\begin{tabular}{|c|c|c|c|c|c|}
\hline No. & valley & location & position & $m / \mathbf{f}$ & date \\
\hline 1 & Mahakali & Darchula & ANCA staff & $\mathrm{m}$ & May'17 \\
\hline 2 & Mahakali & Darchula & ANCA staff & $\mathrm{m}$ & May'17 \\
\hline 3 & Mahakali & Sunsera & Community member & $\mathrm{m}$ & May'17 \\
\hline 4 & Mahakali & Dumblin & ANCA staff & $\mathrm{m}$ & May'17 \\
\hline 5 & Mahakali & Sunsera & Police personal & $M$ & May'17 \\
\hline 6 & Mahakali & Dumblin & Community member & $\mathrm{M}$ & May'17 \\
\hline 7 & Mahakali & Dumblin & ANCA staff & $\mathrm{m}$ & May'17 \\
\hline 8 & Mahakali & Bhuddi & ANCA staff & $\mathrm{m}$ & May'17 \\
\hline 9 & Mahakali & Bhuddi & Police personal & $\mathrm{m}$ & May'17 \\
\hline 10 & Mahakali & Kuntison & Community member & $\mathrm{m}$ & May'17 \\
\hline 11 & Mahakali & Changrue & Community member & $\mathrm{M}$ & May'17 \\
\hline 12 & Mahakali & Changrue & Community member & $\mathrm{M}$ & May'17 \\
\hline
\end{tabular}




\section{Curriculum Viate}

\begin{tabular}{|c|c|c|c|c|c|}
\hline 13 & Mahakali & Changrue & ANCA staff & $\mathrm{m}$ & May '17 \\
\hline 14 & Mahakali & Changrue & ANCA staff & f & May '17 \\
\hline 15 & Mahakali & Rakanpani & Community member & $\mathrm{m}$ & May'17 \\
\hline 16 & Mahakali & Tinker & Community member & $f$ & May'17 \\
\hline 17 & Mahakali & Tinker & Community member & $f$ & May '17 \\
\hline 18 & Mahakali & Tinker & Community member & $\mathrm{m}$ & May '17 \\
\hline 19 & Mahakali & Changrue & Community member & $\mathrm{m}$ & May'17 \\
\hline 20 & Mahakali & Changrue & Community member & $f$ & May '17 \\
\hline 21 & Mahakali & Api Base Camp & ANCA Committee & $\mathrm{m}$ & May'17 \\
\hline 22 & Mahakali & Api Base Camp & Community member & $\mathrm{m}$ & May '17 \\
\hline 23 & Mahakali & Api Base Camp & Community member & $f$ & May'17 \\
\hline 24 & Mahakali & Api Base Camp & Community member & $\mathrm{m}$ & May '17 \\
\hline 25 & Mahakali & Api Base Camp & Community member & f & May '17 \\
\hline 26 & Mahakali & Kuntison site & ANCA Committee & $f$ & May'17 \\
\hline 27 & Mahakali & Kuntison site & Community member & $\mathrm{m}$ & May '17 \\
\hline 28 & Mahakali & Kuntison site & Community member & $\mathrm{m}$ & May'17 \\
\hline 29 & Mahakali & Bhuddi site & Community member & $f$ & May '17 \\
\hline 30 & Mahakali & Bhuddi site & Community member & $f$ & May '17 \\
\hline 31 & Mahakali & Bhuddi site & Community member & $\mathrm{m}$ & May '17 \\
\hline 32 & Mahakali & Dumblin & Government official & $\mathrm{m}$ & May'17 \\
\hline 33 & Mahakali & Darchula & ANCA staff & $M$ & May'17 \\
\hline 34 & Mahakali & Darchula & Local leader & $\mathrm{M}$ & May '17 \\
\hline 35 & Mahakali & Darchula & ANCA staff & $\mathrm{m}$ & May '17 \\
\hline 36 & Mahakali & Sunsera & Local leader & $\mathrm{m}$ & May '17 \\
\hline 37 & Mahakli & Changrue & Community member & $\mathrm{m}$ & May '17 \\
\hline 38 & Chameylia & Makarighad & Community member & $M$ & May'17 \\
\hline 39 & Chameylia & Makarighad & Community member & $f$ & May '17 \\
\hline 40 & Chameylia & Makarighad & Community member & $\mathrm{M}$ & May '17 \\
\hline 41 & Chameylia & Kajekot & Local leader & $M$ & May'17 \\
\hline 42 & Chameylia & Kajekot & Community member & M & May'17 \\
\hline 43 & Chameylia & Kajekot & Community member & $f$ & May'17 \\
\hline 44 & Chameylia & Dhaula Ole & Community member & $\mathrm{m}$ & May '17 \\
\hline 45 & Chameylia & Dhaula Ole & Community member & $\mathrm{M}$ & May'17 \\
\hline 46 & Chameylia & Dhaula Ole & Community member & $M$ & May'17 \\
\hline 47 & Chameylia & Dhaula Ole & Community member & M & May'17 \\
\hline 48 & Chameylia & Dhaula Ole & Community member & $f$ & May '17 \\
\hline 49 & Chameylia & Ghusa & Community member & M & May '17 \\
\hline 50 & Chameylia & Darchula & Community member & $\mathrm{M}$ & May '17 \\
\hline 51 & Chameylia & Paribagar & Community member & $\mathrm{m}$ & May '17 \\
\hline
\end{tabular}

\section{B) India - community level}

\begin{tabular}{|l|l|l|l|l|l|}
\hline No. & valley & location & position & $\mathbf{m} / \mathbf{f}$ & date \\
\hline 1 & Mahakali & Pithoragarh & Van panchayat leader & $\mathrm{m}$ & Aug. '16 \\
\hline 2 & Mahakali & Pithoragarh & Community member & $\mathrm{M}$ & Aug. '16 \\
\hline 3 & Mahakali & Pithoragarh & Community member & $\mathrm{m}$ & Aug. '16 \\
\hline 4 & Mahakali & Dharchula & Van panchayat leader & $\mathrm{m}$ & Jan. '17 \\
\hline 5 & Johar & Munsyari & Community member & $\mathrm{m}$ & Jan. '17 \\
\hline 6 & Johar & Munsyari & Community member & $\mathrm{m}$ & Jan. '17 \\
\hline
\end{tabular}




\section{Acknowledgment}

\begin{tabular}{|c|c|c|c|c|c|}
\hline 7 & Johar & Munsyari & Community member & $\mathrm{m}$ & Jan. '17 \\
\hline 8 & Darma & Baling & Van panchayat leader & $M$ & April '17 \\
\hline 9 & Mahakali & Dharchula & Community member & $\mathrm{m}$ & April '17 \\
\hline 10 & Mahakali & Dharchula & Van panchayat leader & $\mathrm{m}$ & April '17 \\
\hline 11 & Darma & Tejum & Community member & $\mathrm{m}$ & April '17 \\
\hline 12 & Darma & Tejum & Community member & $\mathrm{m}$ & April '17 \\
\hline 13 & Darma & Sundum & Community member & $M$ & April '17 \\
\hline 14 & Darma & Sundum & Community member & $\mathrm{m}$ & April '17 \\
\hline 15 & Mahakali & Pangla & Van panchayat leader & $f$ & April '17 \\
\hline 16 & Mahakali & Pangla & Community member & $f$ & April '17 \\
\hline 17 & Mahakali & Pangla & Local leader & $\mathrm{m}$ & April '17 \\
\hline 18 & Mahakali & Galati / Baling & Community member & $\mathrm{m}$ & April '17 \\
\hline 19 & Mahakali & Dharchula & Community member & $\mathrm{m}$ & April '17 \\
\hline 20 & Mahakali & Dharchula & Forest guard & $M$ & April '17 \\
\hline 21 & Johar & Munsyari & Forest guard & $\mathrm{m}$ & April '17 \\
\hline 22 & Johar & Bona & Local leader & $\mathrm{M}$ & April '17 \\
\hline 23 & Johar & Bona & Community member & $M$ & April '17 \\
\hline 24 & Johar & Bona & Community member & $\mathrm{M}$ & April '17 \\
\hline 25 & Johar & Bona & Community member & $\mathrm{m}$ & April '17 \\
\hline 26 & Johar & Darati & Local leader & $\mathrm{M}$ & April'17 \\
\hline 27 & Johar & Darati & Community member & $m$ & April '17 \\
\hline 28 & Mahakali & Dharchula & Local leader & $\mathrm{m}$ & June '17 \\
\hline 29 & Darma & Baling & Van panchayat leader & $\mathrm{M}$ & June '17 \\
\hline 30 & Darma & Baling & Community member & $\mathrm{m}$ & June '17 \\
\hline 31 & Darma & Baling & Community member & $\mathrm{m}$ & June '17 \\
\hline 32 & Darma & Baling & Community member & $M$ & June '17 \\
\hline 33 & Darma & Baling & Community member & $\mathrm{M}$ & June '17 \\
\hline 34 & Darma & Baling & Community member & $\mathrm{F}$ & June '17 \\
\hline 35 & Darma & Baling & Police personal & $\mathrm{m}$ & June '17 \\
\hline 36 & Darma & Tejum & Community member & $\mathrm{M}$ & June '17 \\
\hline 37 & Darma & Tejum & Community member & $\mathrm{M}$ & June '17 \\
\hline 38 & Darma & Dar & Community member & $M$ & June'17 \\
\hline 39 & Darma & Dar & Community member & $\mathrm{F}$ & June'17 \\
\hline 40 & Darma & Dar & Community member & $\mathrm{m}$ & June '17 \\
\hline 41 & Darma & Dar & Community member & $\mathrm{m}$ & June '17 \\
\hline
\end{tabular}

\section{C) List of interview partners - outside community structures}

\begin{tabular}{|l|l|l|l|l|l|}
\hline No. & country & location & Authority / occupation & $\mathbf{m} / \mathbf{f}$ & date \\
\hline 1 & Nepal & Kathmandu & Researcher & $\mathrm{m}$ & Aug. '17 \\
\hline 2 & Nepal & Kathmandu & Member of trader association Humla & $\mathrm{m}$ & July '17 \\
\hline 3 & Nepal & Kathmandu & President of chamber of commerce Humla & $\mathrm{M}$ & July '17 \\
\hline 4 & Nepal & Kathmandu & Representative of DNPWC & $\mathrm{m}$ & July '17 \\
\hline 5 & Nepal & Kathmandu & Researcher of Tribuhan University & $\mathrm{M}$ & July '17 \\
\hline 6 & Nepal & Darchula & Officer of Police Darchula & $\mathrm{m}$ & April '17 \\
\hline 7 & Nepal & Darchula & Member of trader association Darchula & $\mathrm{m}$ & Jan. '17 \\
\hline 8 & Nepal & Darchula & Officer of Army & $\mathrm{m}$ & May '17 \\
\hline 9 & India & Pithoragarh & Representative of State Forest Department & $\mathrm{m}$ & Aug. '16 \\
\hline 10 & India & Pithoragarh & Researcher & $\mathrm{m}$ & Aug. '16 \\
\hline
\end{tabular}




\section{Curriculum Viate}

\begin{tabular}{|l|l|l|l|l|l|}
\hline 11 & India & Dehra Dun & Researcher & $\mathrm{M}$ & Jan. '17 \\
\hline 12 & India & Pithoragarh & Representative of State Forest Department & $\mathrm{m}$ & Jan. '17 \\
\hline 13 & India & Jaulijibi & Member of NGO & $\mathrm{m}$ & Jan. '17 \\
\hline 14 & India & Dharchula & Representative of State Forest Department & $\mathrm{m}$ & Jan. '17 \\
\hline 15 & India & Munsyari & Journalist & $\mathrm{m}$ & Jan. '17 \\
\hline 16 & India & Nainital & Representative of State Forest Department & $\mathrm{m}$ & Aug. '16 \\
\hline 17 & India & Munsyari & Researcher & $\mathrm{M}$ & April '17 \\
\hline 18 & India & Almora & Researcher & $\mathrm{M}$ & May '17 \\
\hline 19 & India & Dehra Dun & Representative of State Biodiversity Board & $\mathrm{m}$ & June '17 \\
\hline 20 & India & Dharchula & Member of NGO & $\mathrm{m}$ & Jan. '17 \\
\hline
\end{tabular}

\section{Annex 4: List of focus group discussions}

\begin{tabular}{|c|c|c|c|c|c|}
\hline No. & country & valley & location & participants & date \\
\hline 1 & Nepal & Mahakali & $\begin{array}{ll}\text { Api } & \text { Base } \\
\text { Camp } & \end{array}$ & $\begin{array}{l}\text { Community members ANCA committee } \\
\text { members: }\end{array}$ & May'17 \\
\hline 2 & Nepal & Mahakali & Kuntison site & $\begin{array}{l}\text { Community members, ANCA committee } \\
\text { members }\end{array}$ & May '17 \\
\hline 3 & Nepal & Mahakali & Bhuddi site & Women group & May '17 \\
\hline 4 & Nepal & Mahakali & Bhuddi site & Community members, & May '17 \\
\hline 5 & Nepal & Mahakali & Bhuddi site & $\begin{array}{l}\text { Community members, ANCA committee } \\
\text { members }\end{array}$ & May ‘17 \\
\hline 6 & Nepal & Chameylia & Dhaula Ole & Community members & May '17 \\
\hline 7 & India & $\begin{array}{l}\text { Darma and } \\
\text { Chaudans }\end{array}$ & Pithoragarh & Community members & Aug. '16 \\
\hline 8 & India & $\begin{array}{l}\text { Darma and } \\
\text { Chaudans }\end{array}$ & Pithoragarh & $\begin{array}{l}\text { Community members, Van panchayat } \\
\text { leaders }\end{array}$ & Jan. '17 \\
\hline 9 & India & Johar & Munsyari & Community members & Jan. '17 \\
\hline 10 & India & Darma & Tejum & $\begin{array}{l}\text { Community members, Van panchayat } \\
\text { leaders }\end{array}$ & April '17 \\
\hline 11 & India & Mahakali & Galati / Baling & $\begin{array}{l}\text { Community members, Van panchayat } \\
\text { leader }\end{array}$ & April '17 \\
\hline 12 & India & Johar & Bona & $\begin{array}{l}\text { Community members, Van panchayat } \\
\text { leader }\end{array}$ & April '17 \\
\hline 13 & India & Johar & Darati & $\begin{array}{l}\text { Community members, Van panchayat } \\
\text { leader }\end{array}$ & April '17 \\
\hline
\end{tabular}

